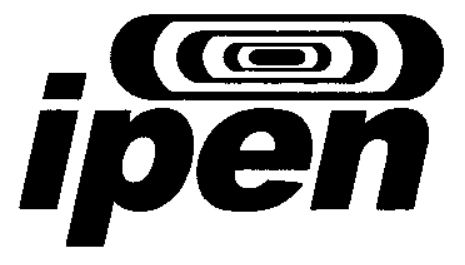

AUTARQUIA ASSOCIADA A UNIVERSIDADE DE SAOO PAULO

\title{
USO DE LIQUENS EPIFÍTICOS NO BIOMONITORAMENTO DA POLUIÇÃO ATMOSFÉRICA DA REGIÃO METROPOLITANA DE SÃO PAULO
}

\author{
ALESSANDRA FUGA
}

Dissertação apresentada como parte dos requisitos para obtençăo do Grau de Mestre em Ciências na Area de Tecnologia Nuclear - Aplicaçбes.

Orientadora:

Dra. Mitiko Salki 
INSTITUTO DE PESQUISAS ENERGÉTICAS E NUCLEARES

Autarquia Associada à Universidade de São Paulo

\section{USO DE LIQUENS EPIFÍTICOS NO BIOMONITORAMENTO DA POLUIÇÃO ATMOSFÉRICA DA REGIÃO METROPOLITANA DE SÃO PAULO}

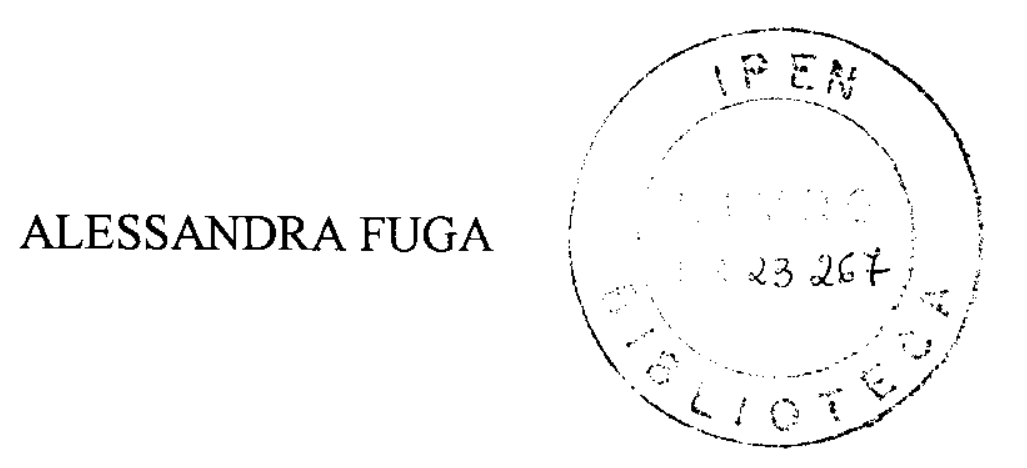

Dissertação apresentada como parte dos requisitos para obtenção do Grau de Mestre em Ciências na Área de Tecnologia Nuclear - Aplicações.

Orientadora:

Dra. Mitiko Saiki

São Paulo

2006 
Aos meus pais, Rinaldo e Sandra Às minhas imãu, Adriana e Aline

Ao Francisco

Pelo amor, paciência e motivação 


\section{AGRADECIMENTOS}

À Dra. Mitiko Saiki, a quem devo a concretização deste trabalho, pela orientação e dedicação contribuindo para a minfia formação profissional e pessoal.

Ao Instituto de Pesquisas Energéticas e $\mathcal{N}$ ucleares (IPEN-CNEN/SP), pela possibilidade de realização da pós-graduação e iniciação científica.

Ao Dr. Cláudio Rodrigues, Superintendente do Instituto de Resquisas Energéticas e $\mathcal{N}$ ucleares - IPEE $\mathcal{N}-C \mathcal{N} E \mathcal{N} / S P$, pela oportunidade que me foi concedida para realizar o presente trabalho.

Aos Dr. José Roberto Rogero e Femado F. Moreira, que me incentivaram no programa de pós-graduação do IPENN.

À Dra. Marina Beatriz Agostini Vasconcellos, Chefe da Divisão de Pesquisas e Desenvolvimento do Centro do Reator de Pesquisas (CRPq) do IPEN, pelo apoio e incentivo para a realização desta dissertação.

Ao Laboratório de Análise por Ativação Neutrônica (CRN) do IPENCNEN $/ S P$, pela oportunidade concedida para realizar o trabalfo experimental.

À FAPESP e ao CNPq, pela concessão da bolsa de estudos e financiamento de auxíío para desenvolvimento da dissertação.

Ao Prof. Dr. Marcelo P. Marcelfi, do Instituto de Botânica (I6ot/SP), pelas elucidações e ensinamentos no âmbito da liquenologia.

Ao Dr. Leonardo Gondim de Andrade e Silva, pelo incentivo e sincera amizade durante estes anos de IPEN. 
Ao José Osman dos Santos, pela amizade e contribuição na interpretação dos resultados estatísticos.

Aos meus pais, exemplos de vida e familiares, sempre presentes com compreensão, apoio e estímulo durante todo o trabalfo.

Aos meus avós, Eunice e, Geraldo, Nair, Atílio (in memorian) pelos momentos de carinfio e afeto em minha vida.

Ao Francisco, pelo amor e incentivo nos momentos mais dificeis.

A todos os amigos e integrantes do Laboratório de Análise por Ativaçāo $\mathcal{N}$ eutrônica, pelo auxílio, conselhos, Goa convivência e, principalmente, pela sincera amizade.

A todas as pessoas que, de alguma forma, contribuiram para a realização deste trabalho.

MUITO OBRIGADA 


\title{
USO DE LIQUENS EPIFÍTICOS NO BIOMONITORAMENTO DA POLUIÇÃO ATMOSFÉRICA DA REGIÃo METROPOLITANA DE SÃO PAULO
}

\author{
Alessandra Fuga
}

RESUMO

Devido aos crescentes problemas relacionados com a poluição atmosférica na região metropolitana de São Paulo que atingem o ambiente e a saúde das populações, toma-se de grande interesse o estabelecimento de metodologias tal como a de monitoramento da qualidade do ar usando organismos cosmopolitas. O biomonitoramento é um método experimental que permite avaliar a resposta de organismos vivos à poluição, oferecendo vantagens como custos reduzidos, eficiência no monitoramento de amplas áreas geográficas e de elementos químicos poluentes presentes em baixas concentrações no ambiente e acumulados no biomonitor ao longo de um período. No presente trabalho, o método de análise por ativação neutrônica foi aplicado à determinação de elementos acumulados em amostras do fungo liquenizado Canoparmelia texana coletadas em duas áreas distintas: (1) Parques Estaduais Carlos Botelho (PECB) e Intervales (PEI), área considerada não-poluída pertencente ao ecossistema de Mata Atlântica - SP e (2) área metropolitana de São Paulo em pontos localizados nas proximidades das estações automáticas de monitoramento da Companhia de Tecnologia de Saneamento Ambiental (CETESB). Os liquens coletados dos troncos de árvores foram previamente limpos, moídos e posteriormente irradiados com nêutrons do reator IEAR1 juntamente com os padrões sintéticos dos elementos. A precisão e exatidão dos resultados analíticos foram avaliadas por meio das análises dos materiais certificados de referência IAEA-336 LICHEN e Mixed Polish Herbs (INCT-MPH-2). Os resultados obtidos nestes materiais de referência foram concordantes com os valores certificados e apresentaram, em geral, uma boa precisão com coeficientes de variação variando de 0,9 a $14,6 \%$. Os resultados das análises de liquens indicaram que os elementos $\mathrm{As}, \mathrm{Co}, \mathrm{Cr}, \mathrm{Cs}, \mathrm{La}, \mathrm{Mo}, \mathrm{Sb}, \mathrm{Sc}, \mathrm{Se}$ e U 
estão presentes aos níveis de $\mathrm{ng}^{-1}, \mathrm{Ba}, \mathrm{Br}, \mathrm{Cl}, \mathrm{Fe}, \mathrm{K}, \mathrm{Mn}, \mathrm{Na}, \mathrm{Rb}$ e $\mathrm{Zn}$ aos níveis de $\mu \mathrm{g} \mathrm{g}^{-1}$ e $\mathrm{Ca}$ aos níveis de $\mathrm{mg} \mathrm{g}^{-1}$. Por meio da aplicação das análises de cluster e de discriminante, aos resultados obtidos nas amostras coletadas em áreas com diferentes níveis de poluição, os pontos de amostragens foram agrupados segundo similaridades químicas no que diz respeito às suas composições elementares. Também foi observado que as amostras do PECB e do PEI separaram-se dos grupos e subgrupos formados pelas amostras da região metropolitana e este resultado indica a preservação das áreas consideradas não-poluídas. Os liquens coletados no PEI apresentaram, em geral, concentrações inferiores àquelas obtidas para a região metropolitana de São Paulo principalmente para os elementos relacionados com ações antrópicas. Os mapas de distribuição das concentrações de elementos permitiram a visualização e identificação de pontos que apresentam concentrações de elementos mais altas na região metropolitana. Estes mapas de distribuição também mostraram que a poluição na região metropolitana de São Paulo apresenta perfis diferentes devido às inúmeras fontes de emissão de poluentes. Os elementos determinados nos liquens da área metropolitana indicaram ser de origens industrial, veicular e do solo. Os resultados obtidos neste trabalho mostraram a viabilidade do uso da C. texana na avaliação da poluição no biomonitoramento passivo de diversos elementos contaminantes presentes na atmosfera da região metropolitana de São Paulo. 


\title{
ATMOSPHERIC POLLUTION BIOMONITORING OF THE SÃO PAULO METROPOLITAN REGION USING EPYPHITIC LICHENS
}

\author{
Alessandra Fuga
}

\begin{abstract}
Due to the increasing problems of atmospheric pollution in the São Paulo metropolitan region that affect the environment and human health the application of biomonitoring methodologies using cosmopolite organisms has now become relevant. Biomonitoring is a method to evaluate the response of live organisms to pollution. This method offers advantages such as reduced costs, efficient monitoring of large geographic areas and accumulated pollutants over a large period in which low concentrations of chemicals elements in the enviroment can be evaluated. In the present study, neutron activation analysis method was applied to determine elements accumulated in Canoparmelia texana lichenized fungi. Samples were collected in two distinct areas: (1) Carlos Botelho (PECB) and Intervales (PEI) State Parks that are considered as non-polluted areas and that belong to the Atlantic Forest - SP ecossystem and (2) São Paulo city metropolitan region in sites near automatic monitoring stations of the Environmental Protection Agency of the State of São Paulo (CETESB). The lichens collected from the bark of the trees were properly treated, and irradiated with neutrons from IEA-Rl nuclear reactor along with synthetic standards of elements. The precision and the accuracy of the results were evaluated by the analyses of IAEA-336 LICHEN and Mixed Polish Herbs (INCT-MPH-2) certified reference materials. The results obtained for these materials were in accordance with the certified values and presented good precision with variation coeficients ranging from 0.9 to $14.6 \%$. Results obtained for lichens showed that elements As, $\mathrm{Co}, \mathrm{Cr}, \mathrm{Cs}, \mathrm{La}, \mathrm{Mo}, \mathrm{Sb}, \mathrm{Sc}, \mathrm{Se}$ and $\mathrm{U}$ are present at $\mathrm{ng} \mathrm{g}^{-1}$ levels, $\mathrm{Ba}, \mathrm{Br}, \mathrm{Cl}, \mathrm{Fe}, \mathrm{K}, \mathrm{Mn}, \mathrm{Na}, \mathrm{Rb}$ and $\mathrm{Zn}$ at $\mu \mathrm{g} \mathrm{g}^{-1}$ and $\mathrm{Ca}$ at $\mathrm{mg} \mathrm{g}^{-1}$. By applying cluster and discriminant analyses to the results for the lichen samples from areas with
\end{abstract}


different levels of pollution, the sampling sites were grouped according to their chemical similarities and their elemental composition. It was also observed that samples from PECB and PEI were separated from groups and subgroups formed by the samples from the metropolitan region. This result indicates the preservation of PECB and PEI areas considered non-polluted. The lichens collected in the PEI presented, in general, lower concentrantions of the elements than those from the metropolitan region of São Paulo in regards to those elements related to anthropogenic actions. The distribution maps of element concentrations allowed identification of sites in the metropolitan region that present higher elemental concentrations. Furthermore the distribution maps also showed that the pollution in the metropolitan region presents different profiles due to many sources and different pollutant emissions. The probable sources of elements determined in lichens from the metropolitan region are industrial, vehicular and soil. Results obtained indicate that the $C$. texana species can be used as a passive biomonitor of element pollution in the São Paulo metropolitan area. This species is abundant in both polluted and non-polluted areas and thus allows to distinguish regions with distintet levels of pollution. 


\section{LISTA DE TABELAS}

TABELA 1.1. Elementos quimicos Página TABELA 4 1. Códigos possiveis fontes de origem. 30 TABELA 4.1. Códigos, locais e datas de coleta das amostras de liquens.......................58

TABELA 4.2. Massas dos elementos nos padrões sintéticos .66

TABELA 4.3. Características dos radioisótopos utilizados neste trabalho. 70

TABELA 4.4. Energia de raios gama e série de contagens dos radioisótopos utilizados na análise dos materiais certificados de referência IAEA-336 LICHEN e Mixed Polish Herbs (INCT-MPH-2) .72

TABELA 5.1. Médias das concentrações de elementos traço no material certificado de referência IAEA-336 LICHEN

TABELA 5.2. Fórmulas utilizadas para o cálculo das grandezas apresentadas na TAB. 5.1 (Vogel, 1992)

TABELA 5.3. Médias das concentrações de elementos traço no material certificado de referência Mixed Polish Herbs (INCT-MPH-2).

TABELA 5.4. Concentrações de elementos obtidas para os liquens coletados nos Parques Estaduais Carlos Botelho e Intervales

TABELA 5.5 Concentrações de elementos obtidas para os liquens coletados em pontos distintos da região metropolitana de São Paulo 


\section{SUMÁRIO}

Página

\section{INTRODUÇÃO}

1.1. Poluição atmosférica

1.1.1. Poluição atmosférica: conceitos

1.1.2. Classificação dos poluentes atmosféricos

1.1.3. Fontes que geram poluentes

1.1.4. Efeitos da poluição atmosférica

Propriedades atmosféricas

Materiais

Vegetação

Seres Humanos

1.2. Monitoramento biológico

1.2.1. Algumas considerações sobre o uso do biomonitoramento

1.2.2. Liquens como biomonitores da poluição do ar

1.2.3. Liquens como biomonitores: um breve histórico

1.2.4. Liquens como biomonitores: estudos e perspectivas

\section{OBJETIVO}

\section{METODOLOGIA}

3.1. Métodos radioquímicos

3.2. Considerações gerais sobre o método de análise por ativação com nêutrons

3.3. Princípio da análise por ativação com nêutrons

3.4. Análise por ativação comparativa

3.5. Instrumentação para análise por ativação neutrônica

3.6. Vantagens e desvantagens da análise por ativação neutrônica 


\section{PARTE EXPERIMENTAL}

4.1. Amostras de líquen para análise

4.1.1. Características da espécie de fungo liquenizado coletada e analisada

4.2. Locais de coleta

4.2.1. Parques Estaduais Carlos Botelho e Intervales

4.2.2. Região metropolitana de São Paulo

4.3. Procedimento experimental para coleta e tratamento das amostras para análise 61

4.4. Pesagem das amostras para análise por ativação neutrônica

4.5. Preparação de padrões elementares para análise por ativação

4.5.1. Padrões sintéticos de elementos

4.6. Procedimento experimental para as irradiações e medições

4.6.1. Irradiações curtas no reator

4.6.2. Irradiações longas no reator

4.7. Análise dos materiais biológicos certificados de referência

4.7.1. Determinação das percentagens de perda de peso nas secagens dos materiais certificados de referência

\section{RESULTADOS E DISCUSSÃO}

5.1. Resultados das análises dos materiais certificados de referência

5.1.1. Material de referência IAEA-336 LICHEN

5.1.2. Material de referência Mixed Polish Herbs (INCT-MPH-2)

5.2. Resultados das análises das amostras de liquens 78

6. CONCLUSÕES 


\section{LISTA DE FIGURAS}

\section{Página}

FIGURA 1.1. Partes anatômicas do talo liquênico: (1) córtex superior, (2) camada de algas,

(3) medula (Barbosa, 2005)

FIGURA 3.1. Esquema da secção horizontal de um reator nuclear (Kellner et al, 1998) ...40

FIGURA 3.2. Diagrama esquemático ilustrando a seqüência de eventos para uma reação $(\mathrm{n}, \gamma)$ típica (figura adaptada da referência IAEA, 1990)

FIGURA 3.3. Diagrama esquemático de um sistema instrumental para espectrometria gama equipado com detector de germânio (Skoog et al., 2002) 46

FIGURA 4.1. Fungo liquenizado Canoparmelia texana. A - aspecto geral do talo; B margem do talo com sorais; $\mathbf{C}$ - detalhe dos sorais (setas); $\mathbf{D}$ - margem do talo e sorais (setas) (Barbosa, 2005)

FIGURA 4.2. Foto aérea do Parque Estadual Carlos Botelho (Parque (a), 2004) ...............52

FIGURA 4.3. Foto aérea do Parque Estadual Intervales (Parque (h), 2004) ......................53

FIGURA 4.4. Foto do ecossistema de Mata Atlântica (Mata Atlântica, 2005) …................55

FIGURA 4.5. Localização da região metropolitana no Estado de São Paulo 57

FIGURA 4.6. Locais de amostragem na região metropolitana de São Paulo (CETESB, 2003) 60

FIGURA 4.7. Observação do liquen no mircroscópio estereoscópico Olympus 62

FIGURA 4.8. Foto do liofilizador Micro Modulyo da Fitwards. 63

FIGURA 4.9. Foto do micro moinho Pulverisette 0 da Fritsh. 63

FIGURA 5.1. Valores de Z-score obtidos para o material certificado de referência IAEA336 LICHEN .78

FIGURA 5.2. Valores de Z-score obtidos para o material certificado de referência Mixed Polish Herbs (INCT-MPH-2).

FIGURA 5.3. Dendrograma obtido por meio da análise de cluster para as amostras de liquens coletadas em áreas com diferentes níveis de poluição. 88 
FIGURA 5.4. Análise discriminante aplicada aos resultados das amostras de liquens coletadas em áreas com diferentes níveis de poluição.

FIGURA 5.5. Concentrações de As obtidas para liquens coletados em diferentes pontos de amostragens

FIGURA 5.6. Concentrações de Rb obtidas para liquens coletados em diferentes pontos de amostragens

FIGURA 5.7. Concentrações de $\mathrm{Br}$ obtidas para liquens coletados em diferentes pontos de amostragens.

FIGURA 5.8. Concentrações de $\mathrm{Cl}$ obtidas para liquens coletados em diferentes pontos de amostragens.

FIGURA 5.9. Mapa da concentração de As, em $\mathrm{ng} \mathrm{g}^{-1}$, obtido para liquens da região metropolitana de São Paulo.

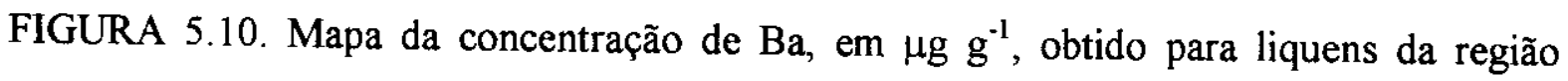
metropolitana de São Paulo.

FIGURA 5.11. Mapa da concentração de $\mathrm{Br}$, em ng $\mathrm{g}^{-1}$, obtido para liquens da região metropolitana de São Paulo.

FIGURA 5.12. Mapa da concentração de $\mathrm{Ca}, \mu \mathrm{g} \mathrm{g}^{-1}$, obtido para liquens da região metropolitana de São Paulo.

FIGURA 5.13. Mapa da concentração de $\mathrm{Cl}$, em $\mu \mathrm{g} \mathrm{g}^{-1}$, obtido para liquens da região metropolitana de São Paulo.

FIGURA 5.14. Mapa da concentração de $\mathrm{Co}$, em $\mathrm{ng} \mathrm{g}^{-1}$, obtido para liquens da região metropolitana de São Paulo.

FIGURA 5.15. Mapa da concentração de $\mathrm{Cr}$, em $\mathrm{ng} \mathrm{g}^{-1}$, obtido para liquens da região metropolitana de São Paulo.

FIGURA 5.16. Mapa da concentração de $\mathrm{Cs}$, em $\mathrm{ng} \mathrm{g}^{-1}$, obtido para liquens da região metropolitana de São Paulo.

FIGURA 5.17. Mapa da concentração de $\mathrm{Fe}, \mu \mathrm{g} \mathrm{g}^{-1}$, obtido para liquens da região metropolitana de São Paulo.

FIGURA 5.18. Mapa da concentração de $\mathrm{K}$, em $\mu \mathrm{g} \mathrm{g}^{-1}$, obtido para liquens da região metropolitana de São Paulo. 
FIGURA 5.19. Mapa da concentração de La, em $\mathrm{ng} \mathrm{g}^{-1}$, obtido para liquens da região metropolitana de São Paulo

FIGURA 5.20. Mapa da concentração de $\mathrm{Mn}$, em $\mu \mathrm{g} \mathrm{g}^{-1}$, obtido para liquens da região metropolitana de São Paulo 109

FIGURA 5.21. Mapa da concentração de Mo, em $\mu \mathrm{g} \mathrm{g}^{-1}$, obtido para liquens da região metropolitana de São Paulo 110

FIGURA 5.22. Mapa da concentração de $\mathrm{Na}$, em $\mu \mathrm{g} \mathrm{g}^{-1}$, obtido para liquens da região metropolitana de São Paulo

FIGURA 5.23. Mapa da concentração de $\mathrm{Rb}$, em $\mu \mathrm{g} \mathrm{g}^{-1}$, obtido para liquens da região metropolitana de São Paulo

FIGURA 5.24. Mapa da concentração de $\mathrm{Sb}$, em $\mathrm{ng} \mathrm{g}^{-1}$, obtido para liquens da região metropolitana de São Paulo

FIGURA 5.25. Mapa da concentração de Sc, em $\mathrm{ng} \mathrm{g}^{-1}$, obtido para liquens da região metropolitana de São Paulo

FIGURA 5.26. Mapa da concentração de $\mathrm{Se}$, em $\mathrm{ng} \mathrm{g}^{-1}$, obtido para liquens da região metropolitana de São Paulo

FIGURA 5.27. Mapa da concentração de $\mathrm{U}$, em $\mathrm{ng} \mathrm{g}^{-1}$, obtido para liquens da região metropolitana de São Paulo

FIGURA 5.28. Mapa da concentração de $\mathrm{Zn}$, em $\mu \mathrm{g} \mathrm{g}^{-1}$, obtido para liquens da região metropolitana de São Paulo 


\section{INTRODUÇÃO}

\subsection{Poluição atmosférica}

Como se sabe, os problemas ambientais estão entre os assuntos diários da vida em todo o mundo, nos últimos 20 anos. Especialmente o crescimento de áreas e instalações industriais tem sido a razão para o aumento da poluição aérea (Aslan et al., 2004).

As indústrias têm sido associadas aos problemas de todos os tipos desde o início da revolução industrial. Entretanto, somente no início dos anos setenta que se tem notado o esforço por parte do governo federal em preservar o meio ambiente, obrigando as indústrias a adotarem critérios de emissões mais restritos (Sell, 1992).

As exigências vinculadas ao crescimento populacional, associadas ao desejo da população por um padrão de vida mais alto estão ocasionando poluição a nível mundial em grande escala (Manahan, 2000).

Segundo Manahan (2000) a poluição ambiental pode ser dividida em categorias, a saber: poluição da água, do ar e do solo as quais estão relacionadas entre si. Por exemplo, alguns gases emitidos para a atmosfera podem ser convertidos a ácidos fortes por processos químicos atmosféricos, precipitar sobre a terra na forma de chuva ácida, e poluir a água e o solo. Também descartes impróprios de lixos perigosos que são lançados juntamente com águas poluídas nos rios podem ser lixiviados para águas subterrâneas.

Geralmente, a poluição atmosférica é caracterizada como sendo um fenômeno exclusivamente de grandes centros urbanos e regiões industrializadas, onde as concentrações de muitas substâncias químicas alcançam valores superiores em relação aos "níveis de base" daquele ambiente. Entretanto, a poluição do ar é um problema global, visto que os poluentes, no fundo, estão dispersos através de toda a atmosfera (Seinfield, 1986). 


\subsubsection{Poluição atmosférica: conceitos}

O termo "poluição atmosférica" pode ser definido como sendo qualquer condição atmosférica na qual substâncias presentes em concentrações acima dos níveis ambientais considerados "normais" são capazes de produzir um efeito mensurável nos humanos, animais, vegetação, ou materiais (Seinfield, 1986; Sell, 1992). Estas "substâncias" (nocivas ou benéficas) podem ser qualquer elemento químico de origem natural ou antrópica, ou até mesmo compostos pertencentes ao material particulado e que podem existir na atmosfera como gases, líquidos voláteis, ou partículas sólidas.

Os poluentes podem ser definidos como sendo substâncias presentes em concentrações mais elevadas do que as concentrações naturais resultantes da atividade humana e apresentando um efeito prejudicial para o ambiente ou para algo de valor naquele ambiente. Contaminantes (os quais não são classificados como poluentes ao menos que apresentem algum efeito prejudicial) causam interferências na composição normal do ambiente (Manahan, 2000).

\subsubsection{Classificação dos poluentes atmosféricos}

Os poluentes atmosféricos podem ser classificados segundo diferentes formas. Uma primeira classificação é de acordo com a composição química. Virtualmente todos os elementos da tabela periódica são encontrados na atmosfera e quando se trata de classificação de poluentes atmosféricos segundo composição química, há grupos majoritários de compostos constituídos de: (1) compostos sulfurosos; (2) compostos nitrogenados; (3) compostos carbônicos; (4) compostos halogenados; (5) substâncias tóxicas; (6) compostos radioativos. Os poluentes atmosféricos também podem ser classificados de acordo com o estado físico os quais se encontram: gasoso, líquido ou sólido. Os últimos dois estados implicam em dizer que o material está presente na atmosfera na forma particulada. Os poluentes também podem ser classificados de acordo com a maneira pela qual eles atingem a atmosfera, e são chamados de: (a) poluentes primários, àqueles emitidos diretamente das fontes de origem; (b) poluentes secundários, aqueles formados na atmosfera por interações químicas dentro dos poluentes primários e constituintes atmosféricos normais (Seinfield, 1986). 


\subsubsection{Fontes que geram poluentes}

Segundo Sell (2002) a poluição atmosférica pode ser gerada por seis grupos principais de fontes poluidoras:

1. Meios de transporte

2. Aquecimento doméstico

3. Geração de energia elétrica

4. Queima de lixo

5. Incêndios de pastagens e florestas

6. Queima de combustíveis industriais e processos envolvendo emissão

As fontes industriais contribuem com cerca de $20 \%$ de toda a poluição atmosférica. Também há uma grande preocupação com a poluição formada durante a geração de energia elétrica. Muitas indústrias consomem grandes quantidades de eletricidade. Esta eletricidade pode ser adquirida de uma companhia de produção ou mesmo ser gerada no local. Em ambos os casos, a indústria é considerada a responsável por problemas ambientais ocasionados pelo uso dessa energia.

\subsubsection{Efeitos da poluição atmosférica}

Muitos estudos têm mostrado que a poluição do ar afeta a saúde dos seres humanos e animais, causa danos à vegetação e ao solo, deteriora materiais, afeta o clima e reduz a radiação solar interferindo na vida dos seres vivos (Seinfield, 1986).

\section{Propriedades atmosféricas}

Os poluentes atmosféricos afetam as propriedades atmosféricas da seguinte forma: (1) redução da visibilidade; (2) formação e precipitação de neblina; (3) redução da radiação solar; (4) alteração da temperatura e distribuição dos ventos; (5) alteração do clima global. 


\section{Materiais}

Os poluentes podem afetar materiais, manchando ou deteriorando-os quimicamente. Elevados niveis de fumaça e material particulado estão associados com manchas em estruturas, e partículas ácidas ou alcalinas, especialmente aquelas contendo enxofre que corroem materiais como pinturas, alvenarias, contatos elétricos, e têxteis. $\mathrm{O}$ ozônio é particularmente efetivo na deterioração de materiais de borracha.

\section{Vegetação}

Os poluentes que são considerados como "fitotoxicantes" (substâncias prejudiciais à vegetação) são: $\mathrm{SO}_{2}$, nitrato de peroxiacetil (um oxidante produzido no smog fotoquímico), e eteno. Outros poluentes considerados menos prejudiciais são: cloro, ácido clorídrico, amônia e mercúrio. Em geral, os poluentes gasosos são absorvidos pela planta através do estômato em contato com o ar no curso da respiração normal da planta. Primeiramente na folha da planta, os poluentes destroem a clorofila e interrompem a fotossíntese. Os danos podem ir desde a redução da taxa de crescimento da planta até sua morte. Os sintomas de danos freqüentemente são manifestados na folha, e sintomas específicos freqüentemente indicam a evidência do poluente responsável.

\section{Seres humanos}

Nos seres humanos, as doenças do sistema respiratório estão geralmente correlacionadas com a poluição do ar. Existem dois tipos de reações causadas pelos poluentes atmosféricos no sistema respiratório: reação aguda, como por exemplo, a "bronquite irritante"; e a reação crônica, como a bronquite crônica e o enfisema pulmonar. 


\subsection{Monitoramento biológico}

$\mathrm{O}$ ar das áreas urbanas e industriais tende a apresentar concentrações indesejáveis de contaminantes, quando que há um sistema abrangente de monitoramento da poluição. A sofisticação dos métodos físico-químicos convencionais de monitoramento requer custos elevados para sua implantação, operação e manutenção. No entanto, estes custos podem ser minimizados pela adoção de uma metodologia complementar de biomonitoramento (Carneiro, 2004).

O biomonitoramento, ou monitoramento biológico é um método experimental que permite avaliar a resposta de organismos vivos à poluição, oferecendo vantagens como custos reduzidos, eficiência no monitoramento de amplas áreas geográficas de poluentes acumulados ao longo de um período e possibilidade de avaliar elementos químicos presentes em baixas concentrações no ambiente.

As medições e registros efetuados por redes convencionais de monitoramento da qualidade do ar permitem verificar se as normas e os limites estabelecidos ou recomendados pela legislação ou de agências ambientais e órgãos de promoção da saúde humana estão sendo respeitados. Entretanto, tal método (convencional) não permite obter conclusões imediatas sobre as conseqüências de poluentes nos seres vivos. Assim, o biomonitoramento deve ser considerado como um método complementar na análise de contaminantes, podendo constituir-se em um outro sistema de informações, além dos inventários de emissões e de concentrações de poluentes ambientais.

O uso de organismos cosmopolitas para avaliação da poluição no meio ambiente vem sendo desenvolvido notavelmente nas últimas décadas (Conti \& Cecchetti, 2001). Estes organismos absorvendo contaminantes ambientais podem ser utilizados como indicadores da biodisponibilidade de um determinado contaminante durante um determinado período, permitindo, em certos casos, comparações entre níveis de contaminação em áreas geograficamente diferentes. 
Um organismo biomonitor acumulador, para ser utilizado na avaliação da poluição atmosférica deve apresentar as seguintes características (Conti \& Cecchetti, 2001):

- Acumular os poluentes sem, entretanto, ser destruido devido aos níveis de contaminantes com os quais esteja em contato;

- Apresentar uma ampla distribuição geográfica;

- Ser abundante, sedentário ou de escassa mobilidade e também, ser representativo na área a ser estudada;

- Estar disponível durante o ano inteiro e permitir a coleta de seus tecidos em quantidades suficientes para análise;

- Ser de fácil coleta e ser útil em estudos de absorção de contaminantes;

- Apresentar um fator de acumulação elevado para o contaminante sob investigação;

- Apresentar uma elevada correlação entre a quantidade de contaminante presente no organismo e a concentração média de contaminante no ambiente circundante;

- Apresentar a mesma correlação do nível do conteúdo do contaminante com o do ambiente ao redor de todos os locais estudados e sob qualquer condição. Este fato deve ser verdadeiro para todos os organismos examinados.

\subsubsection{Algumas considerações sobre o uso do biomonitoramento}

Por várias razões, é de fundamental importância definir os "níveis de referência" para poluentes em um ecossistema quando estudos de monitoramento biológico serão realizados. Nestes estudos os seguintes aspectos devem ser considerados:

- Avaliação do estado de conservação ou degradação do ecossistema em estudo;

- Previsão da incidência de futuras atividades humanas, afim de que sejam estabelecidas as intervenções necessárias;

- Controle da evolução da situação ambiental com o tempo, usando programas de monitoração, se necessário. 
Para avaliar corretamente o grau de contaminação em um dado ecossistema, ou para realizar operações de biomonitoramento, primeiro é necessário que os "níveis de base", ou "valores de referência" dos contaminantes, ambos no ambiente (ar, água, solo) e nos organismos vivos presentes, sejam estabelecidos. Este "nível de base" pode ser interpretado de diferentes formas. Ele pode ser entendido como um nível pré-industrial (anterior a qualquer atividade humana); como um nível natural (condições médias de uma área ou uma região onde pode existir atividade humana, mas se encontra em um bom estado de conservação); como um nível padrão (baseado nas referências geográficas globais); ou mesmo como um nível zero (concentração de um elemento no ambiente ou em um organismo anterior ao desenvolvimento de uma atividade em particular e não depende do grau de conservação) (Carballeira et al., 2000).

\subsubsection{Liquens como biomonitores da poluição do ar}

As plantas são conhecidas como sendo organismos altamente favoráveis no biomonitoramento da qualidade do ar e podem ser muito efetivas como um sistema de alarme preventivo para detectar mudanças ambientais (Markert et al., 1996). Elas podem ser facilmente coletadas em amplas áreas e muitas espécies podem ser utilizadas. Visto que as plantas integram quantidades de elementos pertencentes à biota ao longo do tempo, elas permitem que as variações locais na deposição de muitos elementos sejam determinadas (Reimann et al., 1999).

Dentre um grande número de tipos de materiais biológicos empregados como biomonitores, os liquens têm sido amplamente utilizados para o monitoramento da poluição atmosférica.

Os liquens são uma associação de crescimento vagaroso entre fungos e algas verdes ou cianobactérias. Esta associação simbiótica forma um talo que não possui raízes ou película cerosa e sua sobrevivência depende, principalmente, da deposição atmosférica de nutrientes minerais. Estas características dos liquens, combinadas com sua extraordinária capacidade de crescer em um amplo espaço geográfico e de acumular elementos minerais mais do que necessitam para sua sobrevivência, faz com que sejam considerados como os melhores bioindicadores para a poluição do ar (Garty, 2001). 
O talo liquênico é um corpo vegetativo composto de dois organismos. O componente fúngico (micobionte) é um ascomicete ou basidiomicete que com êxito estabelece uma relação simbiótica com uma alga verde (ficobionte). Quando estes componentes se combinam, o talo resultante forma um organismo discreto e de vida longa que parece ser uma planta distinta das outras, não apresentando semelhança com qualquer outro fungo não-liquenizado ou alga. Os elementos de fungo e alga somente podem ser reconhecidos quando o talo é seccionado e examinado em um microscópio (Hale, 1983).

O talo liquênico folioso típico é constituído das seguintes partes: (a) córtex superior que reveste o talo externamente, constituído por uma a várias camadas de células "para" ou "prosoplectenquimáticas" ou, menos comumente, por um arranjo horizontal ou vertical de hifas em vários graus de compactação. Os tipos destas células, número de camadas e a sua espessura normalmente variam de espécie para espécie; (b) a camada de algas está, na grande maioria dos casos, localizada logo abaixo do córtex superior, constituída de hifas muito frouxamente arranjadas, entre as quais estão instaladas as células das algas. A parede celular do fungo é fina para facilitar a troca de substâncias com a alga, e incrustada de cristais hidrofóbicos de ácidos liquênicos, para manter a água afastada da camada de algas mesmo quando o talo está encharcado, para facilitar as trocas gasosas necessárias ao processo de fotossíntese das algas; (c) a medula (hifa) é a camada localizada logo abaixo da camada de algas, constituída exclusivamente de hifas entrelaçadas, com paredes mais espessas que as da camada de algas, e é esta parte é o local de armazenamento de água e reservas do fungo, constituindo a maior parte do talo (Hale, 1983). A FIG. 1.1. ilustra as partes morfológicas do líquen (Barbosa, 2005).

Comparados com as plantas superiores as quais obtêm pelo menos parte dos seus nutrientes do solo local por um sistema de raízes, as plantas inferiores como os liquens e briófitas não possuem este sistema radicular, o que significa que muitos contaminantes advindos da deposição seca e úmida podem ser absorvidos por toda superficie do líquen (Yenisoy-Karakas \& Tuncel, 2004).

Os liquens são "acumuladores" altamente eficientes de muitos elementos porque eles são organismos perenes, de crescimento vagaroso mantendo uma morfologia uniforme ao longo do tempo e são altamente dependentes da atmosfera para absorverem nutrientes, e não desprendem partes de plantas como, por exemplo, as folhas presentes nas plantas vasculares (Hale 1983, apud Bergamaschi et al. 2004). Freqüentemente se assume 
que os elementos acumulados pelos liquens representam alguma fração dos elementos presentes nos seus ambientes de origem. Conseqüentemente, os liquens com um estado aparentemente saudável devem refletir um equilibrio razoável entre suas necessidades e a disponibilidade dos elementos no ambiente (Brown et al., 1994). Além disso, como os liquens acumulam uma variedade de contaminantes, particularmente metais pesados e radionuclídeos eles têm sido muito úteis na documentação de dados de deposição espacial e temporal de diversos contaminantes (Nash \& Wirth, 1988).

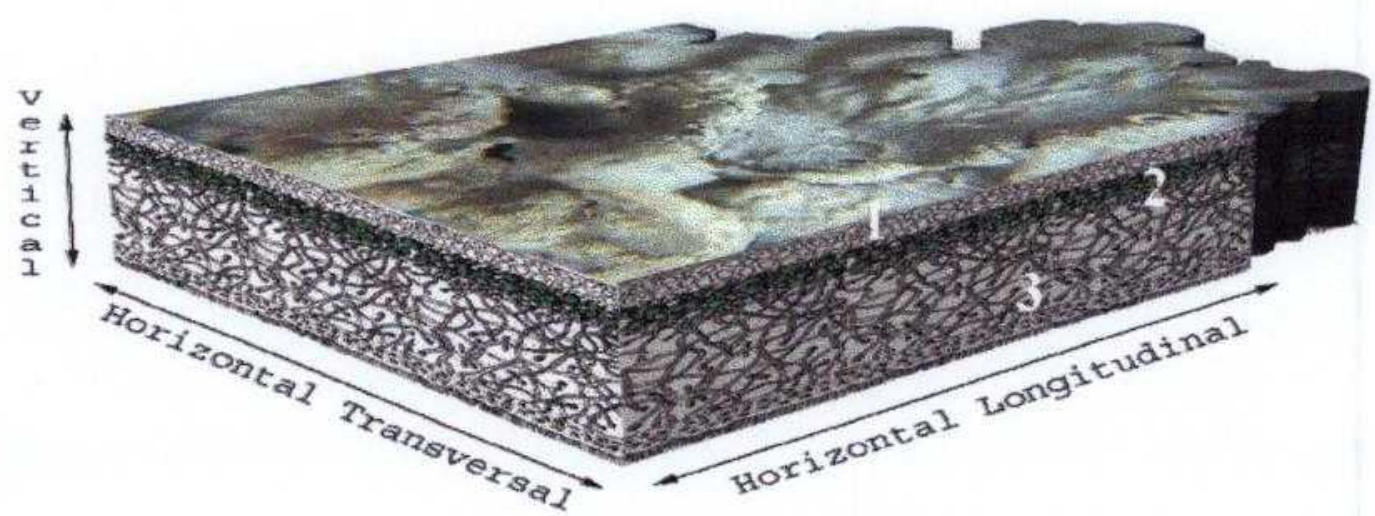

FIGURA 1.1. Partes anatômicas do talo liquênico: (1) córtex superior, (2) camada de algas e (3) medula (Barbosa, 2005).

As inúmeras investigações realizadas nas últimas três décadas sobre as interações existentes entre os liquens e os poluentes atmosféricos têm mostrado que estas espécies podem ser classificadas em três diferentes categorias em termos de suas respostas à poluição do ar (Garty et al. 1977, apud Garty et al. 2003): (1) espécies sensíveis, com vários graus de sensibilidade em relação aos efeitos dos poluentes, mas sucumbindo à poluição do ar; (2) espécies tolerantes, resistentes à poluição, competindo com a comunidade nativa e permanecendo intacta no seu habitat nativo; e (3) espécies substituintes que aparecem depois da destruição da maior parte da comunidade nativa de líquen como resultado da poluição. 


\subsubsection{Liquens como biomonitores: um breve histórico}

As primeiras observações relacionando a ausência de liquens em áreas poluídas constam da época do advento da revolução industrial na Europa, onde naturalistas começaram a observar que liquens não eram mais encontrados onde o ar era tido como "impuro" (Turner \& Borrer 1839, apud Richardson 1998). Em áreas não-poluídas, o crescimento de liquens nos troncos de árvores e nas rochas é freqüentemente observado, formando mancha de colorações cinza, verde ou mesmo alaranjada.

Por volta de 1859 a poluição foi considerada responsável pelo declínio da população liquênica ao redor das cidades. Sobre este fato a seguinte afirmação foi feita por Grindon 1859, apud Richardson 1998: "A qualidade dos liquens, das proximidades de Manchester tem sido muito diminuída nos últimos anos devido ao fluxo de fumaça de fábricas, o qual aparenta ser particularmente prejudicial a estes amantes do ar puro". Entretanto, foi Nylander quem na última metade do século XIX evidenciou, após estudos realizados com os liquens presentes nos arredores de Paris que estes organismos poderiam ser indicadores úteis para estudos relacionados à qualidade do ar. Seus estudos realizados no Jardim de Luxemburgo em Paris mostraram primeiro o declínio e posteriormente o desaparecimento dos liquens nas árvores daquele jardim (Nylander 1866 e 1896, apud Richardson 1998). Atualmente, depois de mais de um século, é interessante notar que os liquens estão voltando a colonizar aquelas árvores devido a uma queda da poluição do ar (Seaward \& Letroit-Galinou, 1991).

Apesar da pesquisa de Nylander ter sido pioneira, foi somente após o trabalho de Skye 1958, apud Richardson 1998 que os limites de tolerância de determinadas espécies começaram a ser documentados. Por volta dos anos setenta, Hawksworth \& Rose 1970, apud Richardson 1998 estabeleceram uma escala qualitativa para estimar a poluição do ar por dióxido de enxofre usando liquens que cresciam nas árvores. Estes pesquisadores examinaram a flora liquênica ao redor das cidades na Inglaterra e no país de Gales e estabeleceram uma relação da distribuição de determinadas espécies de liquens para medir os níveis de dióxido de enxofre $\left(\mathrm{SO}_{2}\right)$ trazidos pelo vento. Estes, identificaram uma área constituída por dez zonas sendo a zona 1 , aquela que não possuía liquens (deserto liquênico) e com niveis $\mathrm{SO}_{2}$ que excediam 170 microgramas por metro cúbico de ar $\left(\mu \mathrm{g} \mathrm{m}^{-3}\right)$ e a zona 10 , constituída de uma ampla faixa de liquens típicos de regiões antigas e com teores de $\mathrm{SO}_{2}$ menores que $10 \mu \mathrm{g} \mathrm{m}^{-3}$. Desde a publicação desta escala, as 
comunidades de liquens sobreviventes foram muitas vezes usadas para avaliar a qualidade do ar em muitas cidades e nos seus arredores através do mundo.

\subsubsection{Liquens como biomonitores: estudos e perspectivas}

Diversos estudos têm mostrado a viabilidade do uso de muitas espécies de liquens para monitoramento biológico, para deteç̧ão da deposição, acúmulos e distribuição da poluição atmosférica ocasionada principalmente por metais. Portanto para um trabalho de biomonitoramento da poluição aérea, um estudo prévio quanto às espécies a serem empregadas como biomonitores deve ser feito. Este estudo prévio sobre as espécies a serem utilizadas no biomonitoramento envolve também as investigações sobre as suas capacidades distintas em acumularem poluentes atmosféricos, entre os quais incluem-se os metais pesados. Além disso, no biomonitoramento, os seguintes aspectos devem ser considerados (Sloof, 1992):

- Ocorrência da espécie a ser empregada, ou seja, sua presença ou não na região sob investigação;

- Localização das espécies a serem utilizadas (proximidade das rodovias de tráfego intenso e fontes de metais);

- Facilidade de amostragem e de tratamento da amostra;

- Tolerância da espécie à poluição;

- Conhecimento das concentrações de base, valores de referência ou de controle de elementos;

- Conhecimento da quantidade de metais presentes na própria atmosfera e em fertilizantes que são amplamente utilizados em atividades agrícolas;

- Conhecimento dos metais contidos no substrato ainda que esteja presente em menor extensão. 
$\mathrm{Na}$ Turquia, por exemplo, no distrito da Província de Erzurum, oito espécies (Cetraria pinastri (Scop.) Gray; Dermatocarpon miniatum (L.) W. Mann; Lecanora muralis (Schreb.) Rabenh.; Pseudevernia furfuracea (L.) Zopf.; Ramalina capitata (Ach.) Nyl.; Rhizoplaca chrysoleuca (sm.) Zopf.; Rhizoplaca melanophthalma (DC.) Leuckert \& Poelt e Xanthoparmelia somloensis (Gyeln.) Hale) foram analisadas para obter-se informações sobre a capacidade de diferentes espécies de líquen, crescendo no mesmo local, em acumular íons metálicos (Aslan et al., 2004). Além disso, este trabalho teve o objetivo de avaliar a qualidade relativa do ar para diferentes íons metálicos em pontos de zonas rural, suburbana e urbana da Província de Erzurum.

Também no Laboratório de Análise por Ativação Neutrônica do IPEN, cinco espécies de fungos liquenizados: Canoparmelia texana (Tuck.) Elix \& Hale, Canoparmelia caroliniana (Nylander) Elix \& Hale, Parmotrema tinctorum (Nylander) Hale, Parmotrema sancti-angeli (Lynge) Hale e Usnea sp. foram coletadas no Instituto de Botânica (São Paulo, Brasil) para a determinação de elementos traço (Coccaro et al., 1999; 2001). Os resultados mostraram que estas cinco espécies podem ser utilizadas para estudos de biomonitoramento visto que elas acumulam os mesmos elementos traço e todos na mesma ordem de grandeza. Neste trabalho também foi verificado que os elementos determinados apresentam variabilidade considerável dentro das amostras de uma mesma espécie e este fato foi atribuído provavelmente, às diferentes idades das amostras ou suas posições em relação ao tronco de árvore o qual foram coletadas.

Ainda referindo-se sobre a escolha de espécies de fungos liquenizados a serem empregados para estudos de biomonitoramento, um estudo realizado com liquens coletados em três países (Alemanha, Itália e Romênia) com diferentes condições climáticas, teve como objetivo, investigar dentre três espécies escolhidas (Cetraria islandica, Evernia prunastri, e Ramalina farinacea), a mais apropriada para transplantes e biomonitoramento de elementos traço presentes no ar (Cercasov et al., 2002). Estas espécies foram expostas em suportes livres de substratos durante o período de Julho de 1996 até Julho de 1997 nos países já mencionados, em seis pontos de amostragem com diferentes tipos de poluentes (dois em cada país). Depois de dois, quatro, seis e doze meses de exposição, porções do talo foram coletadas, preparadas e analisadas. Os quinze elementos ambientalmente relevantes determinados foram: $\mathrm{As}, \mathrm{Br}, \mathrm{Ca}, \mathrm{Co}, \mathrm{Cr}, \mathrm{Cu}, \mathrm{Fe}, \mathrm{K}, \mathrm{Mn}, \mathrm{Ni}, \mathrm{Pb}, \mathrm{S}, \mathrm{Sb}, \mathrm{V}$ e $\mathrm{Zn}$. Estes resultados evidenciaram a capacidade de acumulação para todas as espécies analisadas e para uma comparação entre as distintas espécies foram considerados os 
critérios do conteúdo elementar inicial, fatores de acumulação relativos à deposição interna, fatores de calibração de interespécies e as eficiências de retenção. Estes critérios indicaram que a Evernia prunastri é a mais apropridada, seguida da Ramalina farinacea e por último Cetraria islandica.

Em um outro trabalho, Fuga et al. (2002) aplicando o método de análise por ativação neutrônica determinaram elementos traço em três espécies distintas de fungos liquenizados: Usnea meridionalis, Parmotrema tinctorum e Parmotrema dilatatum. As análises mostraram que as três espécies podem ser utilizadas no monitoramento da poluição ambiental visto que elas acumulam concentrações de elementos na mesma ordem de grandeza. As concentrações dos elementos $\mathrm{Al}, \mathrm{Br}, \mathrm{Ca}, \mathrm{Cl}, \mathrm{Fe}, \mathrm{K}, \mathrm{Mg}, \mathrm{Mn}, \mathrm{Na}, \mathrm{Rb}, \mathrm{V}$ e $\mathrm{Zn}$ foram encontradas nos níveis de $\mu \mathrm{g} \mathrm{g}^{-1}$ e os elementos $\mathrm{As}, \mathrm{Cs}, \mathrm{Cr}, \mathrm{Co}, \mathrm{Hf}, \mathrm{Mo}, \mathrm{Sb}, \mathrm{Sc}$, Se, Th e elementos lantanídeos da ordem de $\mathrm{ng}^{-1}{ }^{-1}$.

Apesar do importante papel que as diferentes espécies de fungos liquenizados desempenham no biomonitoramento de poluentes atmosféricos, há ainda pouca informação sobre a sua fisiologia, por exemplo, como os elementos se distribuem dentro do talo liquênico. Visto que as concentrações de elementos em partes específicas do talo liquênico poderiam indicar possíveis fontes de poluição, na Polônia foi realizado um estudo para verificar as diferenças existentes nas concentrações de elementos presentes nas distintas partes do líquen (córtex superior, camada de algas, medula e córtex inferior) (Budka et al., 2004). Nesta investigação foi realizado o transplante de Hypogymnia physodes (fungo liquenizado de talo estratificado) coletado numa região considerada não-poluída (Floresta Borecka, no Norte da Polônia) para uma região considerada poluída (pontos de florestas a diferentes distâncias de Kraków, no Sul da Polônia). Como metodologia analítica foi empregada a técnica de emissão de raios- $X$ induzida com micro-partículas (micro-PIXE) eos seus resultados indicaram altas concentrações de $\mathrm{P}, \mathrm{S}, \mathrm{Cl}, \mathrm{K}, \mathrm{Ca}, \mathrm{Mn}, \mathrm{Fe}$ e $\mathrm{Zn}$ nas camadas da hifa do talo liquênico.

Um estudo similar utilizando a técnica analitica de micro-PIXE foi também realizado com Xanthoparmelia chlorochroa coletada no oeste dos Estados Unidos para dar continuidade aos estudos sobre caracterização dos efeitos da poluição atmosférica na região de Mountain Rocky (Clark et al., 1999). Neste estudo foi verificado que a maioria dos elementos são encontrados próximos às camadas de algas e córtex inferior. A técnica empregada de micro-PIXE demonstrou-se útil na elucidação da absorção e mecanismo de 
transporte de elementos em liquens, fornecendo não só dados referentes às concentrações elementares, mas também informação espacial básica para entender sobre as suas relações fisiológicas e bioquímicas. Além disso, neste trabalho foi demonstrada a possibilidade de realizar medidas de poluentes em camadas escolhidas ou de partes específicas de interesse dentro do talo transplantado isto é, nas partes superiores do talo onde há um maior contato com os poluentes atmosféricos ou em fragmentos internos que reagiram aos danos causados pela poluição.

Uma vez escolhidas as espécies de acordo com seu potencial para serem empregadas em estudos de biomonitoramento e conhecido um pouco mais sobre fisiologia de liquens, é de interesse estabelecer um "nível de base" de acúmulo de elementos para as espécies selecionadas para que posteriormente estes níveis sejam comparados com os daquelas coletadas em regiões que apresentem diferentes niveis de poluição. Bergamaschi et al. (2004) para estabelecer estes níveis de base no que diz respeito à composição elementar nos liquens, coletaram amostras em regiões de altitudes elevadas: Himalaia (Nepal), Monte Kênia (Kênia) e Alpes (Itália). Neste estudo foi demonstrado que os métodos de análise por ativação neutrônica instrumental (INAA) e de espectrometria de absorção atômica eletro-térmica (ET-AAS) aplicadas à determinação multielementar em amostras de liquens são ferramentas importantes para o biomonitoramento, para a prospecção biogeoquímica e estudo do meio ambiente. Além disso, foi mostrado que os liquens coletados em áreas não-poluídas de altitudes elevadas bem como em áreas com baixos níveis de poluição sofrem influência de fatores antrópicos por meio do transporte atmosférico de poluentes a longas distâncias principalmente para elementos muito voláteis como $\mathrm{Br}, \mathrm{Cd}$ e $\mathrm{Sb}$, os quais foram encontrados amplamente dispersos em grandes áreas.

Ainda referindo-se a "valores de base" ou de "referência" das concentrações de elementos nos liquens, na Turquia estes dados foram obtidos para estabelecer a primeira rede de biomonitoramento na região do Egeu (Yenisoy-Karakas \& Tuncel, 2004). Para esta finalidade, um total de duzentos e trinta e quatro amostras de Xanthoria parietina foram coletadas em uma área de $51.800 \mathrm{~km}^{2}$. Foi estudada a variabilidade entre as concentrações de elementos em liquens coletados em diferentes pontos de amostragens (a nível local e regional). Uma vez estabelecidos os niveis de base, foi feito um estudo da correlação existente entre as deposições elementares com as fontes locais de emissões de indústrias de ferro-aço e queima de carvão nas cidades, atividade industrial e duas termoelétricas importantes na região as quais, geralmente corresponderam aos locais com maior acúmulo 
de elementos nos liquens. Os parâmetros como o tamanho e morfologia dos liquens e influência do substrato nas concentrações de elementos foram analisados como variações locais antes dos geographical patterns of elements serem discutidos. Nos mapas de distribuição das concentrações de oito elementos presentes no fungo liquenizado Xanthoria parietina na região do Egeu foi verificada a relação existente entre a deposição de elementos e a presença de fontes de poluição.

Uma vez identificadas espécies de fungos liquenizados que podem ser empregados para estudos de biomonitoramento e tendo sido estabelecidos os seus "níveis base" de concentrações elementares, as comparações entre niveis de contaminação em áreas geograficamente diferentes têm sido realizadas para identificação da origem dos elementos poluentes.

Relativamente à origem dos elementos contaminantes presentes na atmosfera foi feita uma revisão sobre o assunto o qual está apresentada na TAB. 1.1. Conforme mostra esta Tabela os elementos podem ter as mais variadas origens tais como industriais, veiculares, marinha e do solo. 
TABELA 1.1 - Elementos químicos no meio ambiente e suas possiveis fontes de origem.

\begin{tabular}{|c|c|c|}
\hline Elemento & Vias para o meio ambiente & Referência Bibliográfica \\
\hline As & $\begin{array}{l}\text { Termoelétricas (queima de carvão); } \\
\text { indústrias de tintas, materiais elétricos, } \\
\text { refinarias; indústrias de eletrônicos, de ferro- } \\
\text { aço, de produtos têxteis e químicas; extração } \\
\text { de minérios; fazendas de frango } \\
\text { (frigoríficos); plantas de produção de óleo de } \\
\text { oliva; matéria-prima para produção de } \\
\text { cerâmica; inseticidas; fungicidas e } \\
\text { fertilizantes fosfatados. }\end{array}$ & $\begin{array}{c}\text { Freitas et al., } 1999 \\
\text { Reimann \& Caritat, } 1998 \\
\text { Yenisoy-Karakas \& Tuncel, } \\
2004\end{array}$ \\
\hline $\mathrm{Ba}$ & $\begin{array}{l}\text { Poeiras trazidas pelo vento; erosão de } \\
\text { minerais associados ao } \mathrm{Ba} \text {; fundição de } \mathrm{Cu} \text {; } \\
\text { indústria automobilistica e indústria do aço. }\end{array}$ & Reimann \& Caritat, 1998 \\
\hline $\mathrm{Br}$ & $\begin{array}{l}\text { Queima de combustíveis utilizados em } \\
\text { plantas de processamento de areias; } \\
\text { partículas de minérios; spray marinho; } \\
\text { tráfego de veículos e agricultura. }\end{array}$ & $\begin{array}{l}\text { Dias da Cunha et al., } 2004 \\
\text { Reimann \& Caritat, } 1998\end{array}$ \\
\hline $\mathrm{Ca}$ & $\begin{array}{l}\text { Aerossóis marinhos; particulados do solo; } \\
\text { indústrias de cal e cimento; partículas } \\
\text { orgânicas transportadas pelo ar; fertilizantes. }\end{array}$ & $\begin{array}{l}\text { Dias da Cunha et al., } 2004 \\
\text { Reimann \& Caritat, } 1998\end{array}$ \\
\hline $\mathrm{Cl}$ & $\begin{array}{l}\text { Aerossóis marinhos; partículas de solo; } \\
\text { emissões vulcânicas; indústria de potássio; } \\
\text { moinhos de papel e rodovias que escoam sal. }\end{array}$ & $\begin{array}{l}\text { Dias da Cunha et al., } 2004 \\
\text { Reimann \& Caritat, } 1998\end{array}$ \\
\hline $\mathrm{Co}$ & $\begin{array}{l}\text { Processamento e mineração de } \mathrm{Ni}, \mathrm{Ag}, \mathrm{Pb} \text {, } \\
\mathrm{Cu} \text { e } \mathrm{Fe} \text {; combustão de carvão; poeira do } \\
\text { solo; erosão e fertilizantes. }\end{array}$ & Reimann \& Caritat, 1998 \\
\hline $\mathrm{Cr}$ & $\begin{array}{l}\text { Tráfego intenso de veículos; plantas de } \\
\text { processamento de rochas minerais que } \\
\text { concentram rutilo, ilmenita e zirconita; } \\
\text { influência do solo; indústria química; } \\
\text { indústria de aço; eletrometalurgia; fundição } \\
\text { de } \mathrm{Cu} \text {; combustão de gás natural, gasolina e } \\
\text { carvão; detritos de esgoto; incineração de } \\
\text { lixo e alguns fertilizantes fosfatados. }\end{array}$ & $\begin{array}{l}\text { Dias da Cunha et al., } 2004 \\
\text { Freitas et al., } 1999 \\
\text { Reimann \& Caritat, } 1998\end{array}$ \\
\hline $\mathrm{Cs}$ & $\begin{array}{l}\text { Poeira do solo; erosão de rochas; testes } \\
\text { nucleares e acidentes nucleares. }\end{array}$ & Reimann \& Caritat, 1998 \\
\hline
\end{tabular}


TABELA 1.1 - Elementos químicos no meio ambiente e suas possíveis fontes de origem.

\begin{tabular}{|c|c|c|}
\hline $\mathrm{Fe}$ & $\begin{array}{l}\text { Materiais de construção; indústria de ferro- } \\
\text { aço; combustão de combustíveis fósseis } \\
\text { (queima e carvão); atividades industriais; } \\
\text { poeira do solo; erosão de rochas e spray } \\
\text { marinho. }\end{array}$ & $\begin{array}{c}\text { Dias da Cunha et al., } 2004 \\
\text { Garty et al., } 2003 \\
\text { Reimann \& Caritat, } 1998 \\
\text { Yenisoy-Karakas \& Tuncel, } 2004\end{array}$ \\
\hline $\mathrm{K}^{(\mathbf{a})}$ & $\begin{array}{l}\text { Fertilizantes; spray marinho; poeira do solo } \\
\text { trazida pelo vento; partículas orgânicas } \\
\text { transportadas pelo ar. }\end{array}$ & $\begin{array}{c}\text { Dias da Cunha et al., } 2004 \\
\text { Reimann \& Caritat, } 1998 \\
\text { Yenisoy-Karakas \& Tuncel, } 2004\end{array}$ \\
\hline $\mathrm{La}$ & $\begin{array}{l}\text { Presença de rochas monazíticas; poeira do } \\
\text { solo e mineração e processamento de rochas } \\
\text { alcalinas. }\end{array}$ & $\begin{array}{l}\text { Dias da Cunha et al., } 2004 \\
\text { Reimann \& Caritat, } 1998\end{array}$ \\
\hline $\mathrm{Mn}$ & $\begin{array}{l}\text { Produção de aço, baterias e ligas; indústrias } \\
\text { de ferro-aço; emissões veiculares; erosão de } \\
\text { rochas; poeira trazida pelo vento e } \\
\text { agricultura. }\end{array}$ & $\begin{array}{c}\text { Dias da Cunha et al., } 2004 \\
\text { Reimann \& Caritat, } 1998 \\
\text { Yenisoy-Karakas \&Tuncel, } 2004\end{array}$ \\
\hline Mo & $\begin{array}{l}\text { Mineração de urânio; fundição e mineração } \\
\text { de Mo; refino de óleo; combustão de } \\
\text { gasolina e carvão; fertilizantes fosfatados; } \\
\text { detritos de esgoto; detergentes fosfatados; } \\
\text { poeira geogênica e erosão. }\end{array}$ & Rei \\
\hline $\mathrm{Na}$ & $\begin{array}{l}\text { Spray marinho, rodovias que transportam } \\
\text { sal; fertilizantes; águas residuais e poeira } \\
\text { solo. }\end{array}$ & $\begin{array}{c}\text { Reimann \& Caritat, } 1998 \\
\text { Yenisoy-Karakas \&Tuncel, } 2004\end{array}$ \\
\hline $\mathrm{Rb}$ & $\begin{array}{l}\text { Poeira do solo e erosão de minerais } \\
\text { associados ao } \mathrm{Rb} \text {. }\end{array}$ & 1998 \\
\hline $\mathrm{Sb}$ & $\begin{array}{l}\text { Indústria de semicondutores; aditivos de } \\
\text { borrachas, pigmentos, tintas; termoelétricas } \\
\text { (queima de carvão); particulados do solo; } \\
\text { fundições de } \mathrm{Cu} \text { e } \mathrm{Pb} \text { e detritos de esgoto. }\end{array}$ & $\begin{array}{c}\text { Freitas et al., } 1999 \\
\text { Reimann \& Caritat, } 1998 \\
\text { Yenisoy-Karakas \&Tuncel, } 2004\end{array}$ \\
\hline Sc & $\begin{array}{l}\text { Produção de urânio e poeira do solo trazida } \\
\text { pelo vento. }\end{array}$ & Reimann \& Caritat, 1998 \\
\hline $\mathrm{Se}$ & $\begin{array}{l}\text { Combustão de carvão; fundições de } \mathrm{Cu} \text { e } \\
\mathrm{Pb} \text {; águas residuais e alguns fertilizantes } \\
\text { fosfatados contendo Se. }\end{array}$ & $\begin{array}{c}\text { Freitas et al., } 1999 \\
\text { Reimann \& Caritat, } 1998\end{array}$ \\
\hline $\mathrm{U}$ & $\begin{array}{l}\text { Mineração de U; combustão de carvão e } \\
\text { fertilizantes fosfatados. }\end{array}$ & Reimann \& Caritat, 1998 \\
\hline $\mathrm{Zn}$ & $\begin{array}{l}\text { Spray marinho; fundições de } \mathrm{Zn} \text {; desgaste } \\
\text { de pneus; águas residuais; detritos de esgoto } \\
\text { e poeira do solo. }\end{array}$ & $\begin{array}{l}\text { Dias da Cunha et al., } 2004 \\
\text { Reimann \& Caritat, } 1998\end{array}$ \\
\hline
\end{tabular}

(a) $\mathrm{K}$ é um elemento nutriente para os liquens e não é obtido somente da atmosfera, mas também do quelato advindo de outra folhagem morta. 
Os liquens têm sido usados como biomonitores na localização e identificação de fontes poluidoras do ar. As determinações de elementos traço em liquens e no material particulado possibilitaram a avaliação da poluição atmosférica da região montanhosa de Biella no Norte da Itália, local caracterizado pela presença de instalações de indústrias de lã (Rizzio et al., 2001). Neste trabalho, amostras de material particulado coletadas em filtros, de diferentes espécies de fungos liquenizados e de solo foram analisadas para calcular os fatores de enriquecimento (EFs) de mais de vinte e cinco elementos traço. A comparação entre os fatores de enriquecimento correspondentes mostrou que a Parmelia caperata é a mais apropriada para uso como biomonitor de elementos traço para a região sob investigação. As amostras de $P$. caperata analisadas pelo método de análise por ativação neutrônica para a avaliação da distribuição de elementos traço em quatro pontos de amostragem diferentes indicaram a predominância do transporte dos poluentes.

Em Portugal, o uso de liquens epifiticos no biomonitoramento de poluentes atmosféricos permitiu avaliar a distribuição de alguns elementos poluentes e identificar possíveis fontes de origem de poluentes (Freitas et al., 1999). No caso, em uma campanha de coleta de Parmelia sulcata Taylor foram obtidas amostras em 228 pontos de amostragens ao longo da costa Atlântica e numa área situada no interior de Portugal. As amostras foram analisadas pelo método de análise por ativação neutrônica e pela espectroscopia de emissão de raios-X induzida por prótons e foram determinados os elementos $\mathrm{As}, \mathrm{Cr}, \mathrm{Hg}, \mathrm{Ni}, \mathrm{Pb}, \mathrm{S}, \mathrm{Sb}$, Se e $\mathrm{V}$. A análise destes resultados indicou as seguintes fontes de origem de poluentes: (1) usinas de petróleo no eixo Lisboa-Setúbal para os elementos V e Ni; (2) usinas de carvão em Porto e Sines para S e Se; (3) tráfego veicular na região norte e no eixo Lisboa-Setúbal para o elemento $\mathrm{Pb}$; (4) uma indústria química de Porto para $\mathrm{Hg}$ e As; e (5) influência do solo para o caso de Cr e Sb.

Além da localização e identificação de fontes poluidoras do ar, os liquens podem ser utilizados para a caracterização de transporte de materiais particulados pelo ar. Um estudo realizado em Aldeia Buena localizada na região litorânea do Rio de Janeiro, Brasil teve por objetivo caracterizar os materiais particulados do ar deste local os quais apresentam concentrações elevadas de areais minerais (mineral sands), pois estudos prévios tinham sugerido que, além da ingestão de gêneros alimentícios contendo tório $\mathrm{e}$ urânio, a inalação destes materiais particulados transportados pelo ar também poderia ser considerada como sendo via de contaminação interna (Dias da Cunha et al., 2004). Buena (pequena vila localizada na região costeira do Rio de Janeiro) é um dos principais 
depósitos de minérios do Brasil e local onde está a planta para obter concentrados de monazita, zircônio, rutilo e ilmenita. Num outro trabalho de Dias da Cunha et al. (2003) foi mostrado que, além do tório, os habitantes desta aldeia incorporaram $\mathrm{La}$ e $\mathrm{Ce}$ nos seus organismos, sugerindo que a inalação de areias monazíticas é uma importante via para a incorporação destes elementos. As análises de amostras de aerossóis e fungos liquenizados Ramalina gracilis (Pres.) Nyl. mostraram que os habitantes desta região estão expostos às partículas do ar contendo uma fina fração dos aerossóis. As principais fontes antrópicas de partículas são as usinas de processamento de minerais e tráfego de caminhões, e como fontes naturais de origem, o mar, solo e brejos. Os resultados das análises de liquens mostram que pelo menos há quinze anos que os seus habitantes estão expostos às partículas contendo os elementos $\mathrm{Cl}, \mathrm{K}, \mathrm{Ca}, \mathrm{Ti}, \mathrm{V}, \mathrm{Cr}, \mathrm{Mn}, \mathrm{Fe}, \mathrm{Ni}, \mathrm{Cu}, \mathrm{Zn}, \mathrm{Br}, \mathrm{Sr}, \mathrm{Zn} \mathrm{e} \mathrm{Pb}$ transportados pelo ar. Os resultados obtidos para aerossóis e liquens indicaram que os brejos são uma fonte de partículas contendo os elementos ${ }^{226} \mathrm{Ra}$ e ${ }^{210} \mathrm{~Pb}$ além da poeira monazítica.

Os liquens também têm sido utilizados na avaliação de impactos ambientais ocasionados por fontes poluidoras, acidentes químicos, e até mesmo por guerras e conflitos, sendo estes biomonitores considerados eficazes como um sistema de alarme prévio para detectar mudanças ambientais. Como por exemplo, Di Lella et al. (2004) avaliaram a distribuição de urânio e outros elementos traço em pontos selecionados de Kosovo para verificar a contaminação ambiental causada pelas munições de "urânio empobrecido", utilizadas durante o conflito de Kosovo. Este estudo mostrou que o armamento utilizado não ocasionou uma contaminação ambiental que pudesse causar um aumento relevante de urânio detectável em liquens. As medidas da razão isotópica de ${ }^{235} \mathrm{U} /{ }^{238} \mathrm{U}$ não indicaram a presença de partículas de "urânio empobrecido". Somente em Ksovska Mitrovica foi verificada a contaminação ambiental por muitos metais pesados tóxicos como $\mathrm{Pb}, \mathrm{Zn}$, As e $\mathrm{Cd}$. Num trabalho prévio realizado por Loppi et al. (2003) na região dos Bálcãs sobre avaliação da contaminação ambiental oriunda de urânio empobrecido resultante do conflito de 1999 em Kosovo foi mostrado que as concentrações de $U$ encontradas nos liquens foram concordantes com os valores reportados para liquens de outros paises e muito abaixo dos niveis encontrados em liquens coletados em áreas com fontes naturais e antrópicas de urânio. 
Nos países baixos da Europa, o ${ }^{137}$ Cs resultante do acidente de Chernobyl foi monitorado por meio do uso dos seguintes fungos liquenizados: Parmelia sulcata e Xanthoria parietina (Sloof \& Wolterbeek, 1992). A similaridade entre os dados obtidos para Parmelia sulcata e aqueles da deposição seca e úmida, indicou a validade do uso desta espécie na monitoração de ${ }^{137} \mathrm{Cs}$ da atmosfera. As medições de acúmulo de ${ }^{137} \mathrm{Cs}$ em Xanthoria parietina mostraram que a concentração de atividade poderia ser expressa tanto na base seca como na base de área superficial de contorno (contour surface area basis). A determinação da meia-vida biológica do ${ }^{137} \mathrm{Cs}$ em liquens mostrou estar sujeita a possíveis fontes de erro devido ao crescimento e influxos de ${ }^{137} \mathrm{Cs}$ não-atmosféricos e indiretos.

Os fungos liquenizados Ramalina lacera (With.) J. R. Laund. foram aplicados como biomonitores da poluição do ar em Israel, para avaliar o impacto ambiental causado por uma usina termoelétrica de carvão (Garty et al., 2003). As amostras de líquen foram coletadas numa floresta relativamente não-poluída próxima a HaZorea em Ramoth Menashe, nordeste de Israel e foram transplantadas em dez pontos próximos a usina termoelétrica Oroth Rabin localizada perto da cidade de Hadera. Neste estudo foram examinados três parâmetros fisiológicos do líquen para avaliar os sintomas de estresse causados pela poluição atmosférica originária da atividade antrópica. Portanto, os objetivos deste trabalho foram: (1) descrever a quantidade elementar nos liquens os quais foram coletados em local relativamente não-poluído bem como daqueles transplantados ao redor da usina termoelétrica, (2) comparar os três parâmetros físiológicos da vitalidade de liquens no final do período de exposição e detectar o parâmetro mais favorável para ser utilizado em uma área de estudo com diferentes níveis de poluição do ar, e (3) relacionar os objetivos(1) e (2) do seu trabalho com a direção dos ventos para obter-se informação indireta de fontes poluidoras. Os parâmetros fisiológicos mencionados relacionados com a vitalidade de liquens e com as quantidades elementares neles presentes foram: (a) potencialidade de produção de fotossintese; (b) produção de etileno devido ao estresse provocado pela presença dos elementos $\mathrm{Al}, \mathrm{Ba}, \mathrm{Pb}, \mathrm{S}, \mathrm{V}, \mathrm{Cu}$ e $\mathrm{Sn}$ e; (c) condutividade elétrica que expressa a integridade de membranas celulares apresentando correlação com os elementos $\mathrm{B}, \mathrm{Fe}, \mathrm{Mg}, \mathrm{Mn}, \mathrm{Na}, \mathrm{Pb}, \mathrm{S}, \mathrm{Sn}$ e $\mathrm{Ti}$. Seus resultados permitiram concluir que $R$. lacera é um excelente acumulador, isto é, os elementos, especialmente $\mathrm{Ca}, \mathrm{S}, \mathrm{K}, \mathrm{Al}, \mathrm{Fe}$, $\mathrm{P}$, e $\mathrm{Mg}$, foram acumulados em quantidades consideráveis pelo líquen. A função desta espécie como um sensor ambiental foi claramente demonstrado, visto que os danos 
fisiológicos apresentaram correlação com o acúmulo de certos elementos traço, incluindo metais pesados e enxofre.

Além de identificar as fontes poluidoras e permitir a avaliação dos impactos ambientais, os liquens podem ainda servir para estimar o grau de contaminação de vastas áreas, incluindo áreas remotas bem como do grau de contaminação através da cadeia alimentar. No caso a análise do líquen permitiu também a avaliação do impacto causado por uma mina de urânio localizada no Canadá, dentro da seguinte cadeia alimentar crítica: líquen-rena-humano (Thomas \& Gates, 1999).

Portanto verifica-se que os liquens epifiticos têm sido analisados para diversas finalidades, desde estudos envolvendo físiologia de liquens até para avaliação de impactos ambientais. Conseqüentemente há uma preocupação no que diz respeito à conservação destes espécimes para que sempre possam ser utilizados para diferentes propósitos. Por exemplo, nas florestas boreais da Fenoescândia, devido à sua fragmentação crescente, a presença de muitos liquens epifíticos está começando a ficar ameaçada (Lidén et al., 2004). Num estudo realizado pela Universidade de Ciências Agrárias da Suiça foram examinadas a sobrevivência e a vitalidade de fragmentos de fungos liquenizados Evernia divaricata (L.) Ach. e Ramalina dilacerata (Hoffm.) Hoffm. depois de serem transplantados para os pontos situados ao norte da Suíça. Este estudo mostrou que transplantes de pequenos fragmentos de liquens devem constituir uma opção eficiente para o estabelecimento de novas populações de espécies ameaçadas, ou para ampliar sua população nos pontos de ocorrência. Trata-se de um método para dispersão interlocal, atentando para a reintrodução e/ou novo estabelecimento de espécies ameaçadas em novos ambientes.

O levantamento bibliográfico mostrou que o biomonitoramento vem sendo empregado como alternativa para estudos da poluição atmosférica e de seus impactos ambientais, e mesmo para aplicações em larga escala em diversos países. No Brasil o desenvolvimento de pesquisas que envolvem uso de biomonitores torna-se de grande interesse devido aos crescentes problemas ambientais da poluição atmosférica e desmatamento de ecossistemas como a Mata Atlântica e a Floresta Amazônica.

Há registros de cerca de 2.800 espécies de liquens no território nacional (Marcelli, 1998) e, no entanto, dados quanto ao seu uso em estudos sistemáticos de biomonitoramento e dados sobre sua composição elementar são escassos. 


\section{OBJETIVO}

O objetivo da presente pesquisa é avaliar os níveis de elementos traço da poluição aérea da região metropolitana de São Paulo usando a espécie de fungo liquenizado Canoparmelia texana como biomonitor.

Neste trabalho foram analisadas amostras de $C$. texana coletadas em dois Parques Estaduais (Parque Estadual Carlos Botelho e Parque Estadual Intervales), situados no ecossistema de Mata Atlântica - SP, área considerada não-poluída e em 24 pontos de amostragens na região metropolitana de São Paulo, área considerada poluída.

Para a análise multielementar das amostras de liquens, foi aplicado o método instrumental de análise por ativação com nêutrons e os seguintes elementos foram determinados: As, $\mathrm{Ba}, \mathrm{Br}, \mathrm{Ca}, \mathrm{Cl}, \mathrm{Co}, \mathrm{Cr}, \mathrm{Cs}, \mathrm{Fe}, \mathrm{K}, \mathrm{La}, \mathrm{Mn}, \mathrm{Mo}, \mathrm{Na}, \mathrm{Rb}, \mathrm{Sb}, \mathrm{Sc}, \mathrm{Se}, \mathrm{U}$, e $\mathrm{Zn}$.

As concentrações de elementos obtidas para amostras de liquens coletadas em pontos de diferentes niveis de poluição foram comparadas visando a possível identificação das origens destes elementos acumulados no liquen.

A precisão e exatidão dos resultados foram avaliadas por meio da análise dos materiais certificados de referência IAEA-336 LICHEN e Mixed Polish Herbs (INCTMPH-2) provenientes da Agência Internacional de Energia Atômica (IAEA) e do Instituto de Química Nuclear e Tecnologia (INCT), respectivamente. 


\section{METODOLOGIA}

\subsection{Métodos radioquímicos}

A disponibilidade tanto de isótopos radioativos naturais como artificiais tornou possível o desenvolvimento de métodos analíticos chamados de métodos radioquímicos que são ao mesmo tempo sensiveis e específicos (Skoog et al., 2002). Esses métodos caracterizam-se, em geral, pela exatidão e ampla aplicabilidade e, além disso, alguns minimizam ou eliminam a necessidade de separações químicas que são requeridas em outros métodos analíticos.

Estes métodos radioquímicos podem ser classificados em três diferentes tipos de acordo com a origem da radioatividade. Em análise por ativação, a atividade é induzida por irradiação em um ou mais elementos da amostra por radiação ou por meio de partículas apropriadas (mais comumente nêutrons térmicos obtidos de um reator nuclear) e a radioatividade resultante é então medida. $O$ segundo tipo de método radioquímico consiste na medida da radioatividade introduzida fisicamente na amostra pela adição de uma quantidade mensurável de espécies radioativas chamadas de "traçadores radioativos". 0 terceiro tipo de método radioquímico envolve a medida da radioatividade que ocorre naturalmente em uma amostra. Exemplos desse tipo de método são medidas de radônio no ar do ambiente e de urânio em olarias e materiais cerâmicos (Skoog et al., 2002).

No presente trabalho, a metodologia analitica empregada foi análise por ativação com nêutrons instrumental (INAA), que é considerada um método radioquímico no qual a atividade é induzida por irradiação em um ou mais elementos da amostra com nêutrons advindos de um reator nuclear. 


\subsection{Considerações gerais sobre o método de análise por ativação com nêutrons}

Em 1936, foi publicado por Hevesy e Levi o primeiro artigo descrevendo a análise por ativação neutrônica (INAA) (Hevesy apud IAEA, 1990). Com o desenvolvimento dos reatores nucleares nos anos quarenta e dos detectores de cintilação de iodeto de sódio em meados dos anos cinqüenta, as possibilidades para aplicação da NAA para determinar elementos traço em diferentes tipos de matrizes foram reconhecidas (IAEA, 1990).

$\mathrm{O}$ desenvolvimento da NAA foi rápido. $\mathrm{O}$ aparecimento de detectores $\mathrm{Ge}(\mathrm{Li})$ no estado sólido de alta resolução nos anos sessenta, o avanço dos computadores e a automatização durante os anos setenta e oitenta possibilitaram a aplicação desta metodologia para pesquisar diferentes assuntos envolvendo um grande número de amostras.

Na NAA, a produção de um radionuclídeo a partir de um elemento químico é usada para a identificação e determinação quantitativa do elemento (Vandecasteele \& Block, 1993).

Os métodos de ativação são baseados na medida da radioatividade que tenha sido induzida nas amostras pela irradiação utilizando-se nêutrons ou por partículas carregadas como hidrogênio, deutério ou íons hélio (Skoog et al., 2002).

Três fontes de nêutrons podem ser empregadas nos métodos de ativação por nêutrons: reatores, radionuclídeos e aceleradores de partículas. Os nêutrons térmicos produzidos em reatores nucleares são usados mais freqüentemente para irradiar amostras, mas nêutrons produzidos por um gerador, por irradiação de alvos de berílio com dêuterons acelerados em cíclotrons ou advindos de uma fonte de ${ }^{252} \mathrm{Cf}$ também podem ser usados. $\mathrm{O}$ fluxo de nêutrons obtido por estas fontes é muito menor quando comparado ao fluxo produzido por um reator nuclear, logo para a determinação de elementos traço são utilizados nêutrons advindos de um reator nuclear.

A FIG. 3.1 ilustra, de forma esquemática, a secção transversal de um reator nuclear de pesquisa que produz fluxo de nêutrons para o propósito da NAA (Kellner et al., 1998). O núcleo do reator consiste de varetas combustiveis (1) de urânio enriquecido em ${ }^{235} \mathrm{U}$, o qual é levado à físsão por meio de nêutrons térmicos, e varetas absorvedoras (2) 
feitas de um material capaz de absorver fortemente nêutrons (cádmio, boro) para controlar o processo de fissão via taxa de produção de nêutrons. Neste processo de fissão cerca de dois a três nêutrons rápidos são liberados. O núcleo é circundado por um tanque (3) preenchido com água ou "água pesada". A água possui duas funções distintas: diminuir a velocidade dos nêutrons rápidos e resfriar as varetas combustíveis. Um refletor (4), geralmente feito de grafite, é instalado ao redor do núcleo para reduzir a perda de nêutrons que escapam do mesmo (o princípio utilizado é a reflexão). A blindagem (5), normalmente de concreto, protege os arredores do reator da intensa radiação advinda do núcleo. Numerosos canais experimentais, os quais estão arranjados horizontalmente (6) e verticalmente (7), levam a posições tanto no núcleo do reator como fora dele fornecendo diferentes fluxos de nêtrons de diferentes distribuições de energia. Em muitos reatores grandes, uma coluna térmica (8) em um bloco de grafite está disponivel fornecendo nêutrons térmicos "quase puros" de fluxos moderados.

As fontes de nêutrons empregadas nos métodos de ativação produzem nêutrons de alta energia (no intervalo de $\mathrm{MeV}$ ), que usualmente atravessam materiais moderadores de forma a reduzir suas energias a uns poucos centésimos de elétron-volt (eV). As perdas de energia para o moderador ocorrem por espalhamento elástico, no qual os nêtrons são rebatidos pelos núcleos, transferindo parte de sua energia cinética a cada núcleo do material moderador com os quais se chocam. Finalmente, os núcleos atingem a temperatura de equilibrio com suas vizinhanças. Os nêutrons que possuem essa energia (cerca de $0,04 \mathrm{eV}$ ) são chamados de nêutrons térmicos, e o processo de moderação de nêutrons de alta energia a condições térmicas é chamado de "termalização". Os materiais moderadores mais eficientes são as substâncias de baixo peso molecular, tais como água, óxido de deutério e parafina.

A maioria dos métodos de ativação está baseada em nêutrons térmicos, que reagem eficientemente com a maioria dos elementos de interesse analítico. Para alguns dos elementos mais leves, entretanto, tais como nitrogênio, oxigênio, flúor e silício, os nêutrons rápidos, que possuem energias de cerca de $14 \mathrm{MeV}$, são mais eficientes para induzir a radioatividade. Tais nêutrons são comumente produzidos em aceleradores de partículas. 


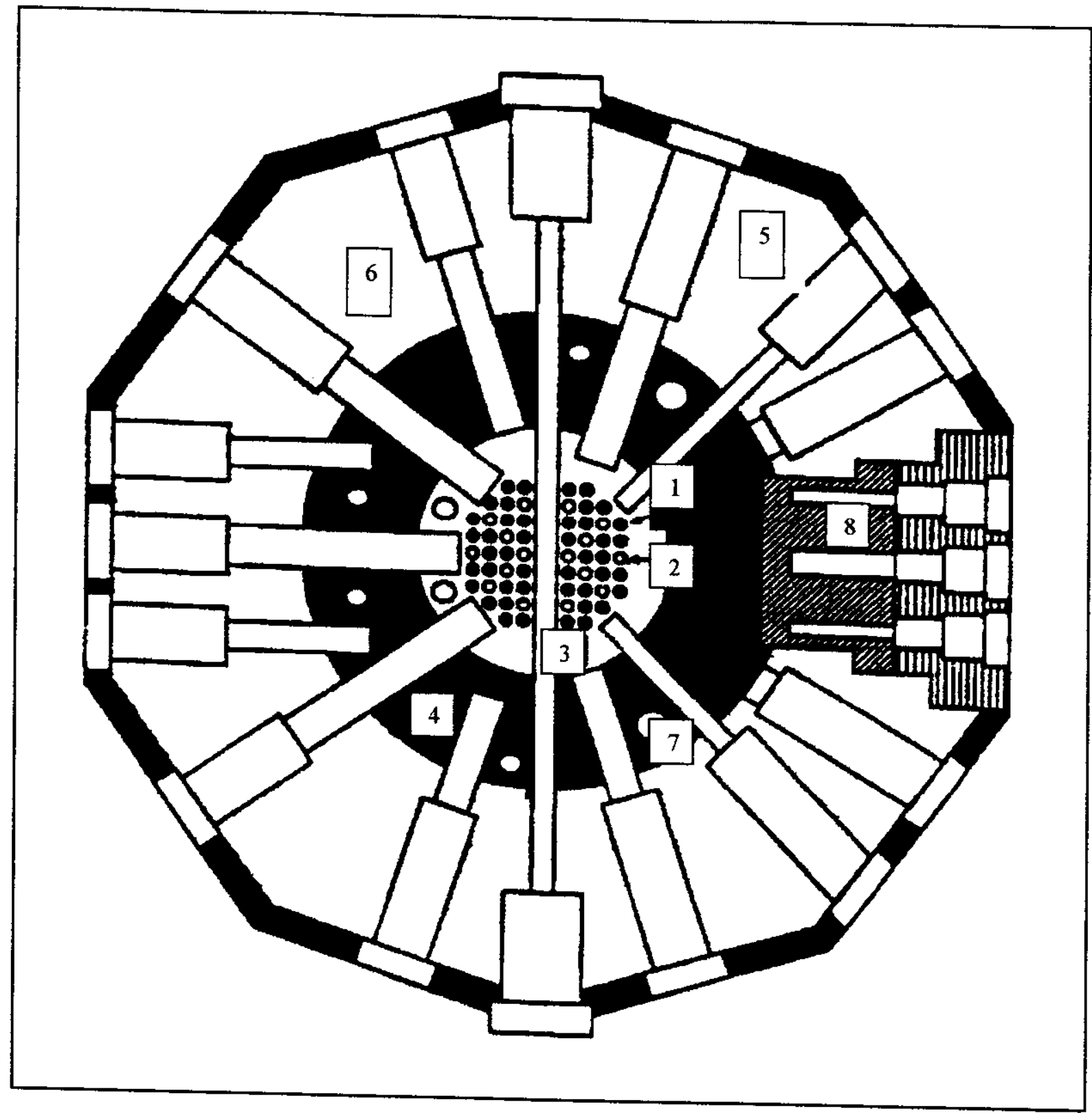

FIGURA 3.1 - Esquema da secção horizontal de um reator nuclear: núcleo do reator consistindo de varetas combustíveis (1), e barras de controle (2), tanque com água ou “água pesada" (3), refletor de grafite (4), blindagem biológica (5), canais experimentais horizontal (6) e vertical (7) e uma coluna térmica (8) (Kellner et al., 1998) 


\subsection{Princípio da análise por ativação com nêutrons}

A análise por ativação se basea na conversão de um nuclídeo estável (A) do elemento a ser determinado em um radionuclídeo (B), chamado "radionuclídeo indicador" (IRN - indicator radionuclide), por meio de uma reação nuclear (Kellner et al., 1998).

A reação é induzida quando um material-alvo é exposto aos projéteis (x) os quais podem ser nêutrons, partículas carregadas (próton, dêuteron, trítio, ${ }^{3} \mathrm{He}$, e partícula alfa), ou fótons. A reação nuclear pode ser representada como se segue:

$$
A+x \rightarrow[C] \rightarrow B+y+Q
$$

ou em uma notação abreviada:

$$
A(x, y) B
$$

onde y é um fóton ou uma partícula (próton, partícula alfa, ou nêutron) emitido, e o valor de $Q$ é a quantidade de energia liberada ou absorvida na reação. Durante a reação nuclear forma-se um radionuclídeo instável (C) de tempo de meia-vida muito curto.

Dentro deste contexto, a análise por ativação neutrônica se baseia nos fenômenos físicos, ou seja, nas propriedades do núcleo, da radioatividade e da interação da radiação com a matéria (IAEA, 1990). A seqüência de eventos durante uma reação do tipo (n, $\gamma$ ) está ilustrada na FIG. 3.2. Quando um nêutron interage com um núcleo-alvo por meio de uma colisão não-elástica, um núcleo-composto é formado em um estado altamente excitado. A alta energia de excitação do núcleo-composto ( $8 \mathrm{MeV}$ em média), é devida à elevada energia de ligação do nêutron com o núcleo. O tempo de vida do núcleo-composto é de cerca de $10^{-16}$ a $10^{-14} \mathrm{~s}$. Este tempo nem sempre é suficientemente longo para que permaneça traços do núcleo-composto e que permitam identificar o seu processo particular de formação, mas é curto o bastante para que o núcleo possa sofrer uma rápida deexcitação para uma configuração mais estável, por meio de diferentes modos dos quais freqüentemente envolve a emissão de partículas nucleares, os "raios gama prontos". Na maioria dos casos, o novo núcleo é radioativo e irá favorecer a de-excitação emitindo os "raios gama de decaimento". O método de NAA implica na medida de tanto das características dos raios gama pronto como dos de decaimento para a identificação de 
elementos e determinação de suas quantidades presentes na amostra. Cerca de $70 \%$ dos elementos possuem nuclídeos com propriedades apropriadas para a NAA.

A identificação dos elementos na amostra (radioisótopos) é feita pelas energias dos raios gama emitidas e das meias-vida de decaimento.

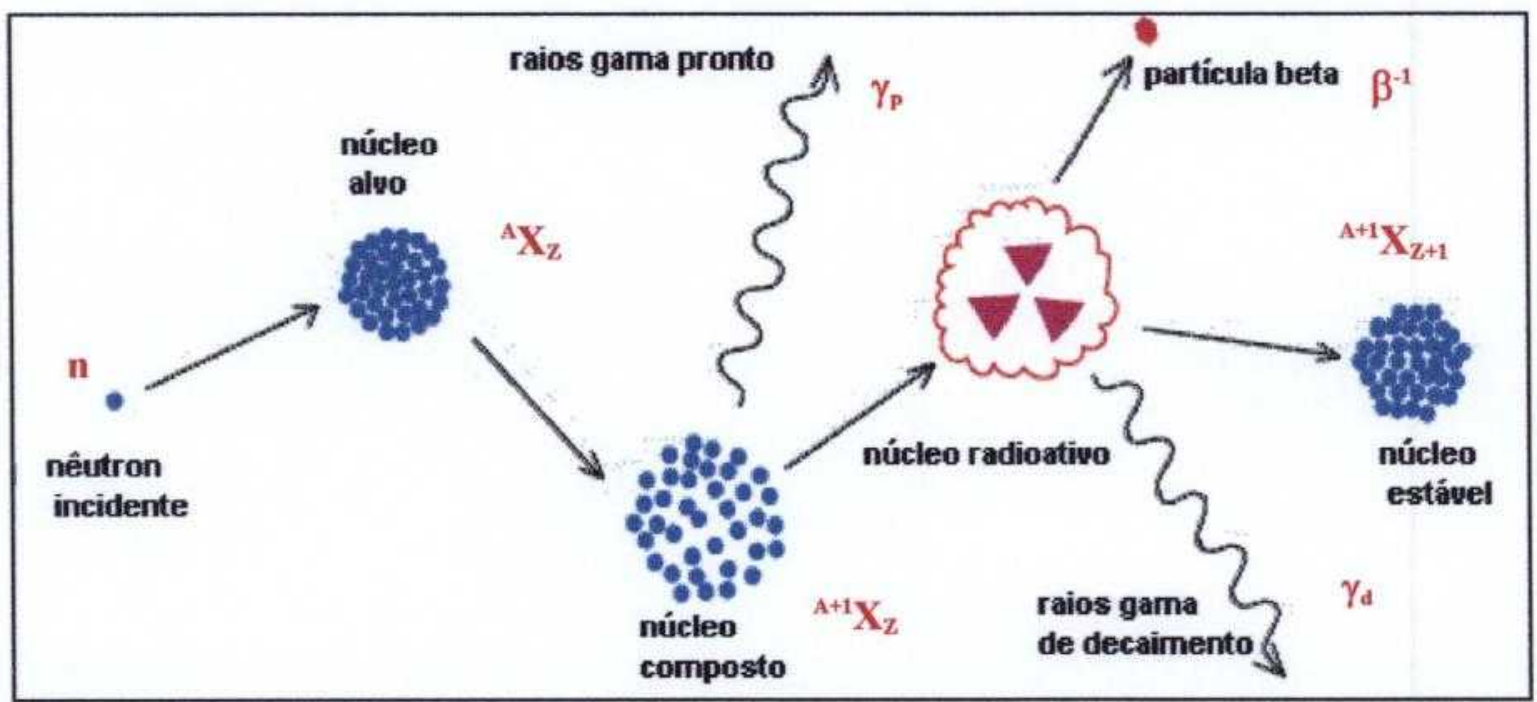

FIGURA 3.2 - Diagrama esquemático ilustrando a sequeência de eventos para uma reação (n, $\gamma$ ) típica (figura adaptada da referência IAEA, 1990)

\subsection{Análise por ativação comparativa}

A análise por ativação comparativa foi utilizada no presente trabalho como metodologia analítica, e este tipo de análise é geralmente empregado quando alguns parâmetros da irradiação como fluxo de nêutrons e do núcleo alvo como secção de choque não são conhecidos com exatidão.

Neste método comparativo, um padrão elementar que possui uma quantidade conhecida $\mathrm{m}_{\mathrm{p}}$ do elemento a ser determinado é irradiado juntamente com a amostra, durante um determinado tempo $\left(\mathrm{t}_{\mathrm{i}}\right)$ e sob o mesmo fluxo $(\phi)$ de nêutrons. 
A equação para calcular-se a atividade induzida em um dado elemento $A\left(t_{0}\right)$ após um certo tempo de irradiação $t_{i}$ é dada pela seguinte relação (De Soete et al., 1972):

$$
A\left(t_{0}\right)=z \sigma \phi N_{A V} \operatorname{mf}\left[1-e^{-0,693 \text { ti } / t_{1 / 2}}\right] / M
$$

onde $\mathrm{A}\left(\mathrm{t}_{0}\right)$ é a taxa de contagem (atividade) medida no tempo de decaimento $\mathrm{t}=0$, no final da irradiação;

z é o coeficiente de deteç̧ão;

$\sigma$ é a secção de choque de ativação em $\mathrm{cm}^{2}$;

$\phi$ é o fluxo de nêutrons em $\mathrm{n} \mathrm{cm}^{-2} \mathrm{~s}^{-1}$

$\mathrm{N}_{\mathrm{AV}}$ é o número de Avogadro $=6,023 \times 10^{23}$ átomos $\mathrm{mol}^{-1}$,

m é a massa do elemento irradiado;

f é a abundância isotópica do nuclídeo alvo;

M é a massa atômica do elemento irradiado;

$t_{i}$ é o tempo de irradiação e

$\mathrm{t}_{1 / 2}$ é a meia-vida do radionuclídeo formado

Após um determinado tempo de decaimento $t$, a atividade do radioisótopo é dada, de acordo com a lei de decaimento, por (Friedlander et al., 1981):

$$
A(t)=A\left(t_{0}\right) e^{-0,693 t / t_{1 / 2}}
$$

Sendo $t_{0}$ o tempo inicial $\left(t_{0}=0\right)$, a partir do qual se quer avaliar a atividade do radioisótopo para um tempo de decaimento $t$. 
Escrevendo a relação (3.3) para um mesmo elemento do padrão e amostra, irradiados nas mesmas condições, obtem-se as seguintes relações:

$$
\begin{aligned}
& A\left(t_{0}\right)_{p}=z \sigma \phi N_{A V} m_{p} f\left[1-e^{-0,693 t i / t_{1 / 2}}\right] / M \\
& A\left(t_{0}\right)_{a}=z \sigma \phi N_{A V} m_{a} f\left[1-e^{-0,693 t_{i} / t_{1} / 2}\right] / M
\end{aligned}
$$

onde os índices a e p referem-se à amostra e padrão, respectivamente.

Dividindo-se a relação (3.6) pela relação (3.5), tem-se:

$$
\mathrm{m}_{\mathrm{a}}=\left[\mathrm{m}_{\mathrm{p}} \mathrm{A}\left(\mathrm{t}_{0}\right)_{\mathrm{a}}\right] / \mathrm{A}\left(\mathrm{t}_{0}\right)_{\mathrm{p}}
$$

Introduzindo-se a relação (3.4) em (3.7) tem-se a relação:

$$
C_{a}=A_{a} \cdot m_{p} \cdot e^{[0,693 \cdot(t a-t p) / t 1 / 2]} / A_{p} M_{a}
$$

onde os índices a e p se referem à amostra e padrão, respectivamente;

$\mathrm{M}_{\mathrm{a}}$ é a massa total da amostra;

t é o tempo de decaimento;

$C_{a}$ é a concentração do elemento na amostra $\left(C_{a}=m_{a} / M_{a}\right)$;

A é a taxa de contagens para tempo de decaimento $t$. 


\subsection{Instrumentação para a análise por ativação neutrônica}

Os recursos básicos necessários para a realização da análise de uma amostra via NAA são uma fonte de nêutrons, instrumentação apropriada para a detecção dos raios gama e um conhecimento detalhado das reações que ocorrem quando os nêutrons interagem com o núcleo alvo.

Para as medições da radiação gama são utilizados os espectrômetros de raios gama. A FIG. 3.3 ilustra um arranjo comum de espectrômetro de raios gama (Skoog et al., 2002).

\subsection{Vantagens e desvantagens da análise por ativação neutrônica}

A análise por ativação neutrônica tem se tornado uma ferramenta importante para as pesquisas geoquímicas, bioquímicas e ambientais no que diz respeito à quantificação de elementos traço nos mais diversos tipos de amostras. Isto se deve ao fato da INAA instrumental apresentar algumas vantagens, tais como (IAEA, 1990):

(a) Ausência de erros sistemáticos. Os processos fisicos envolvidos são bem conhecidos. O aumento da radioatividade com a formação dos radionuclídeos e o decaimento radioativo com o tempo são rigorosamente exponenciais. $O$ número de reações nucleares energeticamente possíveis é pequeno, e todas as possíveis reações podem ser enumeradas por inspeção da tabela dos nuclídeos. A espectroscopia de raios gama de alta resolução proporciona identificação qualitativa dos nuclídeos presentes bem como sua determinação quantitativa.

(b) Complementaridade a outros métodos. Um conjunto de diferentes elementos pode ser medido e determinado tanto pelo uso de reações nucleares além daqueles determinados por meio de reações químicas, e os limites de detecção destes elementos são quantitativamente diferentes para técnicas analíticas distintas. Do mesmo modo são importantes, os tipos de erros em que os métodos nucleares estão envolvidos devido aos diferentes fenômenos físicos e são, portanto, comumente levados a obter resultados incorretos. 


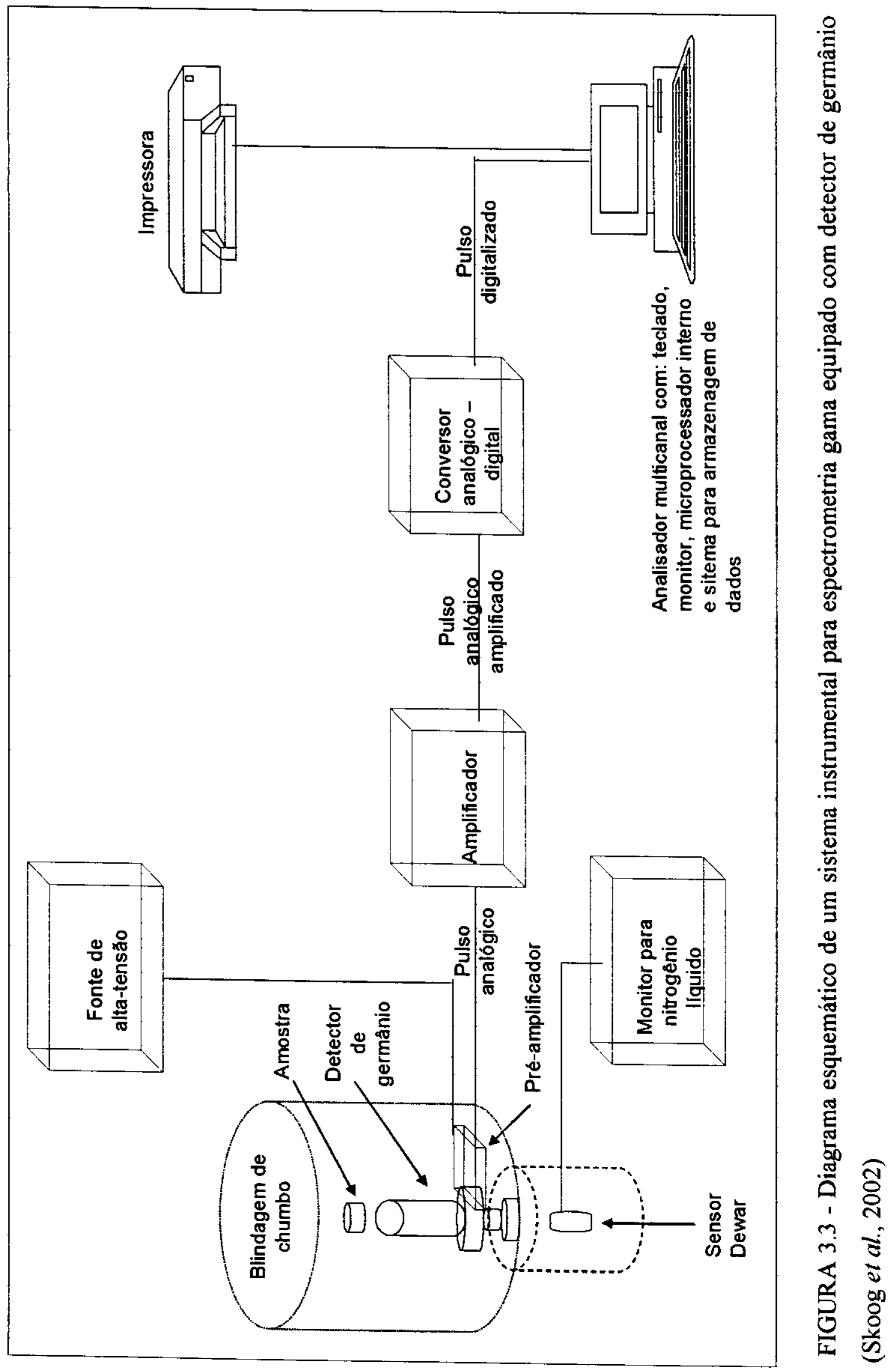


(c) Ausência do branco analítico. A técnica de NAA puramente instrumental também está livre dos problemas de dissolução das amostras. Exceto as etapas de manuseio e de armazenagem realizadas antes da irradiação no reator, na NAA não há problema do branco do reagente no sentido usual. Os métodos analíticos que requerem o analito em solução necessitam das habilidades dos laboratórios químicos muito mais que simples pesagem e armazenagem. Com algumas matrizes (rochas contendo silicatos complexos como cromita ou zircônio; tecidos animais), não é fácil garantir completa dissolução sem usar condições extremas ou várias etapas químicas.

(d) Precisão do resultado. O processo aleatório do decaimento radioativo pode fornecer uma estimativa da variação esperada entre as amostras. A aplicação de um simples teste $t$ mostra facilmente se a contagem estatística é um fator limitante na precisão. A exatidão pode ser comparada à precisão em níveis bem abaixo de $1 \%$, mesmo para uma fonte em decaimento.

(e) Capacidade multi-elementar. A espectrometria de raios gama é um processo analítico multinuclídico. Com o desenvolvimento de detectores de alta resolução, dependendo do tipo de matriz pode-se determinar cerca de quarenta elementos em uma amostra e as diferenças nas meias-vidas e nas energias dos raios gama dos radioisótopos permitem que vários elementos sejam determinados numa mesma amostra. Para elementos químicos cujos radioisótopos correspondentes emitem energias de raios gama bastante próximas, necessita-se fazer primeiramente, uma separação química. Como por exemplo, na determinação de Ti numa matriz de $\mathrm{Cr}$. $\mathrm{O}{ }^{51} \mathrm{Ti}$ possui meia-vida de 5,76 minutos e emite raios gama de $320,08 \mathrm{keV}$ e o ${ }^{51} \mathrm{Cr}$ com meia-vida de 27,7 dias também emite raios gama de energia de $320,08 \mathrm{keV}$.

(f) Sensibilidade. A análise por ativação neutrônica tem-se mostrado aplicável à determinação de muitos elementos em quantidades de sub-picogramas. A opção de separação radioquímica após irradiação é freqüentemente disponível para a remoção do branco e obtenção de espectro gama livre de radioatividades dos interferentes.

\section{(g) Os resultados são independentes do estado químico dos elementos. A NAA se} baseia nos fenômenos físicos e a reação ocorre nos núcleos dos elementos. Como o estado químico do elemento é definido pela ligação atômica, não há influência nos resultados analíticos obtidos para esta técnica. Isto é, não há efeitos devido à matriz como pode 
ocorrer em técnicas analíticas baseadas nas propriedades atômicas e mudanças nas propriedades químicas.

Estas características dos métodos nucleares têm sido amplamente exploradas, particularmente na análise de elementos traço.

Quanto às desvantagens da NAA pode ser citado o fato de certos elementos não poderem ser determinados por este método, devido estes elementos não apresentarem características apropriadas para ativação, emissão de raios gama para medição (como o $\mathrm{Pb}$ ) ou quando as suas concentrações estão abaixo dos seus valores de limite de detecção. Nestes casos torna-se necessário o uso de técnicas alternativas para a determinação de tais elementos, como a espectrometria de absorção atômica com forno de grafite (GF-AAS) (Cheng et al., 1995). Outras técnicas analíticas multielementares, tais como a espectroscopia de massa com fonte de plasma acoplado indutivamente (ICP-MS), espectrometria de emissão atômica (ICP-AES) e fluorescência de raios X (XRF) têm sido recentemente utilizadas (Aguiar, 2001). 


\section{PARTE EXPERIMENTAL}

\subsection{Amostras de líquen para análise}

\subsubsection{Características da espécie de fungo liquenizado coletada e analisada}

Para selecionar uma espécie de fungo liquenizado deve-se lembrar que este espécime é extremamente susceptível às mudanças do ambiente e, portanto, tendem a desaparecer em regiões urbanizadas e/ou poluídas, formando os chamados "desertos liquênicos". Por outro lado, existem espécies que surgem exatamente nestas áreas poluídas e urbanizadas (Coccaro, 2001)

A espécie escolhida no presente trabalho Canoparmelia texana (Tuck.) Elix \& Hale é um fungo liquenizado epífito folioso, da família Parmeliaceae, extremamente abundante em praticamente todas as cidades não litorâneas do Brasil. Esta espécie aparece em regiões de poluição relativamente elevada, onde todas as outras espécies já desapareceram (Marcelli, 1998). Uma descrição mais detalhada do fungo liquenizado Canoparmelia texana pode ser encontrada em Spielmann (2005). A FIG. 4.1 mostra a fotografia do fungo liquenizado C. texana sobre o tronco de uma árvore (Barbosa, 2005). 

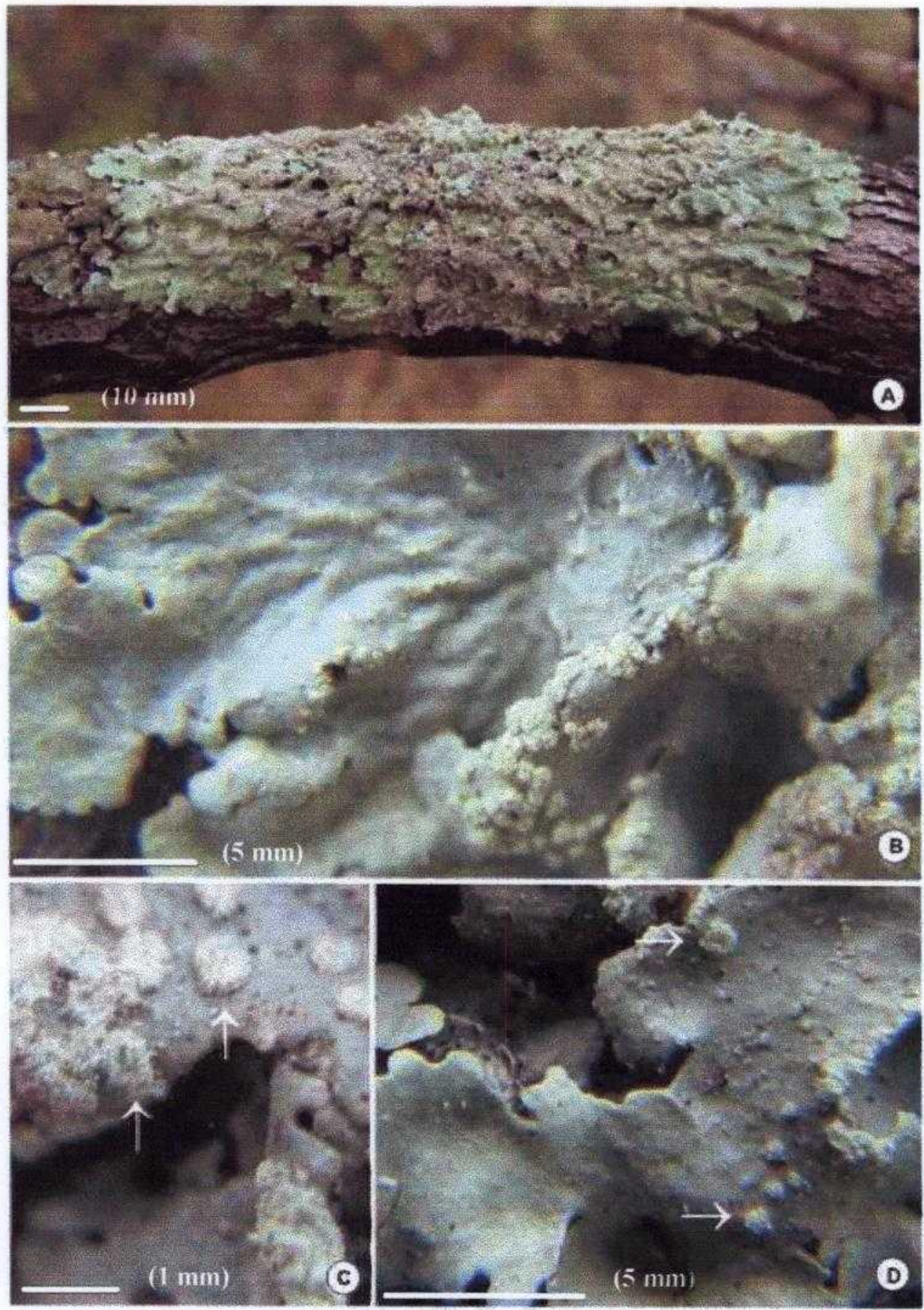

Figura 4.1 - Fungo liquenizado Canoparmelia texana. A - aspecto geral do talo; $\mathbf{B}$ - margem do talo com sorais; $\mathbf{C}$ - detalhe dos sorais (setas); $\mathbf{D}$ - margem do talo e sorais (setas) (Barbosa, 2005). 
A espécie escolhida para o estudo apresenta características relevantes para seu uso como biomonitor uma vez que a C. texana é facilmente encontrada na região de coleta e se trata de uma espécie tolerante à poluição.

$\mathrm{Na}$ realidade, enquanto as outras espécies desapareceram nas regiões poluídas, C. texana é muito mais abundante nessas regiões do que nos ambientes naturais não poluídos, o que a caracteriza como uma espécie indicadora de poluição, com comportamento similar à Lecanora conizaeoides da Europa. Sendo assim, C. texana é um competidor fraco em condições naturais, quando normalmente se restringe aos ramos mais finos das árvores e troncos expostos em pastos e beira de estradas de terra, sempre com baixa frequência. Entretanto, quando os seus competidores desaparecem do ambiente, esta espécie encontra um habitat desocupado e, graças à sua alta tolerância à poluição, ocupa grandes extensões de troncos numa alta freqüência, como é comum se observar nas praças, parques e campus universitários nas grandes cidades (Marcelli, 1998).

\subsection{Locais de coleta}

A coleta das amostras de liquens foi realizada em duas regiões as quais apresentam niveis de poluição distintos, a saber:

- Parques Estaduais Carlos Botelho (PECB) e Intervales (PEI), situados no Estado de São Paulo; áreas consideradas não-poluídas;

- Região Metropolitana de São Paulo, área considerada poluída a qual apresenta diferentes níveis de poluição.

\subsubsection{Parques Estaduais Carlos Botelho e Intervales}

O Parque Estadual Carlos Botelho (S 24 03' 20" WO 47० 59' 35") (Parque (a), 2004) localiza-se na Serra do Paranapiacaba, Vale do Ribeira e é atravessado pela rodovia SP-139 (Parque (b), 2004). A região do Parque, com uma área de aproximadamente 37 mil hectares de relevo acidentado, abrange os municípios de São Miguel Arcanjo, Capão Bonito, Sete Barras e Tapiraí (Parque (c), 2004). O relevo varia de 50 a 975 metros chegando até o Planalto de Guapiara, a precipitação pluviométrica chega a $2189 \mathrm{~mm} / \mathrm{ano}$ e a temperatura varia de $19^{\circ} \mathrm{C}$ a $34^{\circ} \mathrm{C}$ (Parque (d), 2004). A localização serrana possibilita a formação de uma espécie de barreira que impede a entrada de umidade e promove o desenvolvimento de diversas plantas, como espécies de orquídeas, bromélias e palmeiras, 
uma das principais peculiaridades da região (Parque (b), 2004). A unidade de conservação Parque Estadual Carlos Botelho é uma das mais bem preservadas e com uma das maiores taxas de diversidade do país. Junto com outras unidades de conservação da região, 0 parque integra desde 1991 a Zona Núcleo da Reserva da Biosfera da Mata Atlântica. Em 30 de novembro de 1999, foi reconhecido pela UNESCO como Sítio do Patrimônio Mundial Natural (Parque (e), 2004). A FIG. 4.2 mostra uma foto aérea do Parque Estadual Carlos Botelho(Parque (a), 2004).

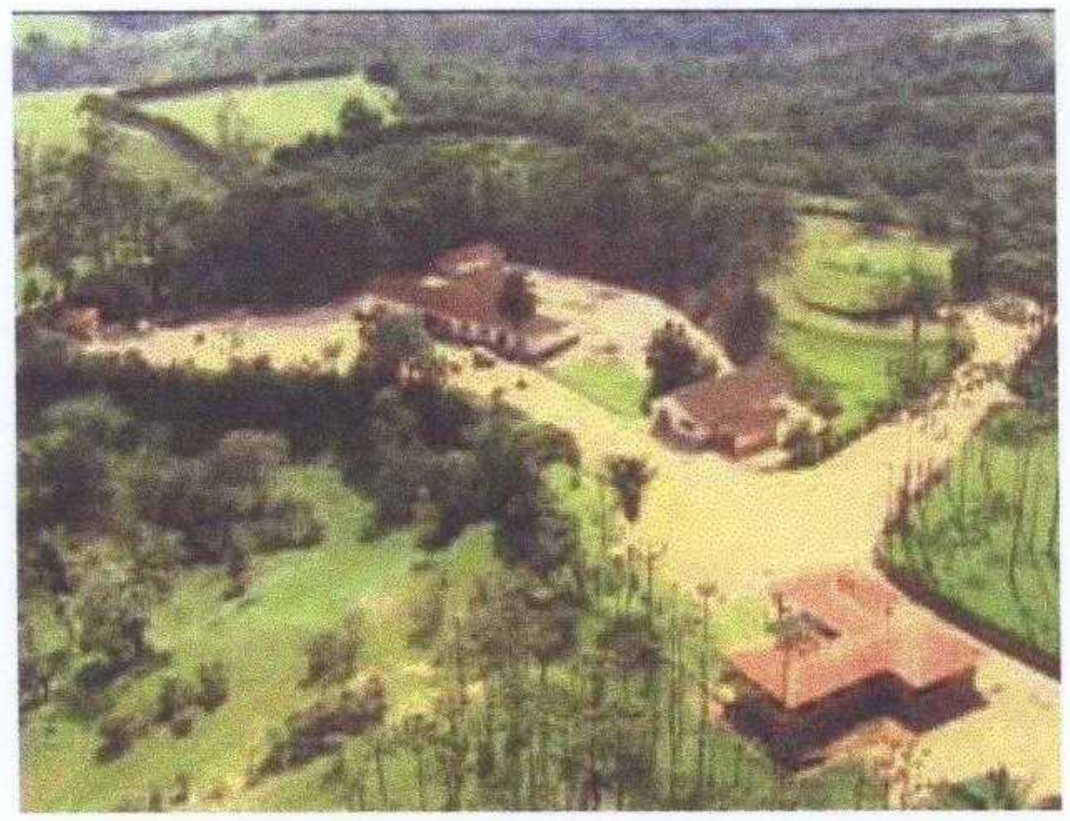

FIGURA 4.2 - Foto aérea do Parque Estadual Carlos Botelho (Parque (a), 2004).

A área do parque sofreu pouca interferência antrópica, devido à falta de acesso, à sua situação geomorfológica acidentada, e a sua vegetação é formada pela Floresta Latifoliada Úmida de Encosta (Mata Atlântica) (Parque (f), 2004). Esta é uma das mais belas e ricas reservas de Mata Atlântica do Estado que, além da flora e da fauna, também abrigam várias e importante nascentes (Parque (d), 2004). 
O Parque Estadual Intervales está localizado no município de Ribeirão Grande e estende-se sobre parte dos municípios de Eldorado, Guapiara, Iporanga e Sete Barras. Com uma área de aproximadamente 42 mil hectares, abrange áreas desde o alto da Serra do Paranapiacaba, ao sul do Estado de São Paulo, até as baixadas do Vale do rio Ribeira de Iguape. A região possui alta precipitação pluviométrica com valores de 2000 a 3000 $\mathrm{mm} / \mathrm{ano}$, e conseqüentemente a umidade relativa do ar é extremamente alta, de 65 a $100 \%$. A altitude do Parque varia de 60 a 1.095 metros. Este fator combinado com a elevada umidade possibilita uma diversidade paisagística, faunística e florística. O clima predominante é o subtropical de altitude sem estação seca. A temperatura média anual para a área da Sede do Parque varia entre $17^{\circ} \mathrm{C}$ e $19^{\circ} \mathrm{C}$ (Parque (g), 2004). A FIG. 4.3 mostra uma vista aérea do Parque Estadual Intervales (Parque (h), 2004).

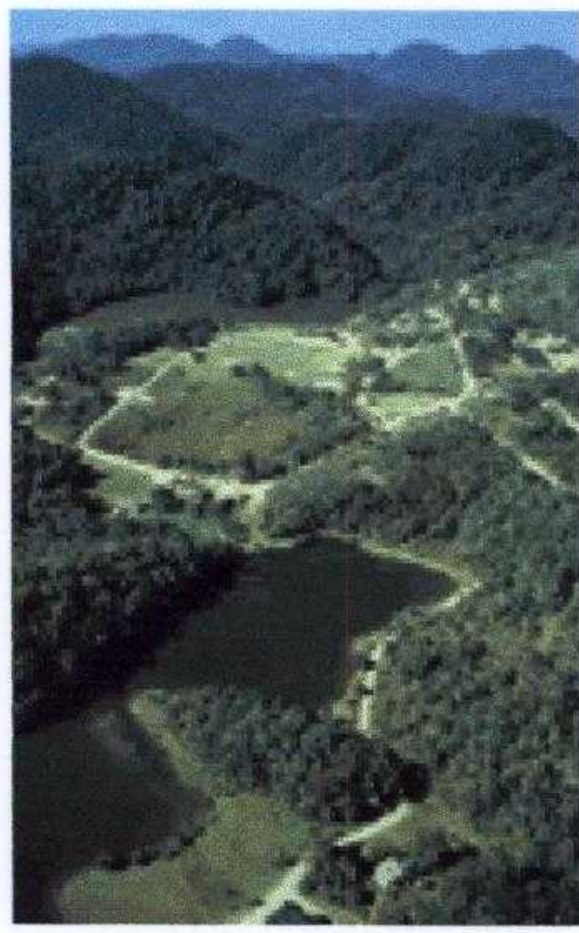

FIGURA 4.3 - Foto aérea do Parque Estadual Intervales (Parque (h), 2004). 
Este parque representa uma das áreas mais significativas dos remanescentes florestais do Estado de São Paulo, pelo seu ótimo estado de conservação e por abrigar inúmeras espécies vegetais. Genericamente, a cobertura vegetal é a Mata Atlântica que possui mais de $50 \%$ de suas árvores endêmicas, o que a transforma na floresta de maior biodiversidade do globo, inclusive maior que a da Amazônia. Esta diversidade se deve à combinação de fatores como relevo, influências de massas de ar continentais e oceânicas, temperatura e chuvas.

O PEI limita-se ao norte com a Estação Ecológica de Xitué, a nordeste com o Parque Estadual Carlos Botelho, ao oeste com o PETAR (Parque Estadual do Alto Ribeira) e ao sul com a Área de Proteção Ambiental da Serra do Mar. Este conjunto de reservas forma o Continuum Ecológico que serve como corredor para todas as espécies da fauna que vive na região e preserva uma grande área densa de Mata Atlântica - grande se não for comparada com a área original da floresta. No início da colonização do Brasil, a Mata Atlântica cobria vasta área do nosso território. Atualmente restam cerca de $8 \%$ de sua área original. No Estado de São Paulo, a mata representa $18 \%$ da remanescente no país, concentradas na Serra do Mar e ao longo de regiões como do Alto Ribeira e Serra de Paranapiacaba (Parque (i), 2004). A Mata Atlântica, aparentemente uniforme, diversificase em função da presença de rochas, da inclinação do terreno, da profundidade dos solos e do clima. Nos topos de morros e nas escarpas, onde o terreno é mais ingreme e mais exposto aos ventos, às chuvas e neblinas e às baixas temperaturas, a vegetação é mais baixa ou rasteira. No fundo dos vales e nas áreas entre escarpas íngremes, mais protegidas dos ventos, de temperatura mais amena, de solo mais profundo e de maior umidade, existem árvores de porte maior. A FIG. 4.4 é uma foto do ecossistema de Mata Atlântica (Mata Atlântica, 2005). 


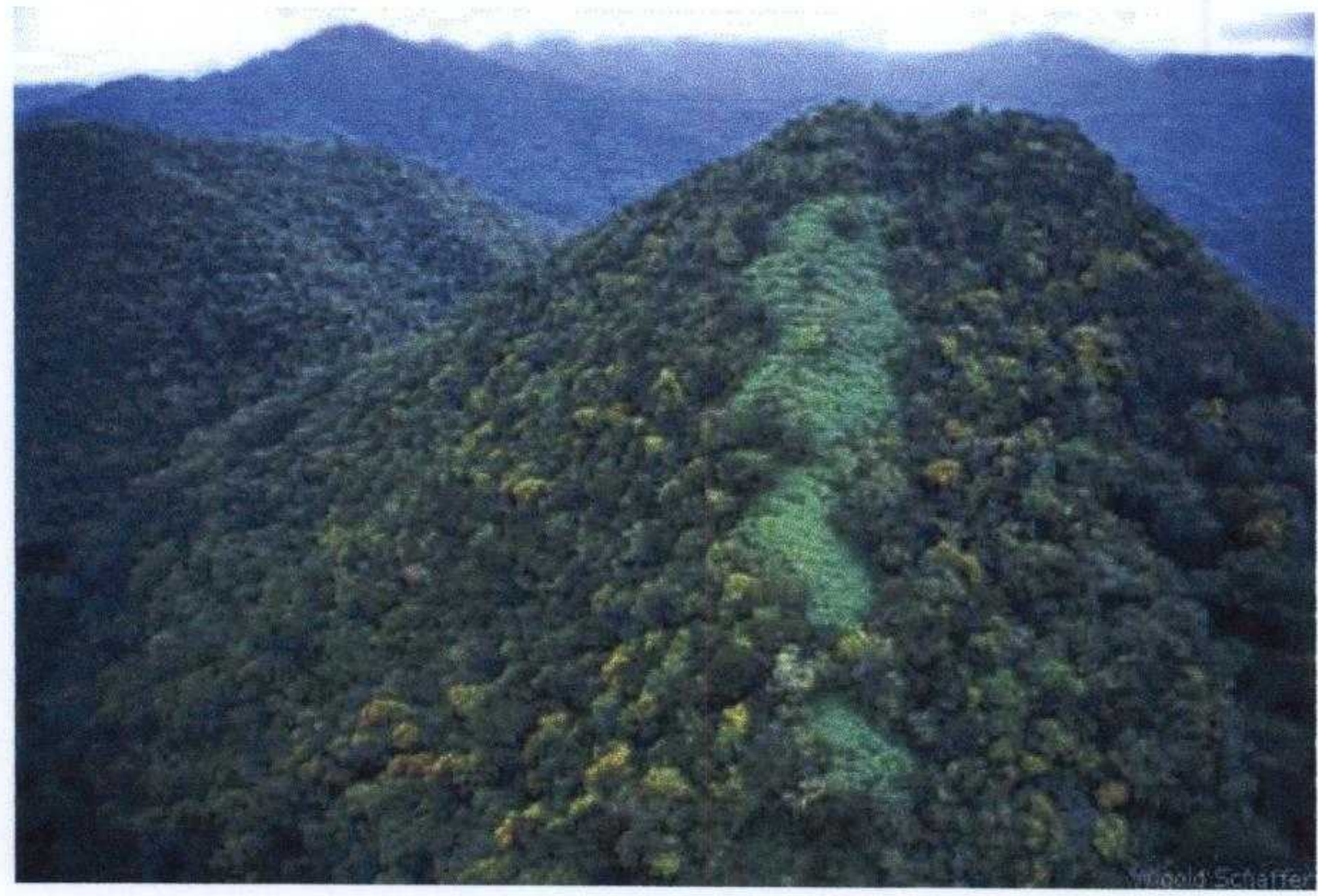

FIGURA 4.4 - Foto do ecossistema de Mata Atlântica (Mata Atlântica, 2005).

O Parque Carlos Botelho e os Parques Estaduais Intervales, Jacupiranga e a Estação do Xitué, formam juntamente a maior área contínua de Mata Atlântica do Brasil, possuindo assim uma riquíssima biodiversidade. Trata-se ainda de uma das maiores áreas de florestas primárias da cobertura vegetal do estado.

\subsubsection{Região Metropolitana de São Paulo}

Além do ecossistema de Mata Atlântica, amostras de liquens foram coletadas na região Metropolitana de São Paulo. A FIG. 4.5 mostra a localização da região metropolitana de São Paulo situada no Estado de São Paulo.

São Paulo é uma cidade brasileira, capital do estado de mesmo nome. A população recenseada em 2000 foi de 10.434.252 habitantes; em 2003, o Instituto Brasileiro de Geografia e Estatística (IBGE) estimava um crescimento para 10.677.019. A área do município, ainda segundo o IBGE, é de $1.523 \mathrm{~km}^{2}$ (Região (a), 2004). Segundo o 
IBGE - Censo de 2005, sua região metropolitana constituida por trinta e nove municípios tem aproximadamente 20,5 milhões de habitantes, o que a torna a cidade mais populosa do Brasil e a segunda da América Latina, depois da Cidade do México. A área urbanizada é de aproximadamente $2.139 \mathrm{~km}^{2}$ (Região (b), 2005). A seguir são mostrados alguns dados referentes à região metropolitana de São Paulo: extensão, 8.051 quilômetros quadrados de área; latitude, 23,533 Sul; longitude, 46,617 Oeste; PIB, US\$(2000), 99 bilhões. Já a cidade de São Paulo possui: indústrias, 33.921; veículos, 4,3 milhões; comércio, 71.256 e serviços, 89.813 (Região (c), 2004).

$\mathrm{Na}$ TAB. 4.1 encontram-se os dados das amostras coletadas neste trabalho com seus respectivos códigos, locais e datas de coleta. 
in

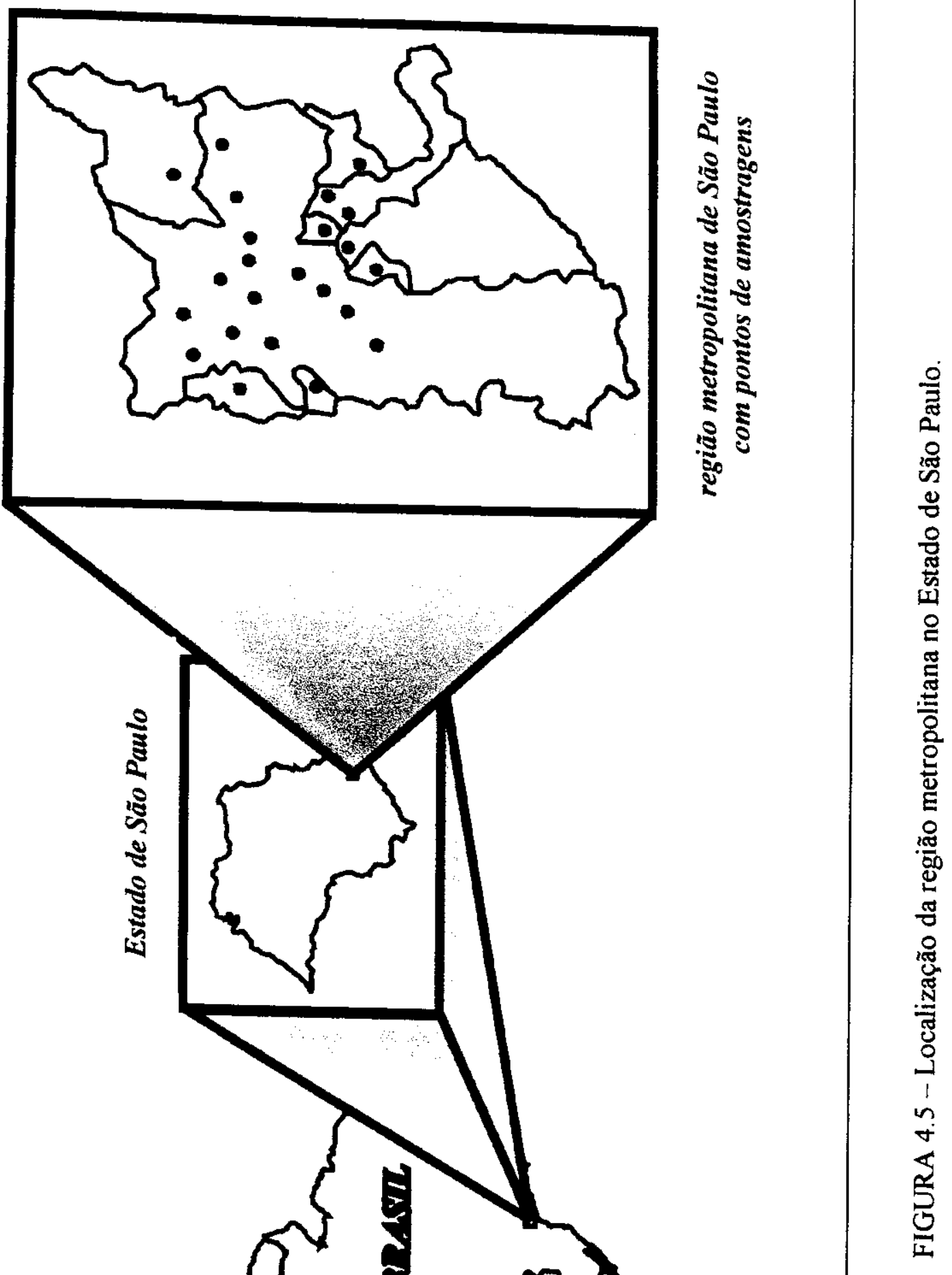


TABELA 4.1 - Códigos, locais e datas de coleta das amostras de liquens.

\begin{tabular}{|c|c|c|c|c|}
\hline Número & Código & Nome & Local da coleta & $\begin{array}{c}\text { Data da } \\
\text { coleta }\end{array}$ \\
\hline 0 & LO & $\mathrm{PECB}^{(\mathrm{a})}$ & Parque Estadual Carlos Botelho & $07 / 02 / 02$ \\
\hline 1 & $\mathrm{~L} 1$ & $\mathrm{PEI}^{(\mathrm{b})}$ & $\begin{array}{c}\text { Parque Estadual Intervales - Pousada } \\
\text { Capivara }\end{array}$ & $30 / 07 / 03$ \\
\hline 2 & $\mathrm{~L} 2$ & PEI & $\begin{array}{c}\text { Parque Estadual Intervales - Pousada } \\
\text { Capivara }\end{array}$ & $30 / 07 / 03$ \\
\hline 3 & $\mathrm{~L} 3$ & PEI & $\begin{array}{c}\text { Parque Estadual Intervales - Castelo de } \\
\text { Pedra }\end{array}$ & $30 / 07 / 03$ \\
\hline 4 & $\mathrm{~L} 4$ & PEI & Parque Estadual Intervales - Mirante & $30 / 07 / 03$ \\
\hline 5 & L5 & Santana & $\begin{array}{c}\text { Av. Santos Dumont, } 1019 \text { - Parque de } \\
\text { Material Aeronáutico }\end{array}$ & $20 / 08 / 03$ \\
\hline 6 & L6 & Congonhas & $\begin{array}{l}\text { Al. dos Tupiniquins, } 1571-\text { E. M. "Prof. } \\
\text { J. C. da Silva Borges" }\end{array}$ & $20 / 08 / 03$ \\
\hline 7 & L7 & $\begin{array}{l}\text { Parque do } \\
\text { Ibirapurera }\end{array}$ & Av. Manoel da Nóbrega, 1985 - Setor 25 & $20 / 08 / 03$ \\
\hline 8 & L8 & $\begin{array}{l}\text { Cerqueira } \\
\text { César }\end{array}$ & $\begin{array}{l}\text { Av. Dr. Arnaldo, } 725 \text { - Faculdade de } \\
\text { Saúde Pública da USP }\end{array}$ & $20 / 08 / 03$ \\
\hline 9 & L9 & Pinheiros & $\begin{array}{l}\text { Av. Prof. Frederico Hermann Júnior, } 345 \\
\text { - CETESB }\end{array}$ & $20 / 08 / 03$ \\
\hline 10 & $\mathrm{~L} 10$ & $\begin{array}{c}\begin{array}{c}\text { São Caetano } \\
\text { do Sul }\end{array} \\
\end{array}$ & $\begin{array}{l}\text { Rua Aurélia, s/no - Vila Paula - E. M. I. } \\
\text { "Fernando Pessoa" }\end{array}$ & $21 / 08 / 03$ \\
\hline 11 & L11 & $\begin{array}{c}\text { Santo André } \\
\text { Centro }\end{array}$ & $\begin{array}{c}\text { Rua das Caneleiras, } 101 \text { - Parque } \\
\text { Municipal Duque de Caxias }\end{array}$ & $21 / 08 / 03$ \\
\hline 12 & $\mathrm{~L} 12$ & Mauá & $\begin{array}{l}\text { Rua Vitorino Del'Antonia, } 150 \text { - E. E. } 1 .^{\circ} \\
2 .^{\circ} \text { Graus "Prof. }{ }^{a} \text { Therezinha Sartori" }\end{array}$ & $21 / 08 / 03$ \\
\hline 13 & L13 & Centro & $\begin{array}{l}\text { Av. São Luiz, s/no - Biblioteca Municipal } \\
\text { "Mário de Andrade" }\end{array}$ & $26 / 01 / 04$ \\
\hline 14 & L14 & $\begin{array}{l}\text { São Miguel } \\
\text { Paulista }\end{array}$ & $\begin{array}{l}\text { Rua Diego Calado, } 112 \text { - E. E. I. } \\
\text { "Antonio Lapenna" }\end{array}$ & $30 / 01 / 04$ \\
\hline 15 & L15 & $\begin{array}{c}\text { Santo André } \\
\text { Capuava }\end{array}$ & $\begin{array}{l}\text { Rua Manágua, } 02 \text { - Posto de Puericultura } \\
\text { do Alto de Capuava }\end{array}$ & $10 / 02 / 04$ \\
\hline 16 & L16 & Moóca & $\begin{array}{l}\text { Rua Bresser, } 2341 \text { - Administração } \\
\text { Regional da Moóca }\end{array}$ & $26 / 01 / 04$ \\
\hline 17 & $\mathrm{~L} 17$ & $\begin{array}{c}\text { Parque D. } \\
\text { Pedro II }\end{array}$ & Parque Dom Pedro II, 319 - Centro & $26 / 01 / 04$ \\
\hline 18 & L18 & Diadema & $\begin{array}{l}\text { Rua Benjamim Constant, } 03 \text { - Centro - } \\
\text { Prefeitura Municipal de Diadema }\end{array}$ & $10 / 02 / 04$ \\
\hline
\end{tabular}


TABELA 4.1 - Códigos, locais e datas de coleta das amostras de liquens.

\begin{tabular}{|c|c|c|c|c|}
\hline 19 & L19 & Penha & $\begin{array}{l}\text { Av. Amador Bueno Veiga, } 2932 \text { - E. E. } \\
\text { de 2. }{ }^{\circ} \text { Grau "Gabriel Ortiz" }\end{array}$ & $30 / 01 / 04$ \\
\hline 20 & $\mathrm{~L} 20$ & Cambuci & $\begin{array}{c}\text { Av. Dom Pedro I, } 100 \text { - IV Comando } \\
\text { Aéreo Regional }\end{array}$ & $26 / 01 / 04$ \\
\hline 21 & $\mathrm{~L} 21$ & Guarulhos & $\begin{array}{l}\text { Av. Monteiro Lobato, } 3246 \text { - Pq. CECAP } \\
\text { - E. E. de } 1 .^{\circ} \text { Grau "Francisco Antunes } \\
\text { Filho" }\end{array}$ & $30 / 01 / 04$ \\
\hline 22 & $\mathrm{~L} 22$ & Lapa & $\begin{array}{l}\text { Av. Emb. Macedo Soares, } 7995 \text { - } \\
\text { Administração Regional da Lapa }\end{array}$ & $03 / 02 / 04$ \\
\hline 23 & $\mathrm{~L} 23$ & $\begin{array}{c}\text { Nossa } \\
\text { Senhora do Ó }\end{array}$ & Av. Ministro Petrônio Portela, 1270 & $23 / 02 / 04$ \\
\hline 24 & L24 & Osasco & $\begin{array}{c}\text { Av. dos Autonomistas, } \mathrm{s} / \mathrm{n}^{\circ}-\mathrm{c} / \mathrm{Rua} \\
\text { Maurício }\end{array}$ & $03 / 02 / 04$ \\
\hline 25 & L25 & $\begin{array}{c}\text { São Bernardo } \\
\text { do Campo }\end{array}$ & $\begin{array}{l}\text { Rua Cásper Líbero, } 340 \text { - E. M. E. F. } \\
\text { "Vicente de Carvalho" }\end{array}$ & $10 / 02 / 04$ \\
\hline 26 & L26 & Água Funda & $\begin{array}{c}\text { Av. Miguel Estéfano, } 3687 \text { - Instituto de } \\
\text { Botânica }\end{array}$ & $26 / 01 / 04$ \\
\hline 27 & $\mathrm{~L} 27$ & $\begin{array}{l}\text { Taboão da } \\
\text { Serra }\end{array}$ & Praça Nicola Vivilechio, 99 & $05 / 02 / 04$ \\
\hline 28 & L28 & Santo Amaro & $\begin{array}{c}\text { Rua Pe. José Maria, } 355 \text { - Centro Educ. } \\
\text { Municipal "Joergi Bruder" }\end{array}$ & $05 / 02 / 04$ \\
\hline
\end{tabular}

(a) Parque Estadual Carlos Botelho

(b) Parque Estadual Intervales; 
Na região Metropolitana de São Paulo, as amostras foram coletadas em locais próximos à Rede de Estações Automáticas da Companhia de Tecnologia de Saneamento Ambiental (CETESB). A FIG. 4.6 mostra os locais aonde foram coletadas as amostras da região metropolitana. Além destes pontos, uma amostra foi coletada no Instituto de Botânica, localizado no bairro da Água Funda, na região metropolitana (CETESB, 2003).

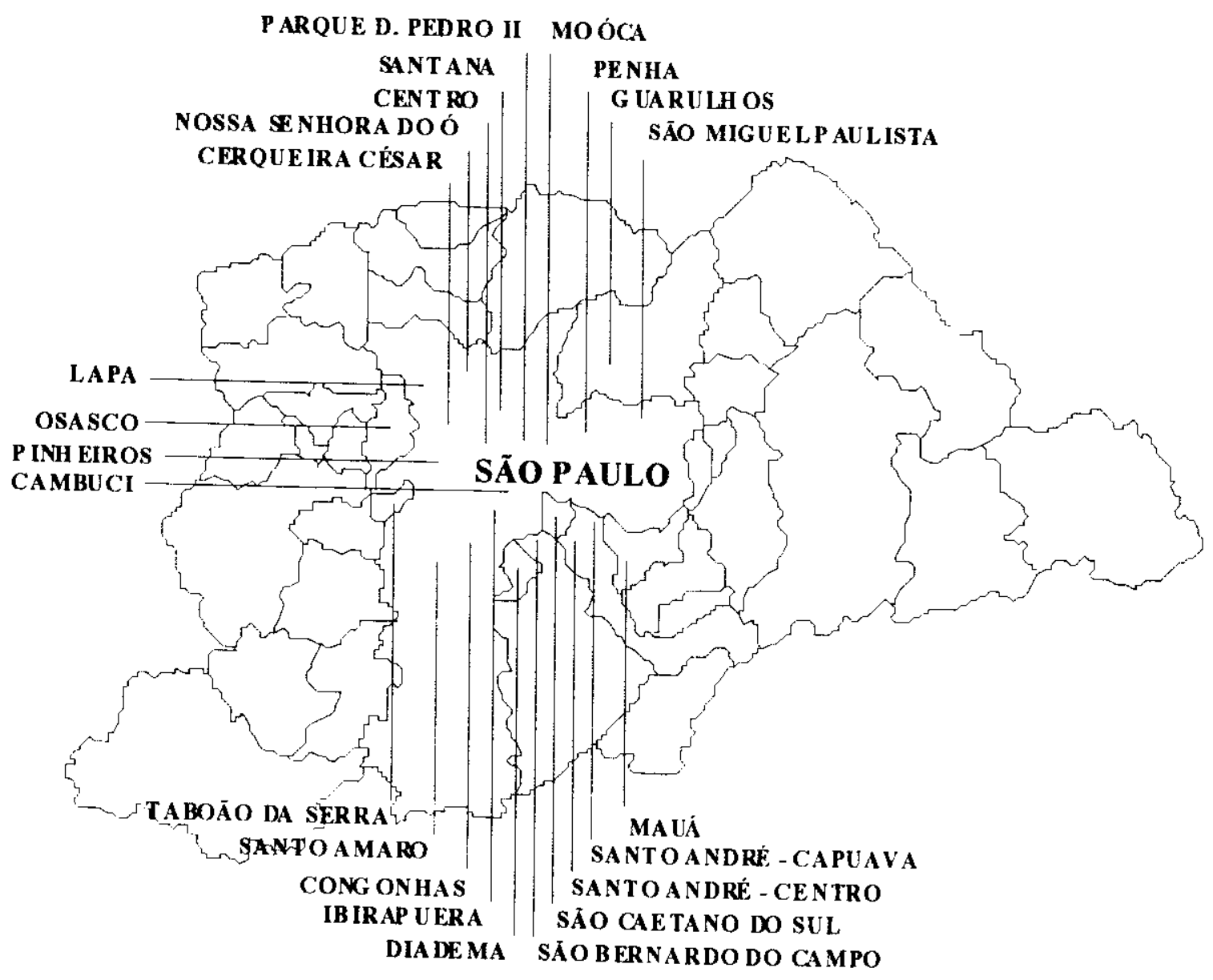

FIGURA 4.6 - Locais de amostragem na região metropolitana de São Paulo (CETESB, 2003). 


\subsection{Procedimento experimental para coleta e tratamento das amostras para análise}

O procedimento experimental de tratamento das amostras de líquen foi realizado conforme trabalhos prévios desenvolvidos no Laboratório de Análise por Ativação Neutrônica, IPEN/CNEN-SP (Saiki et al., 1997; Coccaro et al., 1999; Coccaro 2001; Fuga et al., 2002).

Os liquens foram coletados dos troncos das árvores com o auxílio de uma faca de titânio, a uma altura de aproximadamente 1,50 $\mathrm{m}$ do solo e foram guardados em sacos de papel e não de plástico para evitar formação de bolores. A utilização da faca de titânio de alta pureza evita a contaminação das amostras por outros elementos como aqueles presentes no aço inoxidável.

Para obter-se a amostra de líquen na forma apropriada para determinação de elementos traço foram tomadas as devidas precauções durante o seu tratamento. Desta forma, todas as etapas de preparação das amostras para análise foram realizadas em ambientes limpos, utilizando equipamentos e utensílios feitos de materiais apropriados (teflon, polietileno, titânio) que contém baixos niveis de elementos traço a serem determinados no presente estudo.

No laboratório, para separar a casca da árvore do líquen, utilizou-se uma tesoura, uma pinça de tamanho médio, dentre outros utensílios pertencentes a um kit ortodôntico. Para a limpeza de todos os utensílios foram utilizados papel higiênico especial e álcool etílico p.a para evitar possíveis contaminações.

Todo trabalho de limpeza foi executado sobre uma mesa forrada com papel branco, em sala apropriada para tratamento de amostras (sala limpa). Após a separação do líquen do seu respectivo substrato (casca de árvore), estas amostras foram colocadas em recipientes de plástico.

Após este procedimento, foi iniciada uma limpeza minuciosa das amostras e para esta finalidade utilizou-se um microscópio estereoscópico modelo 4060 da marca Olympus (FIG. 4.7), para examinar o líquen e retirar corpos estranhos ou substratos ainda nele presentes. 


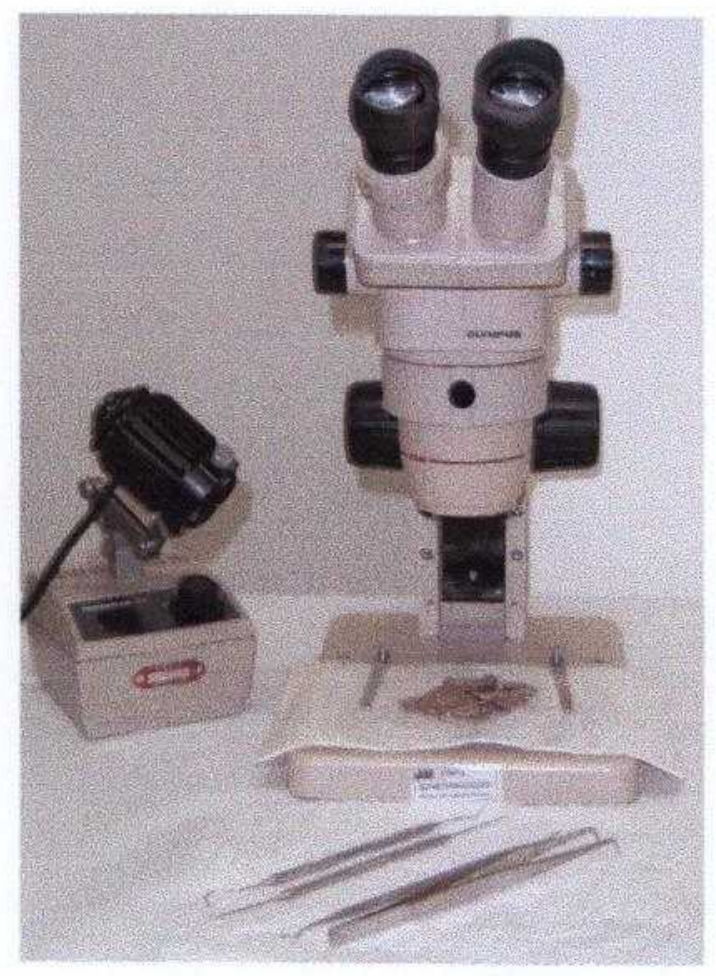

FIGURA 4.7 - Observação do líquen no microscópio estereoscópico Olympus.

Após a limpeza, as amostras foram lavadas com água purificada Milli-Q. Neste procedimento, as amostras permaneceram imersas por cerca de dois minutos. O líquen foi separado da água usando uma peneira com telas de nylon. Após esta limpeza, as amostras colocadas em potes de plástico foram guardadas em freezer $\left(\mathrm{T}=-18{ }^{\circ} \mathrm{C}\right)$ para posterior secagem por liofilização. A liofilização das amostras foi feita por cerca de 16 horas em liofilizador Micro Modulyo da Edwards (FIG. 4.8) a uma pressão de aproximadamente 6,0 x $10^{-2}$ mbar. A moagem das amostras foi feita em micromoinho Pulverisette 0 da Fritsch (FIG.4.9). Após a moagem de cada amostra, o almofariz de ágata do moinho foi lavado com uma espuma de nylon e água deionizada, seguida de secagem com papel higiênico. A amostra pulverizada foi transferida para recipiente de polietileno previamente lavado com solução de ácido nítrico p. $a$ diluída e água Milli-Q. Este recipiente contendo a amostra foi vedado com parafilme, identificado e guardado em um dessecador o qual continha em seu interior sílica como agente dessecante. Desta forma, a amostra esteve armazenada em condições que evitassem a absorção de umidade ou eventual contaminação. 


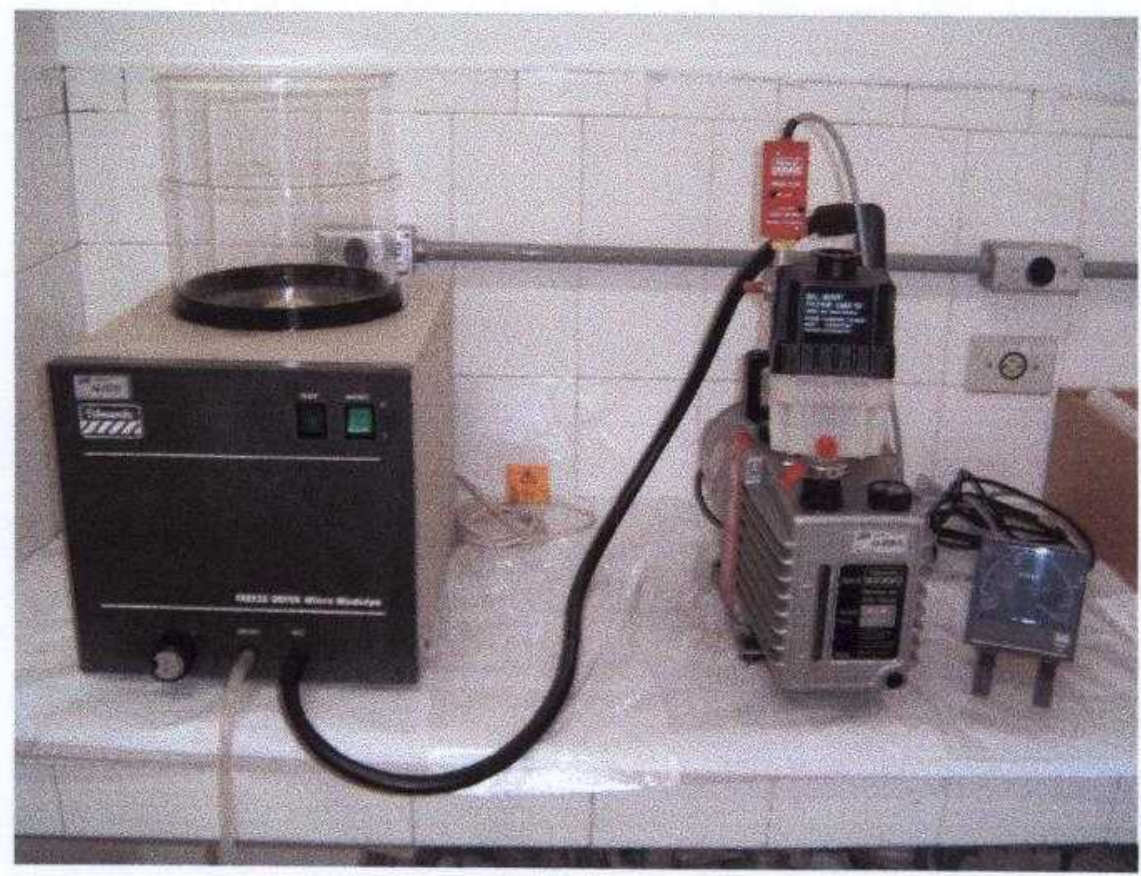

FIGURA 4.8 - Foto do liofilizador Micro Modulyo da Edwards.

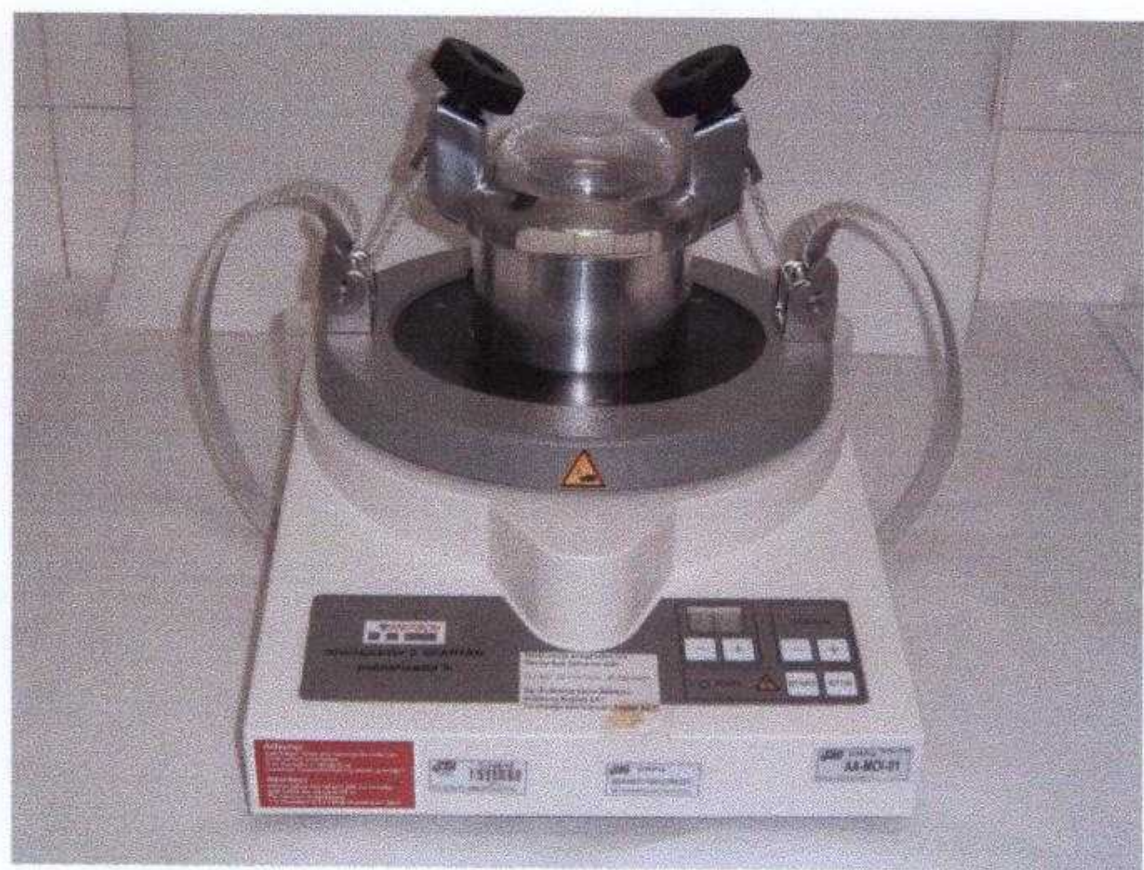

FIGURA 4.9 - Foto do micro moinho Pulverisette 0 da Fritsh. 


\subsection{Pesagem das amostras para análise por ativação neutrônica}

As pesagens das amostras para análise foram feitas em balança analítica do modelo $H 16$ para capacidade até $80 \mathrm{~g}$, da Mettler e precisão de $\pm 0,05 \mathrm{mg}$. Primeiramente, pesou-se um invólucro de polietileno vazio e em seguida, no seu interior, colocou-se a amostra desejada (aproximadamente $150 \mathrm{mg}$ ) e pesou-se novamente. A diferença entre as pesagens nos fornece a massa da amostra pesada. Finalmente, o invólucro contendo a amostra foi selado com o auxílio de uma seladora elétrica. $O$ invólucro de polietileno utilizado para a irradiação das amostras no reator foi confeccionado utilizando uma seladora elétrica e folhas de polietileno que foram previamente lavadas com soluções diluídas de ácido nítrico p.a e água purificada Milli-Q.

\subsection{Preparação de padrões elementares para análise por ativação}

\subsubsection{Padrões sintéticos de elementos}

Para preparação dos padrões sintéticos elementares para análise foram utilizadas soluções padrão estoque dos seguintes elementos: $\mathrm{Al}, \mathrm{As}, \mathrm{Ba}, \mathrm{Br}, \mathrm{Ca}, \mathrm{Cd}, \mathrm{Cl}, \mathrm{Co}$, $\mathrm{Cr}, \mathrm{Cs}, \mathrm{Cu}, \mathrm{K}, \mathrm{Fe}, \mathrm{Mg}, \mathrm{Mn}, \mathrm{Mo}, \mathrm{Na}, \mathrm{Rb}, \mathrm{Sb}, \mathrm{Sc}, \mathrm{Se}, \mathrm{V}, \mathrm{U}$ e $\mathrm{Zn}$ adquiridas da SpexCertiPrep, EUA e somente a de La foi adquirida da Aldrich, EUA.

A partir destas soluções padrão estoques foram preparadas soluções padrão simples ou multielementares por meio da sua diluição em balões volumétricos de 10 ou $25 \mathrm{~mL}$ previamente verificados quanto à sua calibração. A escolha dos elementos para compor um padrão misto foi feita baseando-se nas duas condições de irradiação a serem utilizadas (curtas e longas) bem como de modo a evitar o problema de interferências espectrais. As soluções padrão simples ou multielementares colocadas em frascos de polietileno da Nalgene e com vedadas com parafilme foram rotuladas com seus respectivos códigos, dados de concentração e data da preparação e depois guardadas em uma geladeira à temperatura de $13^{\circ} \mathrm{C}$.

Cinqüenta a cem microlitros, de cada uma das soluções estoque simples e multielementares foram pipetados sobre tiras de papel de filtro Whatman No. 42, de dimensões $1,3 \mathrm{~cm}$ x $2,0 \mathrm{~cm}$, usando um pipetador automático da Eppendorf previamente verificado quanto à sua calibração. Estas tiras de papel foram colocadas em um dessecador para secagem à temperatura ambiente. Posteriormente, elas foram dobradas e colocadas em 
invólucros de polietileno para irradiação no reator junto com as amostras. As massas de cada um dos elementos dos padrões pipetados estão na TAB.4.2.

\subsection{Procedimento experimental para as irradiações e medições}

Duas séries de irradiações foram realizadas no reator nuclear IEA-R1 do Instituto de Pesquisas Energéticas e Nucleares (IPEN-CNEN/SP): irradiações curtas e longas.

\subsubsection{Irradiações curtas no reator}

$\mathrm{Na}$ irradiação curta, duas amostras e os padrões sintéticos elementares com os códigos NA2, CL2, A4, KM4 e MG4, foram colocados juntos em um segundo invólucro de polietileno maior e este foi acondicionado no interior de um dispositivo de plástico para irradiação denominado "coelho". Como calço para este dispositivo, foram utilizadas espumas de nylon. Em todas as irradiações, as aletas dos "coelhos" foram trocadas e foi observado o estado de conservação do mesmo para que não ocorresse a quebra pelos impactos. A irradiação curta de cinco minutos foi realizada por meio da Estação Pneumática $n^{\circ} 4$ do reator IEA-R1 e sob fluxo de nêutrons térmicos da ordem de $5 \times 10^{11} \mathrm{n}$ $\cdot \mathrm{cm}^{-2} \cdot \mathrm{s}^{-1}$.

Um cronômetro foi utilizado para o controle do tempo de irradiação desejado, assim como para registrar o início e o final das contagens para posteriormente serem usados no cálculo do tempo de decaimento e nas determinações das concentrações dos elementos. As amostras e os padrões sintéticos dos elementos foram fixados em um suporte denominado "panelinha" de aço inoxidável com fita crepe para realizar as medições. $O$ uso de fita crepe para a fixação da amostra no suporte de aço inoxidável evita o rompimento do invólucro de polietileno que contém as amostras e os padrões radioativos evitando desta maneira eventuais contaminações e, também para as contagens das amostras e padrões na mesma geometria no detetor de Ge hiperpuro. 


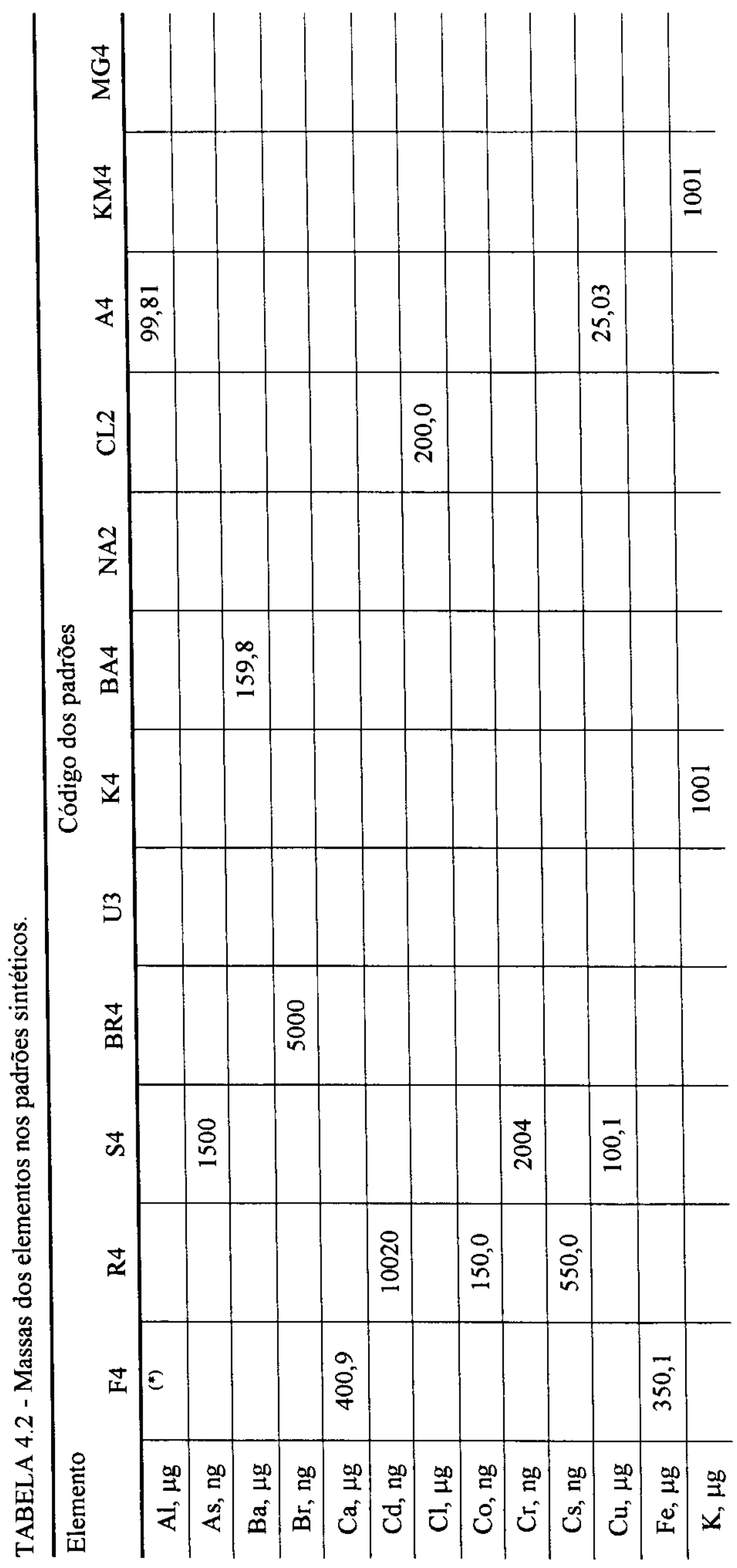


$\widehat{\varsigma}$

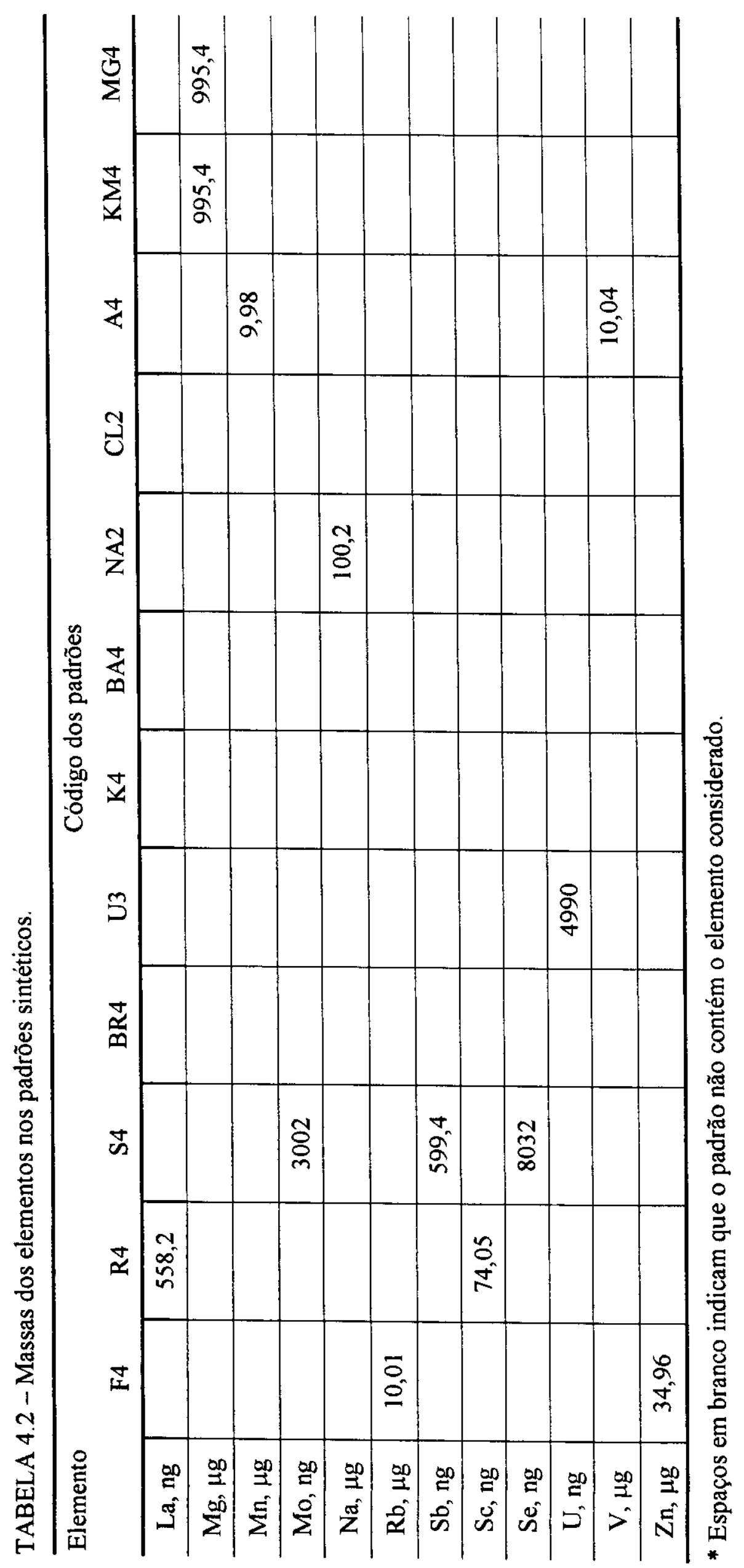


As amostras e os padrões, após a irradiação, foram transportados dentro de um "castelo de chumbo" para evitar a exposição à radiação. As medições foram realizadas usando um detector de Ge hiperpuro Modelo GX2020 acoplado a um Processador Integrado de Sinais Modelo 1510 e Placa Analisador Multicanal Sistema 100, ambos da Canberra. A resolução do sistema de contagem utilizada foi de $1,06 \mathrm{keV}$ para o fotopico de $121,97 \mathrm{keV}$ do ${ }^{57} \mathrm{Co}$ e de $2,0 \mathrm{keV}$ para o fotopico de $1331,49 \mathrm{keV}$ do ${ }^{60} \mathrm{Co}$. Diariamente, foram realizadas as medições de uma fonte de ${ }^{57} \mathrm{Co}+{ }^{60} \mathrm{Co}$ para verificar o funcionamento do sistema de contagens.

As medições das amostras e padrões foram realizadas em dois diferentes tempos de decaimento: a primeira contagem foi realizada logo após a irradiação para determinação dos elementos $\mathrm{Al}, \mathrm{Cl}, \mathrm{Cu}, \mathrm{Mg}$ e V e o tempo da contagem foi de $200 \mathrm{~s}$; e a segunda contagem, com tempo de medida de 300 a $600 \mathrm{~s}$ foi realizada após cerca de uma hora de decaimento para determinação dos elementos $\mathrm{Cl}, \mathrm{K}, \mathrm{Mn}$ e $\mathrm{Na}$. A posição para contagem no detector foi escolhida de modo que o tempo morto do sistema não superasse o valor de $15 \%$ e não ocorresse a saturação do detector. Para aquisição dos dados foi utilizado o programa $S 100$ da Canberra e os espectros de raios gama foram gravados em disquete.

O processamento do espectro foi realizado usando o programa VERSAO2 uma nova versão do programa VISPECT 2 que fornece as energias dos raios gama e as taxas de contagens. A identificação dos radioisótopos foi feita pelas energias dos raios gama e a meia-vida, consultando a tabela de dados nucleares de radioisótopos para análise por ativação compilados pela Agência Internacional de Energia Atômica (IAEA, 1990). As concentrações dos elementos foram calculadas pelo método comparativo usando os programas de computação apropriados nos quais utilizam a relação (3.8). Para os dados da primeira contagem da irradiação curta utilizou-se o programa de computador denominado $P A K I$ e, os da segunda contagem o programa de computador denominado ESPECTRO. A diferença entre os programas $P A K I$ e ESPECTRO está no fato do primeiro considerar o tempo de decaimento durante a contagem. 


\subsubsection{Irradiações longas no reator}

No caso das irradiações longas, as amostras e os padrões sintéticos elementares F4, R4, S4, BR4, U3, K4 e BA4 foram envoltos em folhas de alumínio e a seguir acondicionados em "coelhos" de alumínio para irradiação no reator IEA-R1 por um período de 16 horas e sob um fluxo de nêutrons térmicos da ordem de $5 \times 10^{12} \mathrm{n} \cdot \mathrm{cm}^{-2} \cdot \mathrm{s}^{-1}$. Após cerca de 4 dias de decaimento as amostras e os padrões foram fixados em "panelinhas"de aço inoxidável e medidos no detector de Ge hiperpuro, o mesmo sistema utilizado para as amostras da irradiação curta. Também foi escolhida a geometria de contagem de maneira que a medida não fosse realizada com um tempo morto maior do que $15 \%$.

O tempo de contagem para os padrões foi de $6.000 \mathrm{~s}$ e para as amostras variou de $25.000 \mathrm{~s}$ a $40.000 \mathrm{~s}$. Foram realizadas neste caso, três séries de contagens em diferentes tempos de decaimento para determinar um número maior de elementos e também evitar o problema de interferências na análise. A primeira contagem foi feita após cerca de quatro dias de decaimento para a determinação dos elementos de meias-vida de até uma semana, isto é, dos elementos $\mathrm{As}, \mathrm{Ba}, \mathrm{Br}, \mathrm{Ca}, \mathrm{Cd}, \mathrm{Cu}, \mathrm{K}, \mathrm{La}, \mathrm{Mo}, \mathrm{Na}, \mathrm{Sb}$ e $\mathrm{U}$. $\mathrm{Na}$ segunda contagem, após cerca de dez dias de decaimento foram determinados os elementos $\mathrm{Ba}, \mathrm{Cd}$, $\mathrm{Cr}, \mathrm{Fe}, \mathrm{Rb}, \mathrm{Sb}, \mathrm{Se}$ e $\mathrm{Zn}$. Após cerca de vinte dias de decaimento foi feita a terceira contagem. Nesse caso determinaram-se os elementos $\mathrm{Co}, \mathrm{Cr}, \mathrm{Cs}, \mathrm{Fe}, \mathrm{Rb}, \mathrm{Sc}, \mathrm{Se}$ e $\mathrm{Zn}$ cujos radioisótopos correspondentes apresentam tempos de meia-vida longos.

A identificação dos radioisótopos, nos espectros de raios gama, foi feita por meio das energias dos raios gama e tempos de meia-vida. As concentrações dos elementos foram calculadas pelo método comparativo de análise usando os programas de computação apropriados nos quais utilizam-se da relação (3.8).

$\mathrm{Na}$ TAB. 4.3 estão as características dos radioisótopos utilizados neste trabalho. 
TABELA 4.3 - Características dos radioisótopos utilizados neste trabalho.

\begin{tabular}{|c|c|c|c|c|}
\hline Elemento & Radioisótopo & Energia (keV) & Meia-vida & Reação \\
\hline $\mathrm{Al}$ & ${ }^{28} \mathrm{Al}$ & 1778,99 & $2,24 \mathrm{~min}$ & ${ }^{27} \mathrm{Al}(\mathrm{n}, \gamma)$ \\
\hline As & ${ }^{76}$ As & 559,10 & $26,32 \mathrm{~h}$ & ${ }^{75}$ As $(\mathrm{n}, \gamma)$ \\
\hline $\mathrm{Ba}$ & ${ }^{132} \mathrm{Ba}$ & $373,19 / 496,26$ & $11,8 \mathrm{~d}$ & ${ }^{131} \mathrm{Ba}(\mathrm{n}, \gamma)$ \\
\hline $\mathrm{Br}$ & ${ }^{82} \mathrm{Br}$ & 776,52 & $35,3 \mathrm{~h}$ & ${ }^{81} \mathrm{Br}(\mathrm{n}, \gamma)$ \\
\hline $\mathrm{Ca}$ & ${ }^{47} \mathrm{Ca}$ & $159,38 / 1297,09$ & $4,54 \mathrm{~d}$ & ${ }^{46} \mathrm{Ca}(\mathrm{n}, \gamma)$ \\
\hline $\mathrm{Cd}$ & ${ }^{115} \mathrm{Cd}$ & 527,91 & $53,46 \mathrm{~h}$ & ${ }^{114} \mathrm{Cd}(\mathrm{n}, \gamma)$ \\
\hline $\mathrm{Cl}$ & ${ }^{38} \mathrm{Cl}$ & 1642,69 & $37,24 \mathrm{~min}$ & ${ }^{37} \mathrm{Cl}(\mathrm{n}, \gamma)$ \\
\hline $\mathrm{Co}$ & ${ }^{60} \mathrm{Co}$ & 1173,24 & $5,27 \mathrm{a}$ & ${ }^{59} \mathrm{Co}(\mathrm{n}, \gamma)$ \\
\hline $\mathrm{Cr}$ & ${ }^{51} \mathrm{Cr}$ & 320,08 & $27,7 \mathrm{~d}$ & ${ }^{50} \mathrm{Cr}(\mathrm{n}, \gamma)$ \\
\hline $\mathrm{Cs}$ & ${ }^{134} \mathrm{Cs}$ & 795,85 & $2,06 \mathrm{a}$ & ${ }^{133} \mathrm{Cs}(\mathrm{n}, \gamma)$ \\
\hline $\mathrm{Cu}$ & ${ }^{64} \mathrm{Cu}$ & 1345,77 & $12,7 \mathrm{~h}$ & ${ }^{63} \mathrm{Cu}(\mathrm{n}, \gamma)$ \\
\hline $\mathrm{Cu}$ & ${ }^{66} \mathrm{Cu}$ & 1039,2 & $5,10 \mathrm{~min}$ & ${ }^{65} \mathrm{Cu}(\mathrm{n}, \gamma)$ \\
\hline $\mathrm{Fe}$ & ${ }^{59} \mathrm{Fe}$ & $1099,25 / 1291,60$ & $44,5 \mathrm{~d}$ & ${ }^{58} \mathrm{Fe}(\mathrm{n}, \gamma)$ \\
\hline $\mathrm{K}$ & ${ }^{42} \mathrm{~K}$ & 1524,58 & $12,36 \mathrm{~h}$ & ${ }^{4 \mathrm{l}} \mathrm{K}(\mathrm{n}, \gamma)$ \\
\hline $\mathrm{La}$ & ${ }^{140} \mathrm{La}$ & $815,77 / 1596,21$ & $40,27 \mathrm{~h}$ & ${ }^{139} \mathrm{La}(\mathrm{n}, \gamma)$ \\
\hline $\mathrm{Mg}$ & ${ }^{27} \mathrm{Mg}$ & $843,76 / 1014,43$ & $9,46 \min$ & ${ }^{26} \mathrm{Mg}(\mathrm{n}, \gamma)$ \\
\hline $\mathrm{Mn}$ & ${ }^{56} \mathrm{Mn}$ & $846,76 / 1810,72$ & $2,58 \mathrm{~h}$ & ${ }^{55} \mathrm{Mn}(\mathrm{n}, \gamma)$ \\
\hline Mo & ${ }^{99} \mathrm{Mo}$ & 140,51 & 65,94 & ${ }^{98} \mathrm{Mo}(\mathrm{n}, \gamma)$ \\
\hline $\mathrm{Na}$ & ${ }^{24} \mathrm{Na}$ & 1368,60 & $14,96 \mathrm{~h}$ & ${ }^{23} \mathrm{Na}(\mathrm{n}, \gamma)$ \\
\hline $\mathrm{Rb}$ & ${ }^{86} \mathrm{Rb}$ & 1076,60 & $18,66 \mathrm{~d}$ & ${ }^{85} \mathrm{Rb}(\mathrm{n}, \gamma)$ \\
\hline $\mathrm{Sb}$ & ${ }^{122} \mathrm{Sb}$ & 564,24 & $2,70 \mathrm{~d}$ & ${ }^{121} \mathrm{Sb}(\mathrm{n}, \gamma)$ \\
\hline $\mathrm{Sc}$ & ${ }^{46} \mathrm{Sc}$ & 889,28 & $83,81 \mathrm{~d}$ & ${ }^{45} \mathrm{Sc}(\mathrm{n}, \gamma)$ \\
\hline $\mathrm{Se}$ & ${ }^{75} \mathrm{Se}$ & 264,66 & $119,77 \mathrm{~d}$ & ${ }^{74} \mathrm{Se}(\mathrm{n}, \gamma)$ \\
\hline $\mathrm{U}^{*}$ & ${ }^{239} \mathrm{~Np}$ & $106,12 / 277,60$ & $2,36 \mathrm{~d}$ & ${ }^{238} \mathrm{U}(\mathrm{n}, \gamma)$ \\
\hline V & ${ }^{52} \mathrm{~V}$ & 1434,8 & $3,75 \mathrm{~min}$ & ${ }^{51} \mathrm{~V}(\mathrm{n}, \gamma)$ \\
\hline $\mathrm{Zn}$ & ${ }^{65} \mathrm{Zn}$ & 1115,55 & $243,9 d$ & ${ }^{64} \mathrm{Zn}(\mathrm{n}, \gamma)$ \\
\hline
\end{tabular}




\subsection{Análise dos materiais biológicos certificados de referência}

O controle da qualidade dos resultados com relação à precisão e exatidão foi feito por meio da análise dos seguintes materiais biológicos certificados de referência: IAEA-336 LICHEN, proveniente da Agência Internacional de Energia Atômica, Áustria e Mixed Polish Herbs (INCT-MPH-2) do Instituto de Química Nuclear e Tecnologia, Polônia. As condições experimentais utilizadas para a análise dos materiais certificados de referência foram as mesmas utilizadas para as análises de liquens.

$\mathrm{Na}$ TAB. 4.4 estão os fotopicos das energias dos raios gama e as séries de contagens utilizadas para calcular-se as concentrações dos elementos nos materiais certificados de referência IAEA-336 LICHEN e Mixed Polish Herbs (INCT-MPH-2) (IAEA, 1990).

\subsubsection{Determinação das percentagens de perda de peso nas secagens dos materiais certificados de referência}

Como os valores certificados são expressos na base seca do material, foram feitas as determinações dos teores de umidade nos materiais certificados de referência.Para isso, cerca de $250 \mathrm{mg}$ de cada material pesados em pesa-filtro foram submetidos à secagem de acordo com a temperatura recomendada no certificado de cada material $\left(100^{\circ} \mathrm{C}\right.$ para IAEA-336 LICHEN e, $70^{\circ} \mathrm{C}$ para Mixed Polish Herbs, INCT-MPH-2). Primeiramente, cada material foi submetido à secagem por quatro horas. As secagens subseqüentes foram feitas até que os materiais apresentassem peso constante.

Os resultados de percentagens de perda de peso obtidos foram de $9,76 \%$ para o IAEA-336 LICHEN e de 6,11\% para o Mixed Polish Herbs (INCT-MPH-2). Estes valores foram usados no cálculo das concentrações na base seca do material.

As condições experimentais definidas na análise destes materiais foram utilizadas posteriormente para análise de liquens. Para o controle da qualidade dos resultados as análises dos materiais de referência foram realizadas de vez em quando durante todo o periodo em que amostras de liquens foram analisadas. 
TABELA 4.4 - Energia de raios gama e série de contagens dos radioisótopos utilizados na análise dos materiais certificados de referência IAEA-336 LICHEN e Mixed Polish Herbs (INCT-MPH-2).

\begin{tabular}{|c|c|c|c|c|}
\hline \multirow[t]{2}{*}{ Radioisótopo } & \multicolumn{2}{|c|}{ IAEA-336 Lichen } & \multicolumn{2}{|c|}{$\begin{array}{l}\text { Mixed Polish Herbs } \\
\text { (INCT-MPH-2) }\end{array}$} \\
\hline & Energia & $\begin{array}{c}\text { Série de } \\
\text { contagem }\end{array}$ & Energia & $\begin{array}{c}\text { Série de } \\
\text { contagem }\end{array}$ \\
\hline${ }^{28} \mathrm{Al}$ & 1778,99 & Primeira & 1778,99 & Primeira \\
\hline${ }^{76}$ As & 559,1 & Primeira & 559,1 & Primeira \\
\hline${ }^{132} \mathrm{Ba}$ & 496,26 & Primeira & 496,26 & Primeira \\
\hline${ }^{82} \mathrm{Br}$ & 776,52 & Primeira & 776,52 & Primeira \\
\hline${ }^{47} \mathrm{Ca}$ & 1297,09 & Segunda & 1297,09 & Segunda \\
\hline${ }^{115} \mathrm{Cd}$ & (a) & & 527,91 & Segunda \\
\hline${ }^{38} \mathrm{Cl}$ & 1642,69 & Segunda & 1642,69 & Segunda \\
\hline${ }^{60} \mathrm{Co}$ & 1173,24 & Terceira & 1173,24 & Terceira \\
\hline${ }^{51} \mathrm{Cr}$ & 320,08 & Segunda & 320,08 & Segunda \\
\hline $\begin{array}{l}{ }^{134} \mathrm{Cs} \\
{ }^{64} \mathrm{Cu}\end{array}$ & 795,85 & Terceira & 795,85 & Terceira \\
\hline${ }^{66} \mathrm{Cu}$ & & & & \\
\hline${ }^{59} \mathrm{Fe}$ & 1099,25 & Segunda & 1099,25 & Segunda \\
\hline${ }^{42} \mathrm{~K}$ & 1524,58 & Primeira & 1524,58 & Primeira \\
\hline${ }^{140} \mathrm{La}$ & 1596,21 & Primeira & 1596,21 & Primeira \\
\hline${ }^{27} \mathrm{Mg}$ & 843,63 & Primeira & 843,76 & Primeira \\
\hline${ }^{56} \mathrm{Mn}$ & 846,76 & Segunda & 846,76 & Segunda \\
\hline${ }^{99} \mathrm{Mo}$ & 140,51 & Segunda & 140,51 & Primeira \\
\hline${ }^{24} \mathrm{Na}$ & 1368,6 & Segunda & 1368,6 & Segunda \\
\hline${ }^{86} \mathrm{Rb}$ & 1076,6 & Segunda & 1076,6 & Segunda \\
\hline${ }^{122} \mathrm{Sb}$ & 564,24 & Segunda & 564,24 & Segunda \\
\hline${ }^{46} \mathrm{Sc}$ & 889,28 & Segunda & 889,28 & Segunda \\
\hline${ }^{75} \mathrm{Se}$ & 264,66 & Terceira & 264,66 & Segunda \\
\hline${ }^{239} \mathrm{~Np}$ & 277,6 & Primeira & 277,6 & Primeira \\
\hline${ }^{52} \mathrm{~V}$ & 1434,08 & Primeira & & \\
\hline${ }^{65} \mathrm{Zn}$ & 1115,55 & Terceira & 1115,55 & Terceira \\
\hline
\end{tabular}

(a) Espaço em branco indica que o elemento não foi detectado nas condições da análise. 


\section{RESULTADOS E DISCUSSÃO}

\subsection{Resultados das análises dos materiais certificados de referência}

Para avaliar-se a precisão e a exatidão do método analítico empregado foram analisados dois materiais certificados de referência: IAEA- 336 LICHEN e Mixed Polish Herbs (INCT-MPH-2).

\subsubsection{Material de referência IAEA-336 LICHEN}

$\mathrm{Na}$ TAB. 5.1 estão os resultados da média aritmética $(X)$ das concentrações de elementos, desvios padrão das médias $\left(\mathrm{s}_{\mathrm{x}}\right)$, coeficientes de variação (C.V.) expressos em percentagens, limites de confiança (L.C.) e os valores de $t$ de Student calculados e tabelados para o material certificado de referência IAEA-336 LICHEN. Estes parâmetros estatísticos foram calculados de acordo com Vogel (1992) e Magalhães et al. (2004). Nesta Tabela, são também apresentados os valores recomendados e informativos do certificado para este material de referência (IAEA, 1999), para comparação. Na TAB. 5.2 estão as fórmulas utilizadas para o cálculo dos parâmetros obtidos na TAB.5.1. 
I

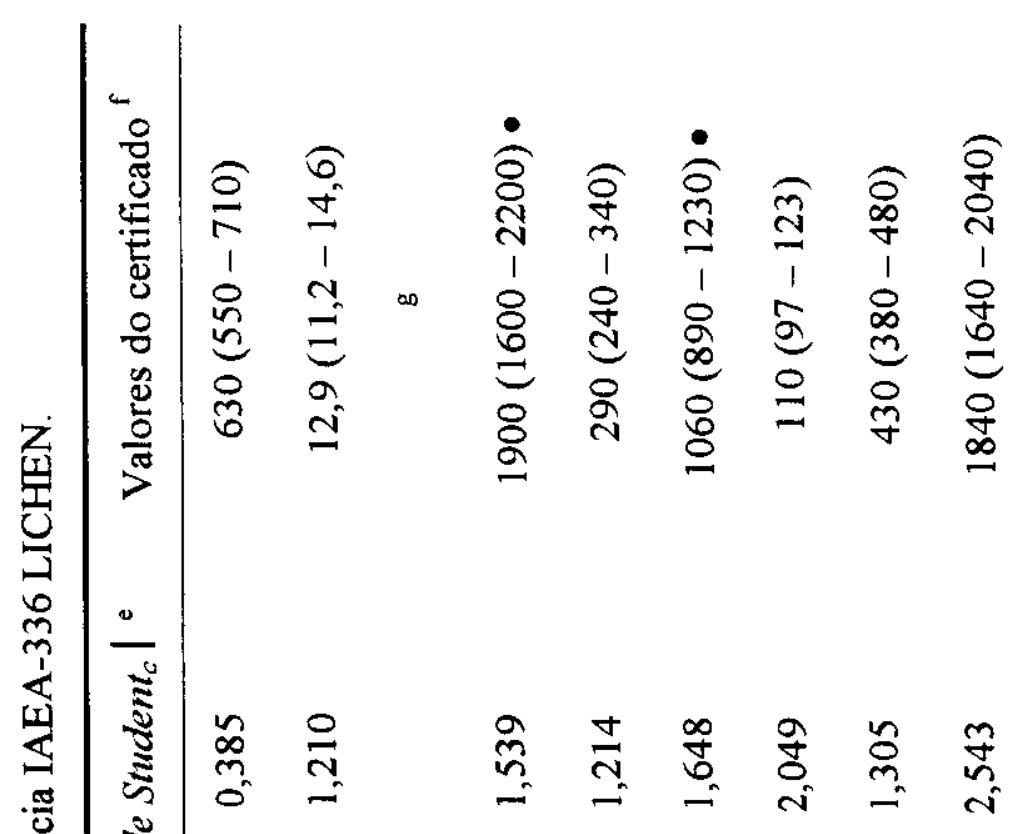

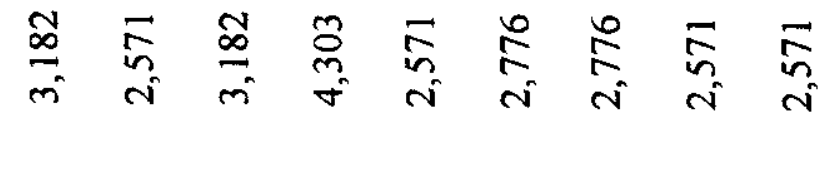

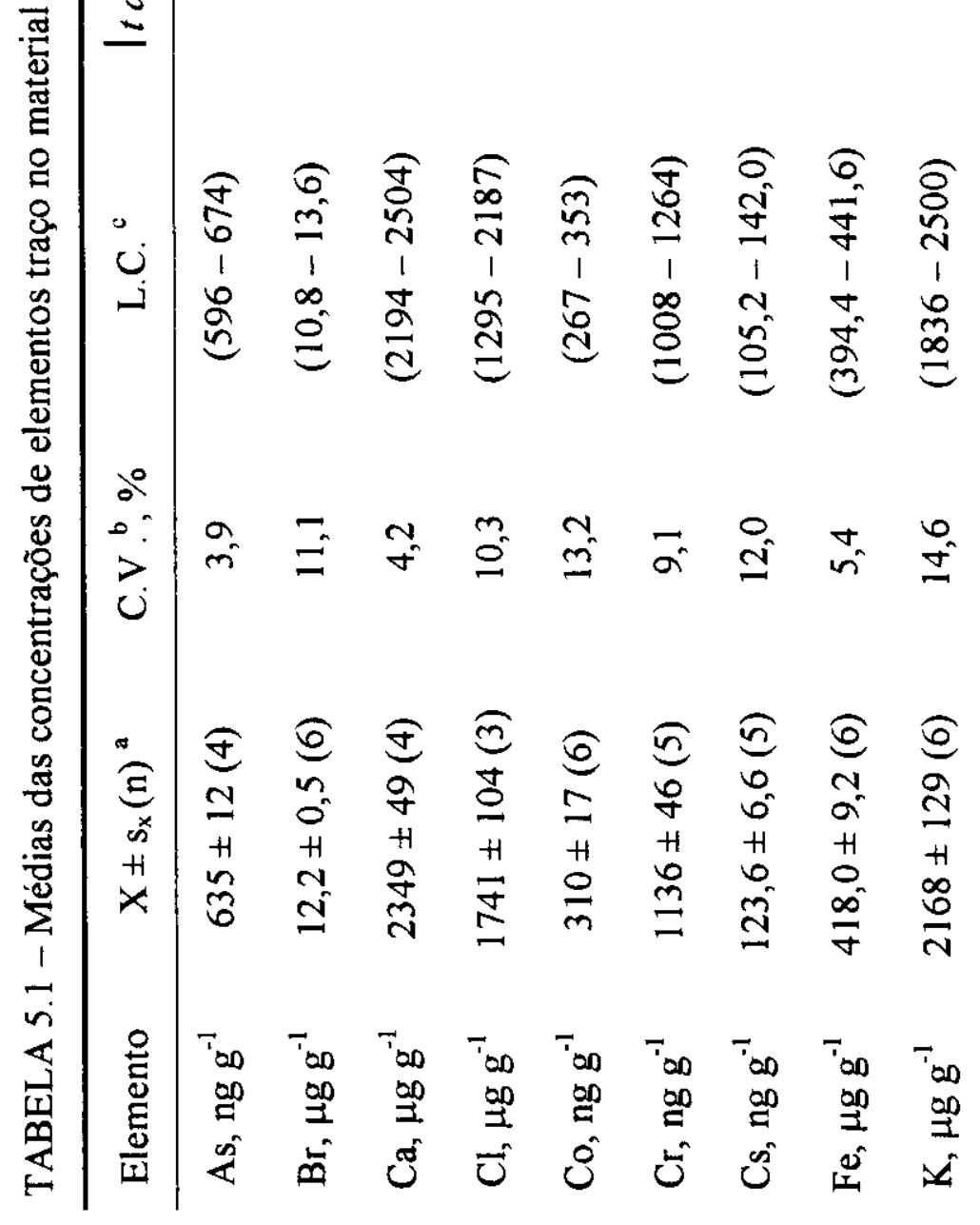


$\approx$

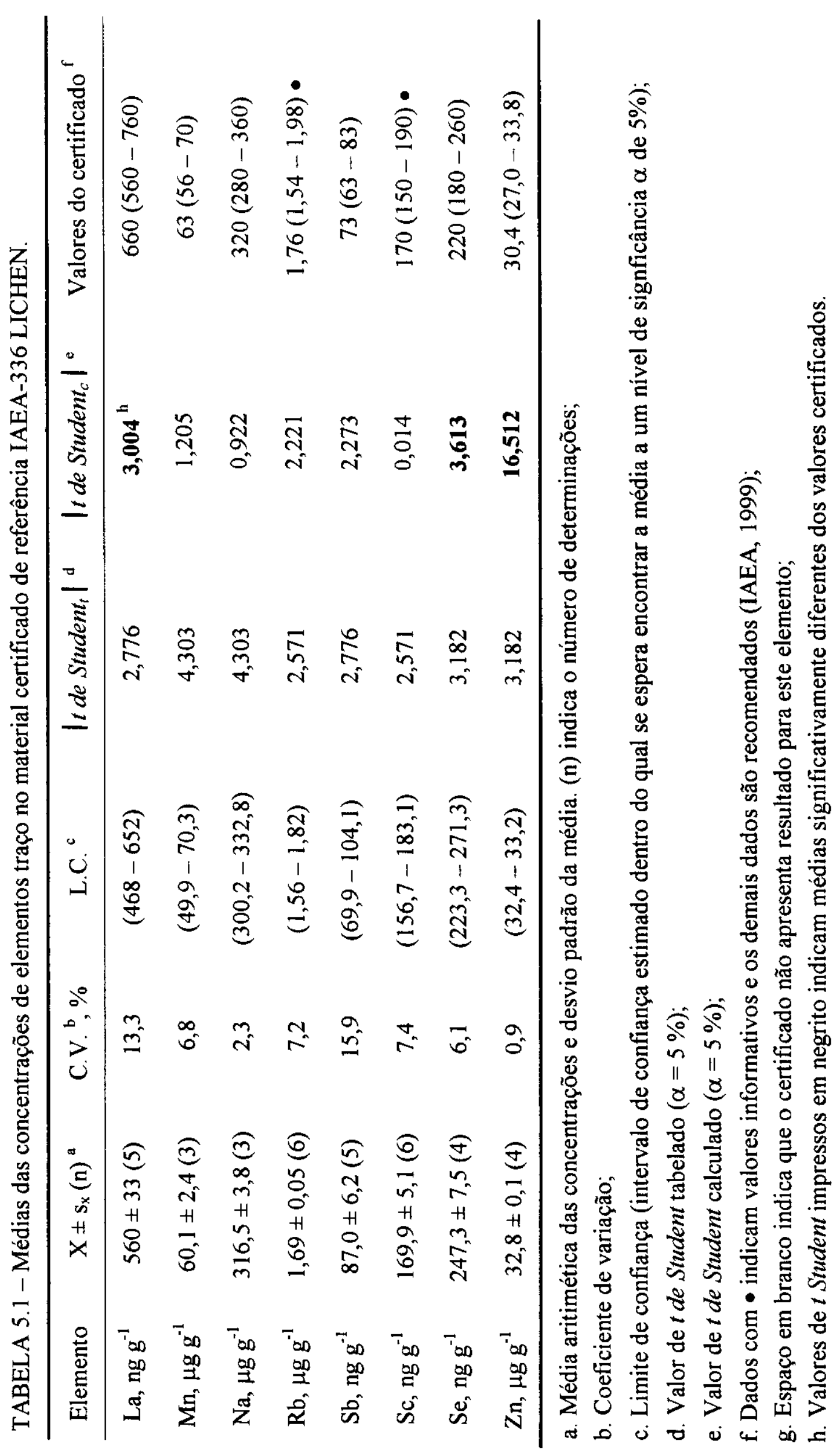


TABELA 5.2 - Fórmulas utilizadas para o cáiculo das grandezas apresentadas na TAB. 5.1 (Vogel, 1992; Magalhães et al., 2004).

\begin{tabular}{|c|c|}
\hline Grandeza & Fórmula \\
\hline Média das concentrações & $X=\left(X_{1}+X_{2}+X_{3 \ldots}+\ldots+X_{n-1}+X_{n}\right) / n$ \\
\hline Desvio padrão & $\mathrm{s}=\left\{\left[\Sigma\left(\mathrm{X}_{\mathrm{n}}-\mathrm{X}\right)^{2}\right] / \mathrm{n}-1\right\}^{1 / 2}$ \\
\hline Desvio padrão da média & $\mathrm{s}_{\mathrm{x}}=\mathrm{s} /(\mathrm{n})^{1 / 2}$ \\
\hline Coeficiente de variação $(\%)$ & C.V. $=(\mathrm{s} \times 100) / \mathrm{X}$ \\
\hline Limite de confiança & $\begin{array}{c}\text { L.C. }=(\mathrm{t} \times \mathrm{s}) /(\mathrm{n})^{1 / 2} \text {, onde } \mathrm{t} \text { é um parâmetro que } \\
\text { depende do número de graus de liberdade }(v) \text { e do nível } \\
\text { de confiança }\end{array}$ \\
\hline $\mathrm{t}$ de Student & $\mathrm{t}=\left[(\mathrm{X}-\mu) \times(n)^{1 / 2}\right] / \mathrm{s}$, onde $\mu$ é o valor certificado \\
\hline
\end{tabular}

Conforme mostra a TAB.5.1, os resultados obtidos apresentaram uma boa precisão para a maioria dos elementos com coeficientes de variação variando de 0,9 a 14,6\%. Para o elemento $\mathrm{Sb}$ foi obtido um resultado de menor precisão, com coeficiente de variação superior a $15 \%$ devido provavelmente ao baixo teor deste elemento no material. Os limites de confiança indicam a medida da proximidade em que a média da concentração do elemento considerado $(\mathrm{X})$ pode estar da média verdadeira, ou seja, do valor dado pelo certificado. Desta forma, foi possível calcular um intervalo de confiança dentro do qual se espera encontrar a média a um nível de significância de 5\%.

Para comparar a média da concentração obtida para um determinado elemento com o valor do certificado foi aplicado o teste $t$ de Student com um nível de significância de $5 \%$. Os valores de $t$ de Student foram obtidos por meio do programa ORIGIN 5.0. Este programa, além de calcular o valor de $t$ de Student permite verificar se a média obtida apresenta diferença significativa do valor certificado. Na TAB. 5.1 estão indicados em negrito os elementos para os quais as médias obtidas são significativamente diferentes do valor certificado. A comparação de dados desta Tabela mostra que os resultados obtidos apresentam, em geral, uma boa concordância com os valores do certificado. Entretanto, os elementos $\mathrm{La}, \mathrm{Se}$ e $\mathrm{Zn}$ apresentaram médias significativamente diferentes dos valores certficados ao nível de significância de $5 \%$. 
Para avaliar a exatidão dos resultados obtidos foram também calculados os valores de Z-score, ou também conhecido como diferença padronizada (Bode, 1996) aplicando-se a seguinte relação:

$$
\text { Z-score }_{i}=\left(\mathrm{C}_{\mathrm{i}}-\mathrm{C}_{\mathrm{ref}, \mathrm{i}}\right) /\left(\sigma_{\mathrm{i}}^{2}+\sigma_{\text {ref,i }}^{2}\right)^{1 / 2}
$$

onde:

$\mathrm{C}_{\mathrm{i}}$ é a concentração do elemento i obtido na análise do material de referência;

$\mathrm{C}_{\text {ref,i }}$ é a concentração apresentada no certificado para o elemento i;

$\sigma_{\mathrm{i}}$ é a incerteza da concentração do elemento i obtida da análise do material de referência;

$\sigma_{\text {ref,i }}$ é a incerteza do valor certificado para o elemento $i$.

Os valores de Z-score obtidos para os elementos analisados no material certificado de referência IAEA-336 LICHEN são apresentados na FIG.5.1. Estes valores foram calculados somente para os elementos que apresentam valores certificados (recomendados). Como se pode observar na FIG.5.1, os valores obtidos para Z-score foram $|Z|<3$. Isto significa que os resultados obtidos para o material certificado de referência estão dentro das faixas de valores apresentados no certificado a um nível de significância de $1 \%$ (Bode, 1996). 


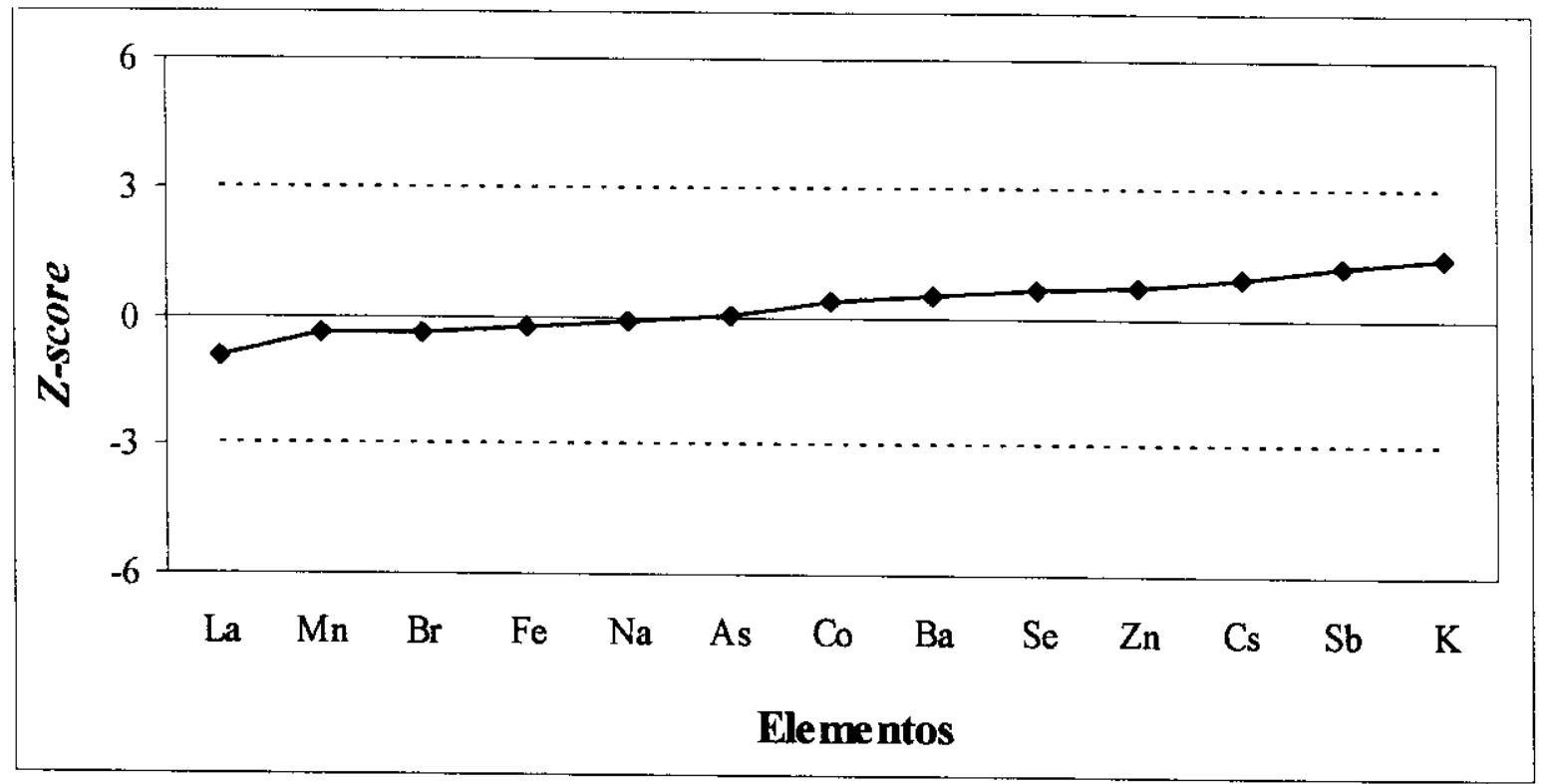

FIGURA 5.1 - Valores de Z-score obtidos para o material certificado de referência IAEA336 LICHEN.

\subsubsection{Material de referência Mixed Polish Herbs (INCT-MPH-2)}

$\mathrm{Na}$ TAB. 5.3 estão apresentados os valores da média aritimética $(\mathrm{X})$, desvios padrão das médias $\left(\mathrm{s}_{\mathrm{x}}\right)$, coeficientes de variação (C.V.), limite de confiança (L.C.) e valores de $t$ de Student calculados e tabelados para o material certificado de referência Mixed Polish Herbs (INCT-MPH-2). Nesta Tabela também são apresentados os valores certificados e informativos (INCT, 2002) para comparação. 
2

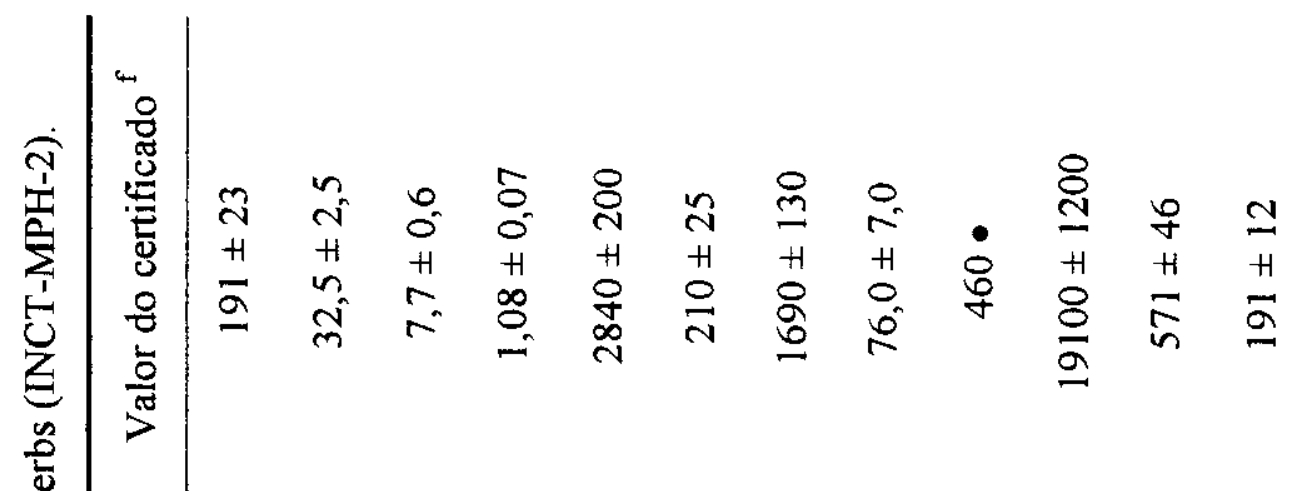

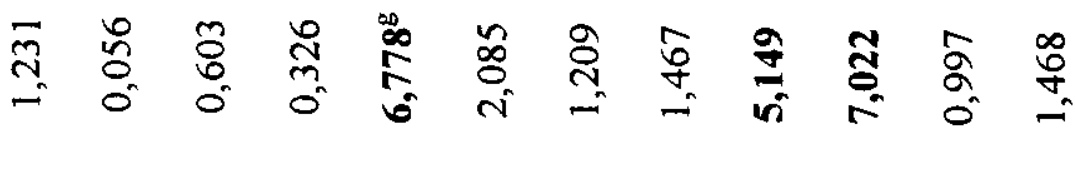

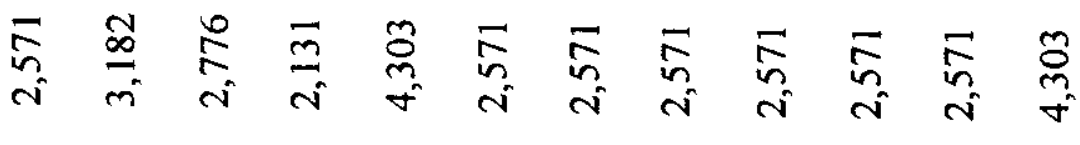

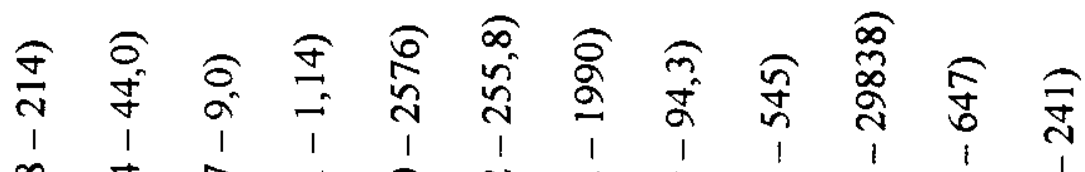

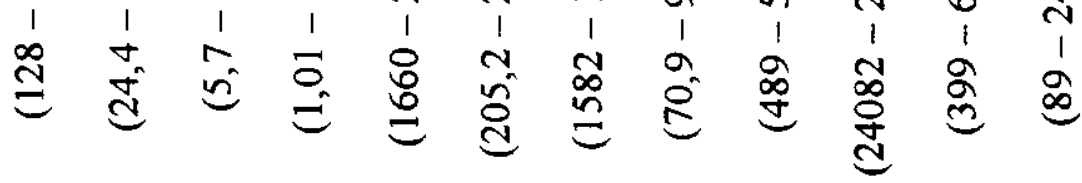

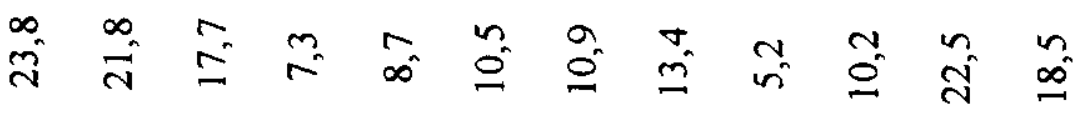

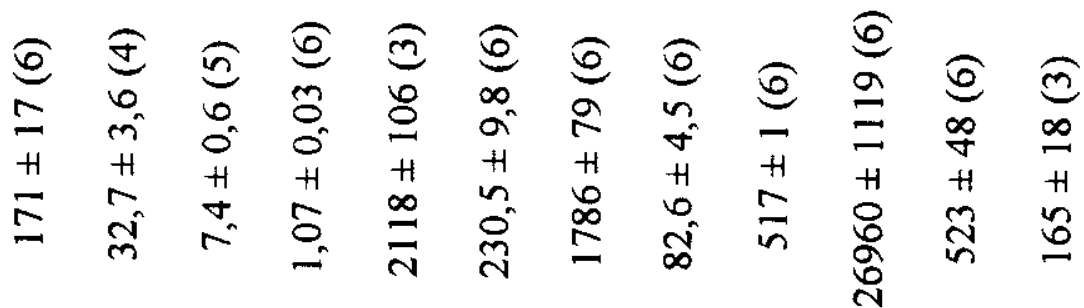

帒

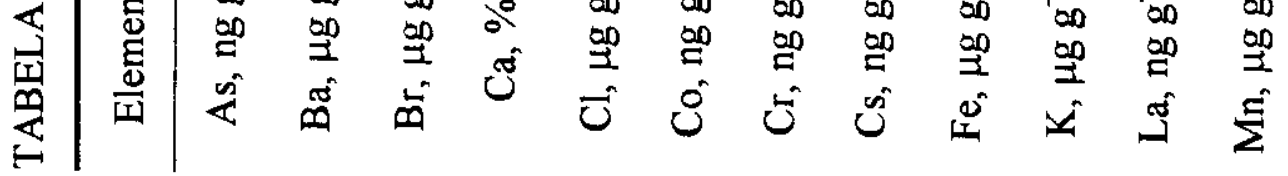


$\infty$

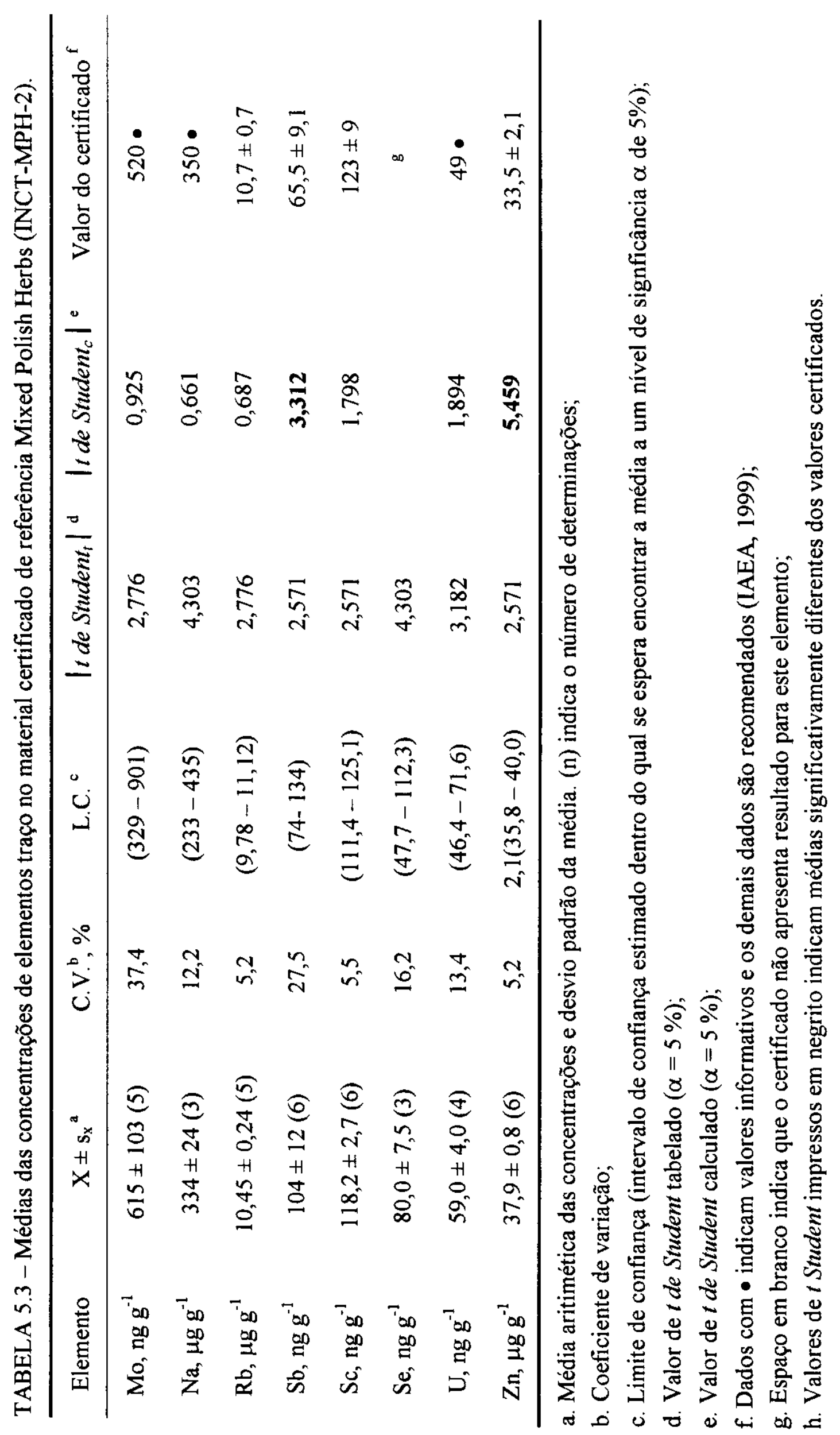


Pode-se observar na TAB.5.3, que os resultados obtidos para o material Mixed Polish Herbs apresentaram uma boa precisão para os elementos $\mathrm{Ca}, \mathrm{Cl}, \mathrm{Co}, \mathrm{Cr}, \mathrm{Cs}, \mathrm{Fe}, \mathrm{K}$, $\mathrm{Mg}, \mathrm{Na}, \mathrm{Rb}, \mathrm{Sc}, \mathrm{U}$ e $\mathrm{Zn}$, com valores de coeficientes de variação entre 5,2 e $13,4 \%$. Os resultados menos precisos, com coeficientes de variação superiores a $15 \%$, foram obtidos para os elementos $\mathrm{As}, \mathrm{Ba}, \mathrm{Br}, \mathrm{La}, \mathrm{Mn}, \mathrm{Mo}, \mathrm{Sb}$ e Se.

Para o material certificado de referência Mixed Polish Herbs (INCT-MPH-2) também foram calculados os valores de $t$ de Student para avaliar a exatidão dos resultados. A TAB. 5.3 mostra que os resultados apresentam, em geral, uma boa concordância com os valores dados pelo certificado. Os elementos $\mathrm{Cl}, \mathrm{Fe}, \mathrm{K}, \mathrm{Sb}$ e $\mathrm{Zn}$ apresentaram médias significativamente diferentes dos valores certificados quando aplicado este teste ao nível de significância de $5 \%$.

Os valores de Z-score obtidos para o Material Mixed Polish Herbs apresentados na FIG.5.2 foram $|Z|<3$ exceptuando-se para os elementos $\mathrm{Cl}, \mathrm{K}$ e Mg. Isto significa que os resultados obtidos, para a maioria dos elementos com exceção de $\mathrm{Cl}$ e $\mathrm{K}$, estão dentro das faixas de valores apresentados no certificado a um nível de significância de $1 \%$. 


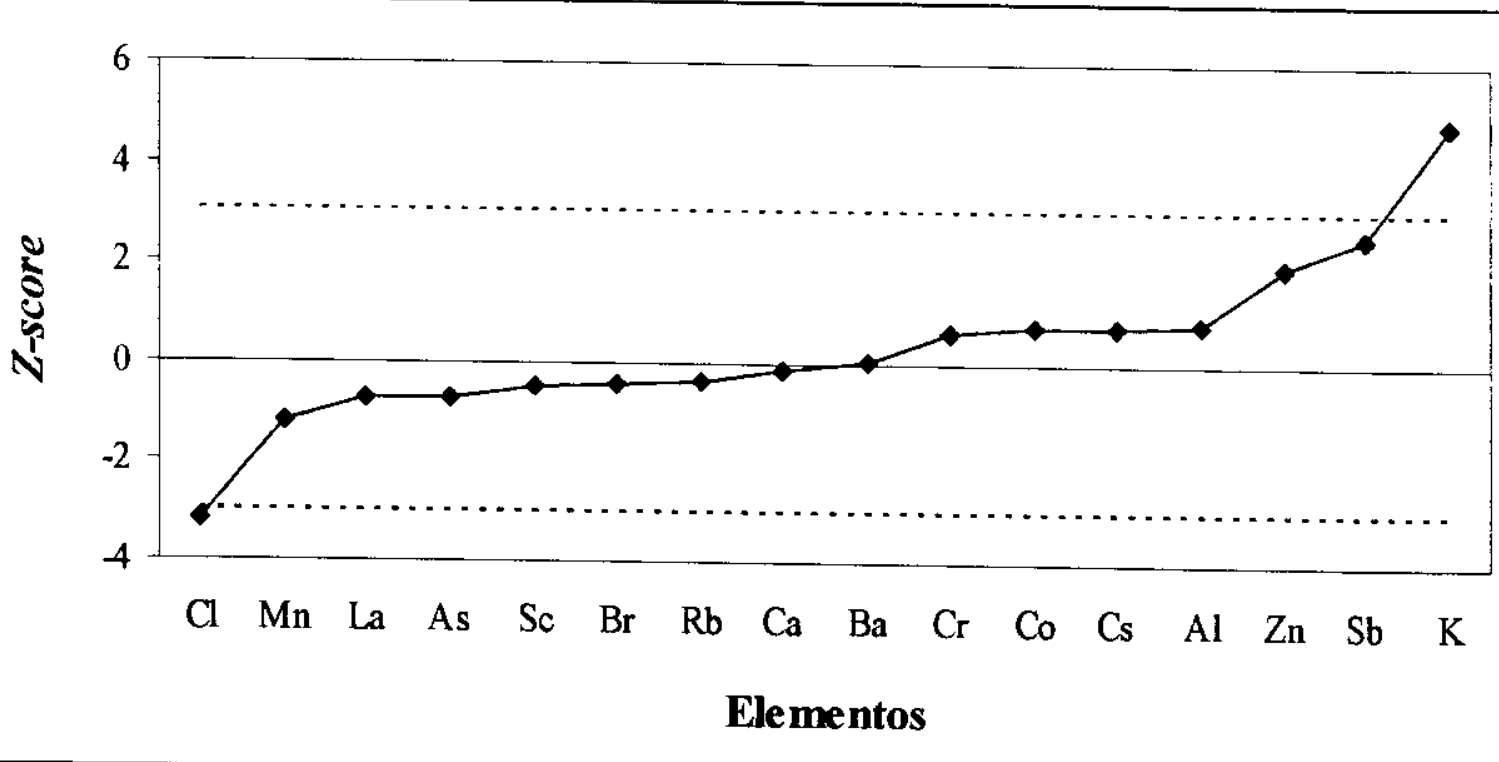

FIGURA 5.2 - Valores de Z-score obtidos para o material certificado de referência Mixed Polish Herbs (INCT-MPH-2).

\subsection{Resultados das análises das amostras de liquens}

Os resultados das análises dos liquens coletados na área considerada limpa (Parques Estaduais Carlos Botelho e Intervales) e na região metropolitana da cidade de São Paulo são apresentados nas TAB. 5.4 e 5.5, respectivamente. Nestas análises de liquens foram obtidas as concentrações mais baixas para $\mathrm{As}, \mathrm{Co}, \mathrm{Cr}, \mathrm{Cs}, \mathrm{La}, \mathrm{Mo}, \mathrm{Sb}, \mathrm{Sc}, \mathrm{Se}$ e U aos níveis de $\mathrm{ng} \mathrm{g}^{-1}$, os elementos $\mathrm{Ba}, \mathrm{Br}, \mathrm{Cl}, \mathrm{Fe}, \mathrm{K}, \mathrm{Mn}, \mathrm{Na}, \mathrm{Rb}$ e $\mathrm{Zn}$ aos níveis de $\mu \mathrm{g} \mathrm{g}^{-1} \mathrm{e}$ o Ca da ordem de $\mathrm{mg} \mathrm{g}^{-1}$. Nas condições experimentais adotadas neste trabalho os elementos $\mathrm{Al}$, $\mathrm{Cu}$ e $\mathrm{V}$ não foram detectados em algumas amostras. 
TABELA 5.4 - Concentrações de elementos obtidas para os liquens coletados nos Parques Estaduais Carlos Botelho e Intervales.

\begin{tabular}{|c|c|c|c|c|c|}
\hline Elemento & $\begin{array}{l}\mathrm{PECB}^{\mathrm{a}} \\
\mathrm{X} \pm \mathrm{s}_{\mathrm{x}}{ }^{\mathrm{c}}\end{array}$ & $\begin{array}{l}\text { PEIl }{ }^{b} \\
X \pm s_{x}\end{array}$ & $\begin{array}{l}\text { PEI2 }^{d} \\
X \pm s_{x}\end{array}$ & $\begin{array}{c}\text { PEI3 } \\
X \pm s_{x}\end{array}$ & $\begin{array}{l}\text { PEI4 } \\
X \pm s_{x}\end{array}$ \\
\hline As, ng g $^{-1}$ & $686 \pm 9$ & $282 \pm 3$ & $283 \pm 6$ & $209 \pm 7$ & $336 \pm 14$ \\
\hline $\mathrm{Ba}, \mu \mathrm{g} \mathrm{g}^{-1}$ & $55 \pm 23$ & $20 \pm 9$ & $7 \pm 1$ & $33 \pm 1$ & $10 \pm 1$ \\
\hline $\mathrm{Br}, \mathrm{ng} \mathrm{g}^{-1}$ & $44050 \pm 1604$ & $6556 \pm 144$ & $2342 \pm 50$ & $5573 \pm 151$ & $9750 \pm 4$ \\
\hline $\mathrm{Ca}, \mu \mathrm{g} \mathrm{g}^{-1}$ & $1218 \pm 51$ & $4530 \pm 195$ & $2694 \pm 123$ & $10404 \pm 840$ & $974 \pm 91$ \\
\hline $\mathrm{Cl}, \mu \mathrm{g} \mathrm{g}^{-1}$ & $1205 \pm 58$ & $492 \pm 22$ & $115 \pm 13$ & $359 \pm 24$ & $921 \pm 50$ \\
\hline $\mathrm{Co}, \mathrm{ng} \mathrm{g}^{-1}$ & $142 \pm 3$ & $289 \pm 11$ & $196 \pm 19$ & $137 \pm 11$ & $166 \pm 2$ \\
\hline $\mathrm{Cr}, \mathrm{ng} \mathrm{g}^{-1}$ & $1921 \pm 78$ & $1612 \pm 118$ & $1036 \pm 81$ & $930 \pm 12$ & $1306 \pm 28$ \\
\hline Cs, ng g ${ }^{-1}$ & $211 \pm 23$ & $141 \pm 3$ & $87 \pm 6$ & $355 \pm 17$ & $417 \pm 1$ \\
\hline $\mathrm{Fe}, \mu \mathrm{g} \mathrm{g}^{-1}$ & $848 \pm 14$ & $911 \pm 39$ & $629,4 \pm 4,0$ & $614 \pm 47$ & $736 \pm 11$ \\
\hline $\mathrm{K}, \mu \mathrm{g} \mathrm{g}^{-1}$ & $2738 \pm 305$ & $3333 \pm 81$ & $4701 \pm 9$ & $2023 \pm 7$ & $2355 \pm 7$ \\
\hline $\mathrm{La}, \mathrm{ng} \mathrm{g}^{-1}$ & $1044 \pm 104$ & $814 \pm 71$ & $491 \pm 48$ & $575 \pm 5$ & $715 \pm 7$ \\
\hline $\mathrm{Mn}, \mu \mathrm{g} \mathrm{g}^{-1}$ & $90 \pm 7$ & $66 \pm 4,6$ & $33 \pm 1$ & $76 \pm 4$ & $19 \pm 1$ \\
\hline Mo, $\mathrm{ng} \mathrm{g}^{-1}$ & $735 \pm 40$ & $370 \pm 41$ & $465 \pm 52$ & $143 \pm 21$ & $276 \pm 9$ \\
\hline $\mathrm{Na}, \mu \mathrm{g} \mathrm{g}^{-1}$ & $139 \pm 10$ & $70 \pm 4$ & $90 \pm 7$ & $52 \pm 1$ & $84 \pm 1$ \\
\hline $\mathrm{Rb}, \mu \mathrm{g} \mathrm{g}^{-1}$ & $8,3 \pm 0,3$ & $12,6 \pm 0,6$ & $12,6 \pm 0,9$ & $10,6 \pm 0,7$ & $10,1 \pm 0,1$ \\
\hline $\mathrm{Sb}, \mathrm{ng} \mathrm{g}^{-1}$ & $64 \pm 7$ & $69 \pm 2$ & $93 \pm 12$ & $60 \pm 1$ & $92 \pm 3$ \\
\hline Sc, ng g $^{-1}$ & $301 \pm 5$ & $290 \pm 16$ & $191 \pm 14$ & $185 \pm 10$ & $237 \pm 1$ \\
\hline Se, $\mathrm{ng} \mathrm{g}^{-1}$ & $244 \pm 19$ & $196 \pm 18$ & $203 \pm 16$ & $106 \pm 10$ & $242 \pm 14$ \\
\hline $\mathrm{U}, \mathrm{ng} \mathrm{g}^{-1}$ & $68,6 \pm 0,2$ & $76,4 \pm 4,0$ & $57,8 \pm 5,5$ & $56,8 \pm 0,6$ & $50,2 \pm 0,6$ \\
\hline $\mathrm{Zn}, \mu \mathrm{g} \mathrm{g}^{-1}$ & $25,4 \pm 0,5$ & $29,5 \pm 1,0$ & $17,0 \pm 0,7$ & $26,2 \pm 0,1$ & $39,5 \pm 1,0$ \\
\hline
\end{tabular}

a. Parque Estadual Carlos Botelho;

b. Parque Estadual Intervales;

c. Média das concentrações e desvios padrão das médias;

d. As amostras do Parque Intervales foram coletadas em três pontos distintos, sendo que as amostras PEI1 e PEI2 são alíquotas de uma mesma amostra porém com colorações distintas. 


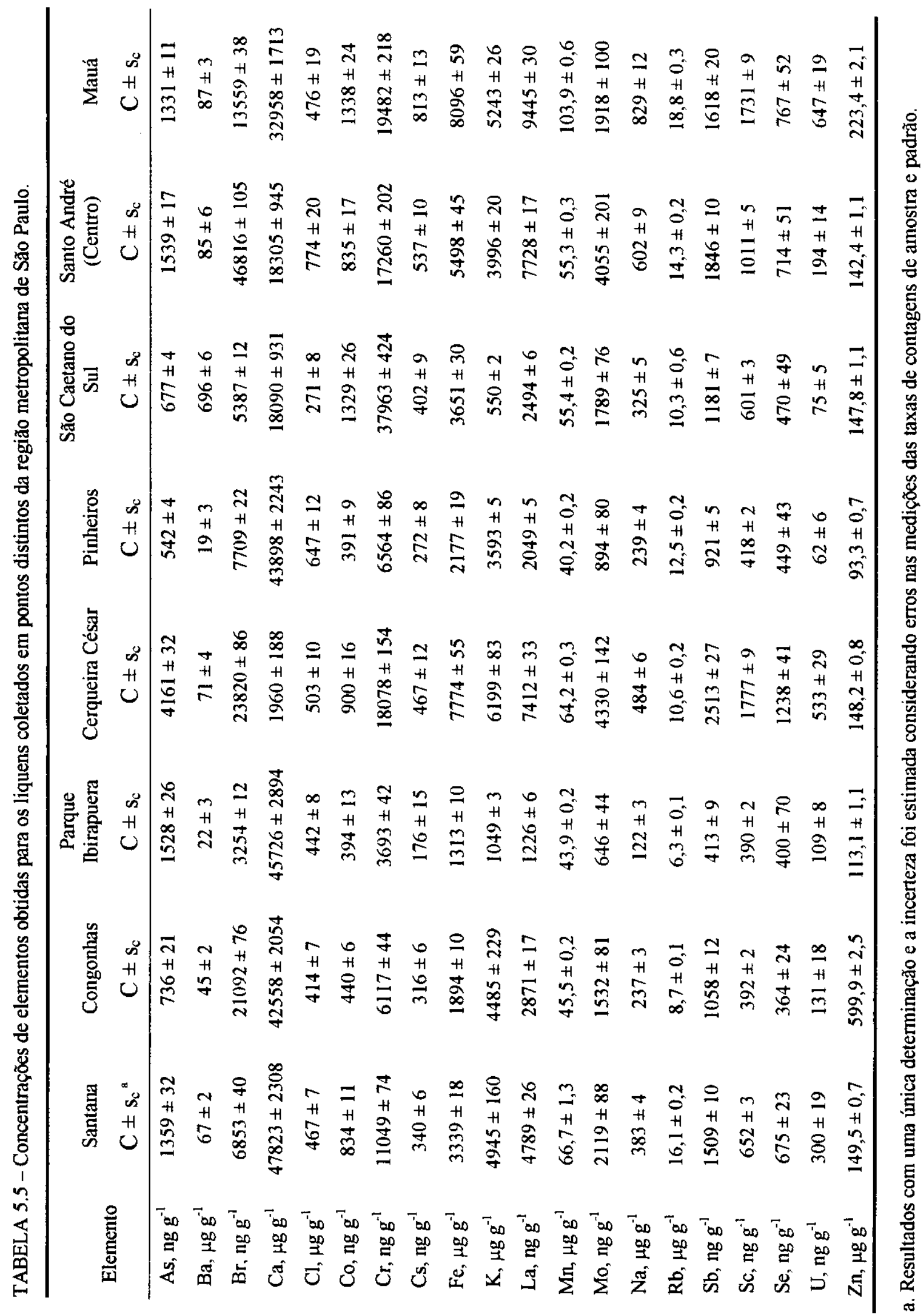




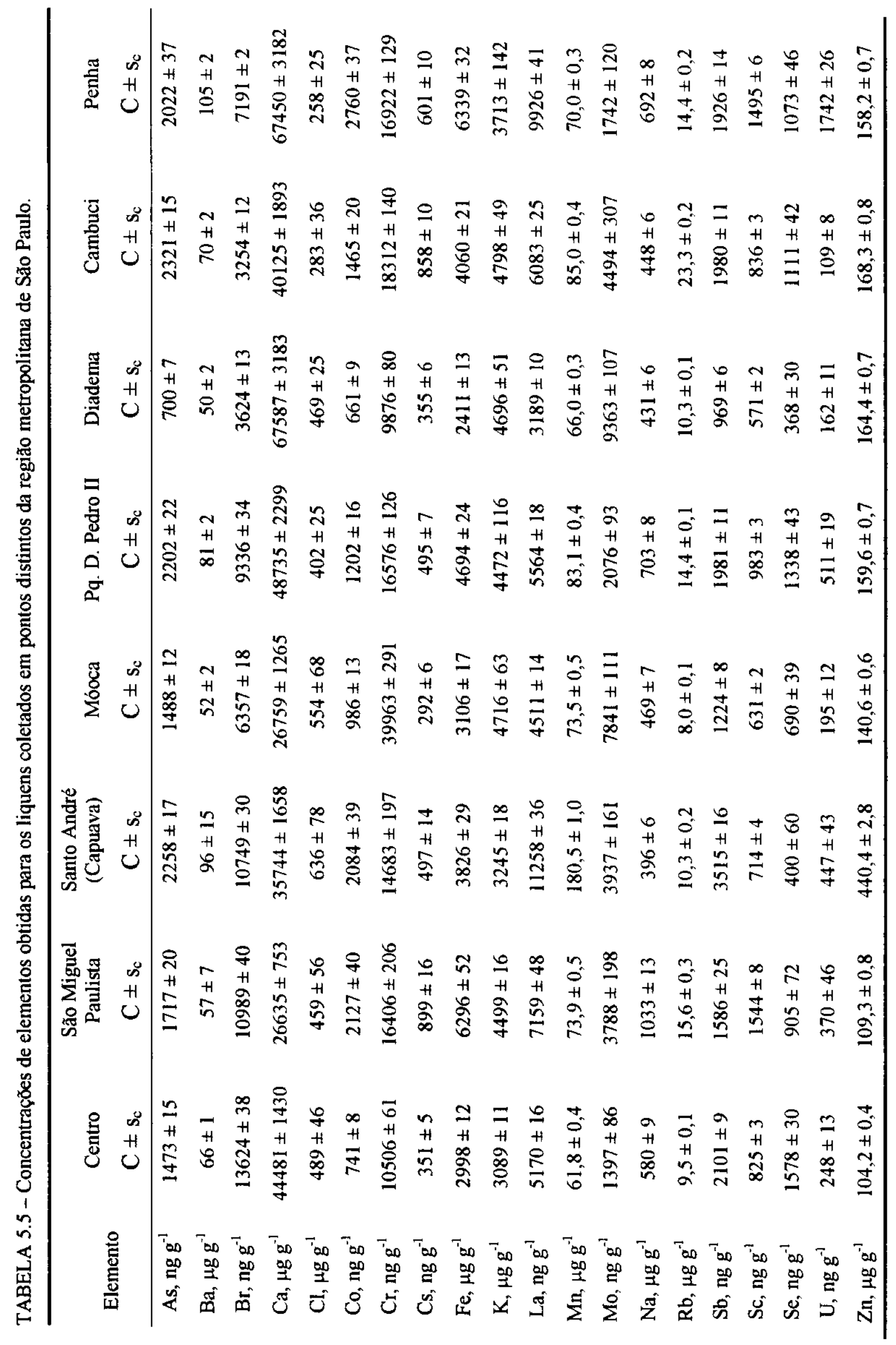




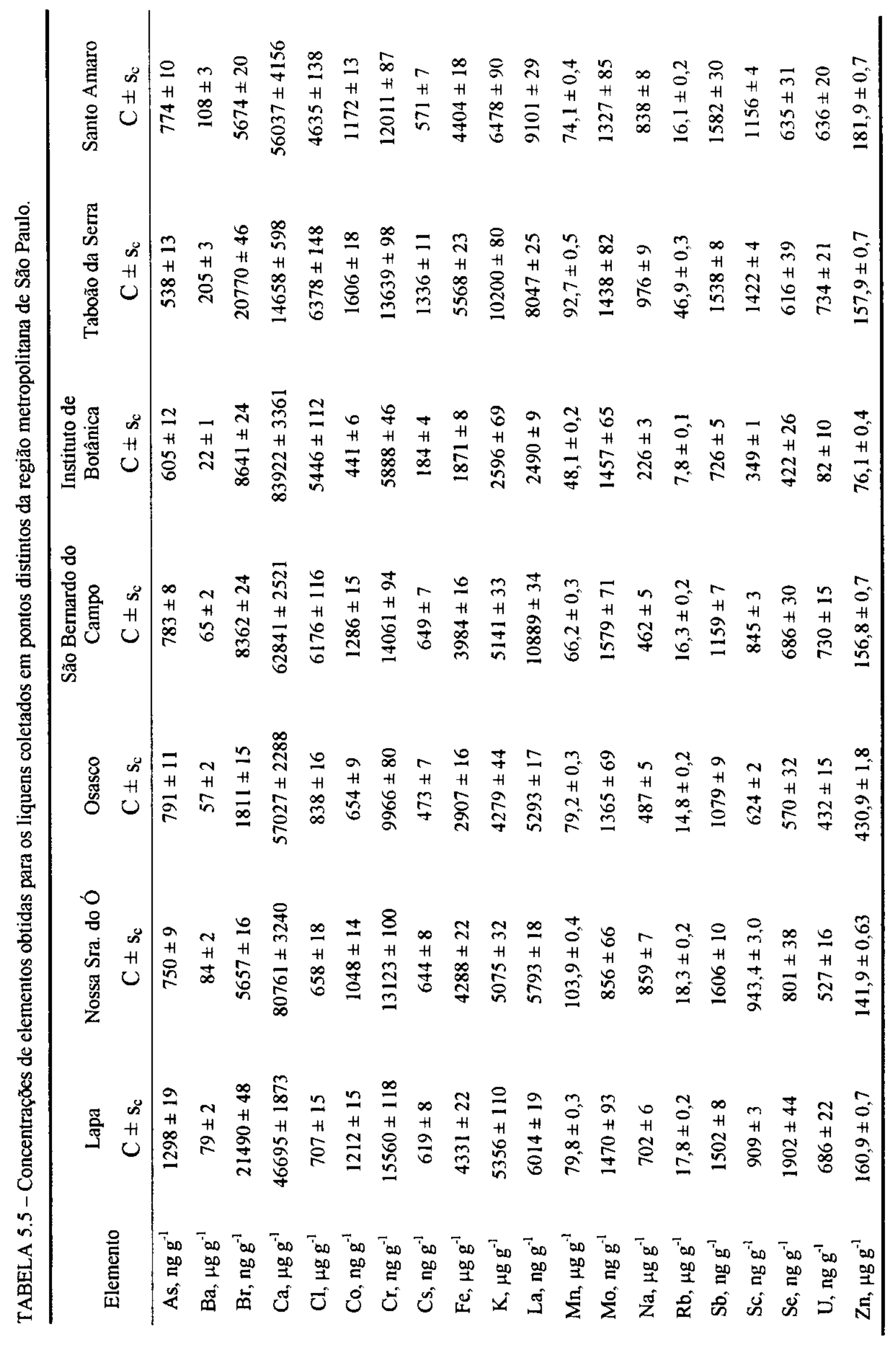


Para interpretação dos resultados das análises de liquens com relação aos diferentes locais de amostragem os dados das Tabelas 5.4 e 5.5 foram submetidos ao tratamento de análise de cluster que é um tipo de técnica exploratória multivariada. $\mathrm{Na}$ análise de cluster, por meio do programa STATISTICA 6.0, foi obtido o dendrograma apresentado na FIG.5.3. A análise de cluster permitiu que os diferentes pontos de coleta fossem agrupados segundo similaridades no que se referem às concentrações dos elementos químicos determinadas. 


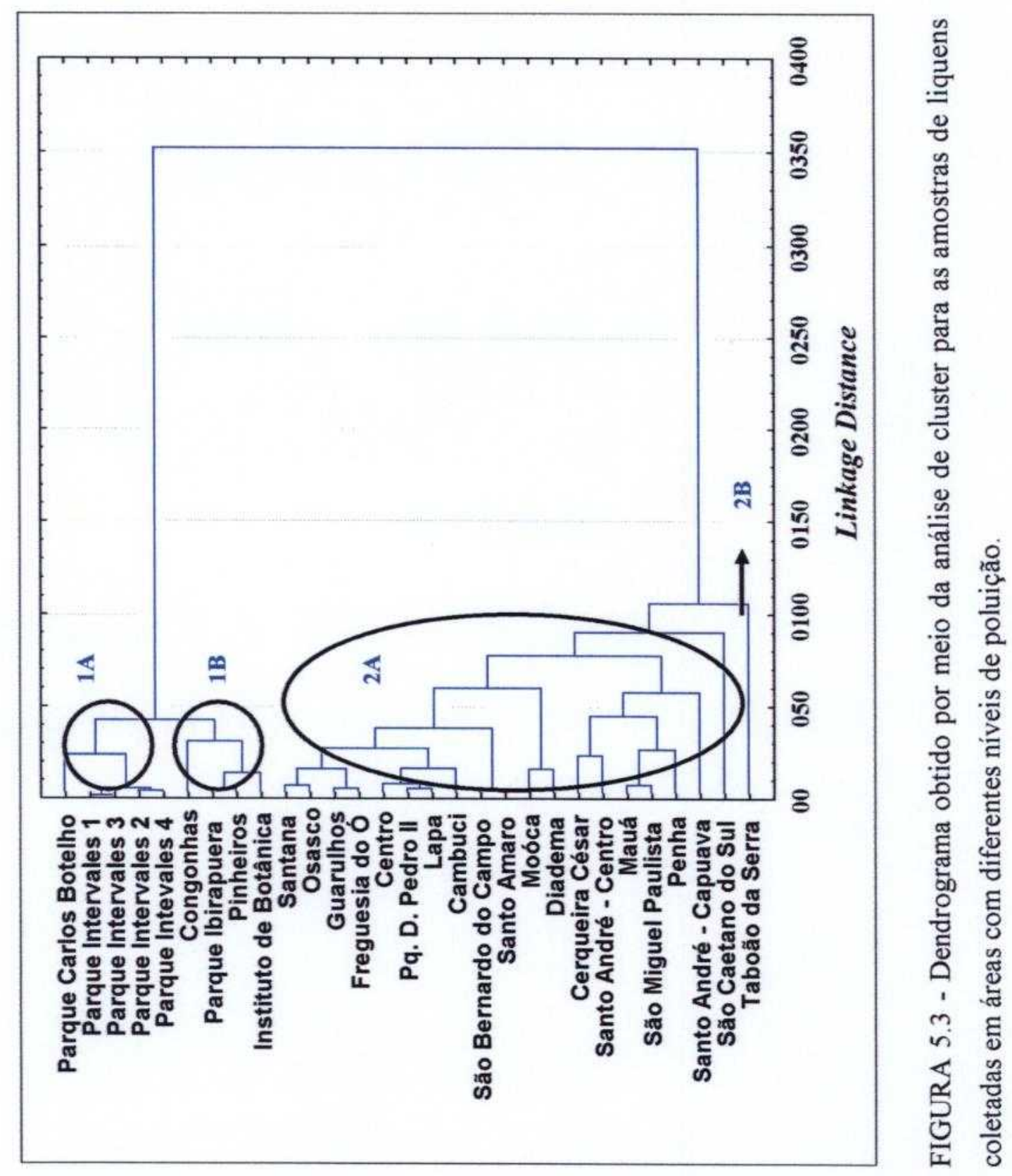


A FIG. 5.3 mostra que os pontos de amostragem se dividiram basicamente em dois grupos principais ( 1 e 2). O primeiro grupo (1) é formado pelas amostras dos Parques Estaduais Carlos Botelho (PECB) e Intervales (PEI) além das amostras de Congonhas, Parque Ibirapuera, Pinheiros e Instituto de Botânica. É importante ressaltar que dentro deste grupo (1) também foram obtidos subgrupos relevantes (1A e 1B), isto é, as amostras dos parques separaram-se das amostras da região metropolitana. Este fato indica que as concentrações da maioria dos de elementos nos liquens da região limpa são diferentes das concentrações obtidas na região metropolitana e, somente alguns pontos da região metropolitana apresentaram características similares às de regiões consideradas nãopoluídas.

Ainda no subgrupo $1 \mathrm{~A}$, pode-se observar que as amostras subdividiram-se por parque estudado isto é, a amostra do PECB formou um outro subgrupo distinto das amostras do PEI. Esta subdivisão pode estar relacionada ao fato da coleta do líquen do PECB ter sido realizada às margens de estrada enquanto que as amostras do PEI foram coletadas mais internamente ao parque com menor influência de ações antrópicas.

O segundo grupo (2) formado refere-se a praticamente todas amostras da região metropolitana de São Paulo (subgrupos 2A e 2B) e pode-se notar que, em geral, as amostras estão associadas entre si com um menor ou maior grau de similaridade. A amostra do Taboão da Serra por sua vez, é a amostra a qual apresentou maior dissimilaridade e pode ser considerada como sendo um subgrupo de classificação de pontos de amostragem dentro do grupo (2) (subgrupo 2B) diferente dos demais subgrupos. $\mathrm{Na}$ amostra do Taboão da Serra foram obtidas concentrações de elementos relativamente mais elevadas, quando comparadas com as demais amostras, para os seguintes elementos: $\mathrm{Ba}, \mathrm{Br}, \mathrm{Cl}, \mathrm{Cs}, \mathrm{K}$ e $\mathrm{Rb}$. Para estes elementos, com exceção de $\mathrm{Br}$ e $\mathrm{Cl}$, suas origens podem estar associadas à poeiras trazidas pelos ventos e intemperismos de rochas minerais.

Para uma confirmação da formação dos grupos e subgrupos obtidos na análise de cluster foi aplicado aos resultados, o procedimento de análise discriminante também por meio do programa STATISTICA 6.0. Na FIG. 5.4 são apresentados os resultados dos agrupamentos obtidos segundo a análise discriminante para os resultados das análises de liquens. 


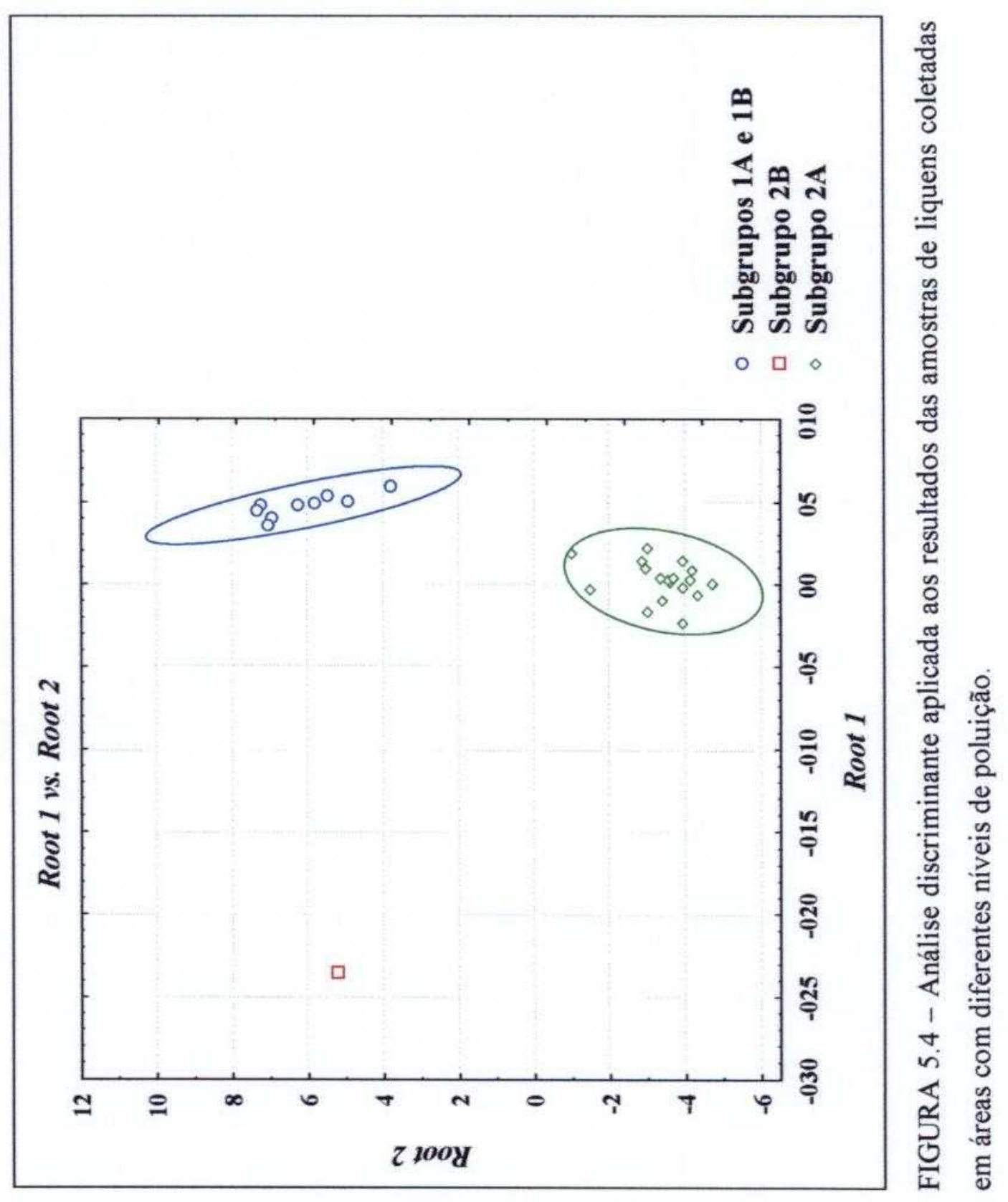


A FIG. 5.4 confirma a classificação dos locais da amostragem em grupos obtidos na análise de cluster, ou seja, tem-se um grupo formado pelas amostras dos Parques Estaduais Carlos Botelho e Intervales, Congonhas, Parque Ibirapuera, Pinheiros e Instituto de Botânica (subgrupos 1A e 1B). Outro grupo formado pelas amostras de Santana, Cerqueira César, São Caetano do Sul, Santo André - Centro, Mauá, Centro, São Miguel Paulista, Santo André - Capuava, Moóca, Pq. D. Pedro II, Diadema, Penha, Cambuci, Guarulhos, Lapa, Freguesia do Ó, Osasco, São Bernardo do Campo e Santo Amaro (subgrupo 2A). Também foi confirmada a dissimilaridade apresentada pela amostra do Taboão da Serra a qual faz parte do subgrupo $2 B$.

Uma vez classificados os pontos de amostragem segundo suas similaridades químicas, algumas considerações relevantes foram observadas para os resultados apresentados nas TAB. 5.4 e 5.5 .

As concentrações dos elementos As, $\mathrm{Co}, \mathrm{Cr}, \mathrm{Fe}, \mathrm{La}, \mathrm{Mo}, \mathrm{Na}, \mathrm{Sb}, \mathrm{Sc}, \mathrm{Se}$, e Zn obtidas para as amostras do Parque Estadual Intervales (PEI), área considerada nãopoluída, são inferiores às obtidas para os pontos da região metropolitana; área considerada poluída. A FIG. 5.5 mostra como exemplo, a concentração de As para todos os pontos de amostragem ilustrando o comportamento observado. Segundo Reimann et al. (1998), as origens destes elementos na atmosfera, com exceção do Sc, podem estar associadas às mais variadas atividades antrópicas como queima de combustíveis fósseis (termoelétricas) e de gás natural; mineração e processamento de $\mathrm{Ni}, \mathrm{Ag}, \mathrm{Pb}, \mathrm{Cu}$ e $\mathrm{Fe}$, rochas alcalinas e $\mathrm{U}$; atividades envolvendo aço e eletrometalurgia; queima e fundição de minérios enxofidricos, de $\mathrm{Cu}, \mathrm{Mo}$ e $\mathrm{Zn}$; detritos de porcos e aves domésticas, detritos de lodo; incineração de lixo; fertilizantes fosfatados; detergentes fosfatados; inseticidas e fungicidas; rodovias que transportam sal; águas residuais; tráfego (desgaste de pneus) e emissões veiculares.

Para os elementos $\mathrm{Ba}, \mathrm{Cs}, \mathrm{K}, \mathrm{Mn}$ e $\mathrm{Rb}$ a ação do solo tem sido geralmente considerada mais importante do que as fontes antrópicas, ou seja, as origens destes elementos deve-se principalmente às poeiras trazidas pelos ventos e intemperismos (Reimann et al., 1998). Esta informação, provavelmente, explica o fato de os liquens da região limpa apresentarem concentrações de $\mathrm{Ba}, \mathrm{Cs}, \mathrm{K}, \mathrm{Mn}$ e $\mathrm{Rb}$ da mesma ordem de grandeza de alguns pontos da região metropolitana. Este fato está exemplificado na FIG. 5.6 a qual ilustra as concentrações de Rb obtidas nas amostras de liquens. 


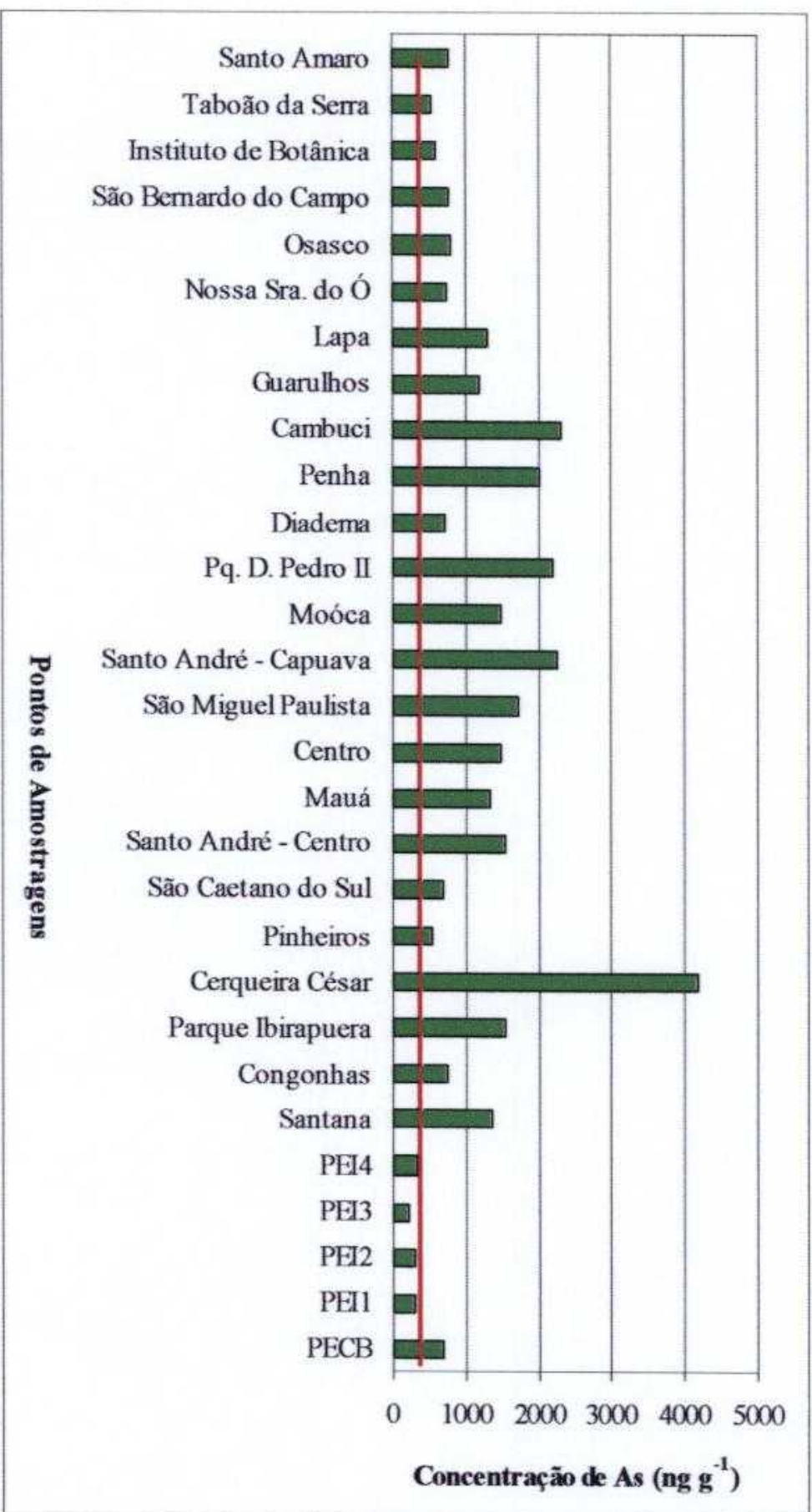

FIGURA 5.5 - Concentrações de As obtidas para liquens coletados em diferentes pontos de amostragens. 


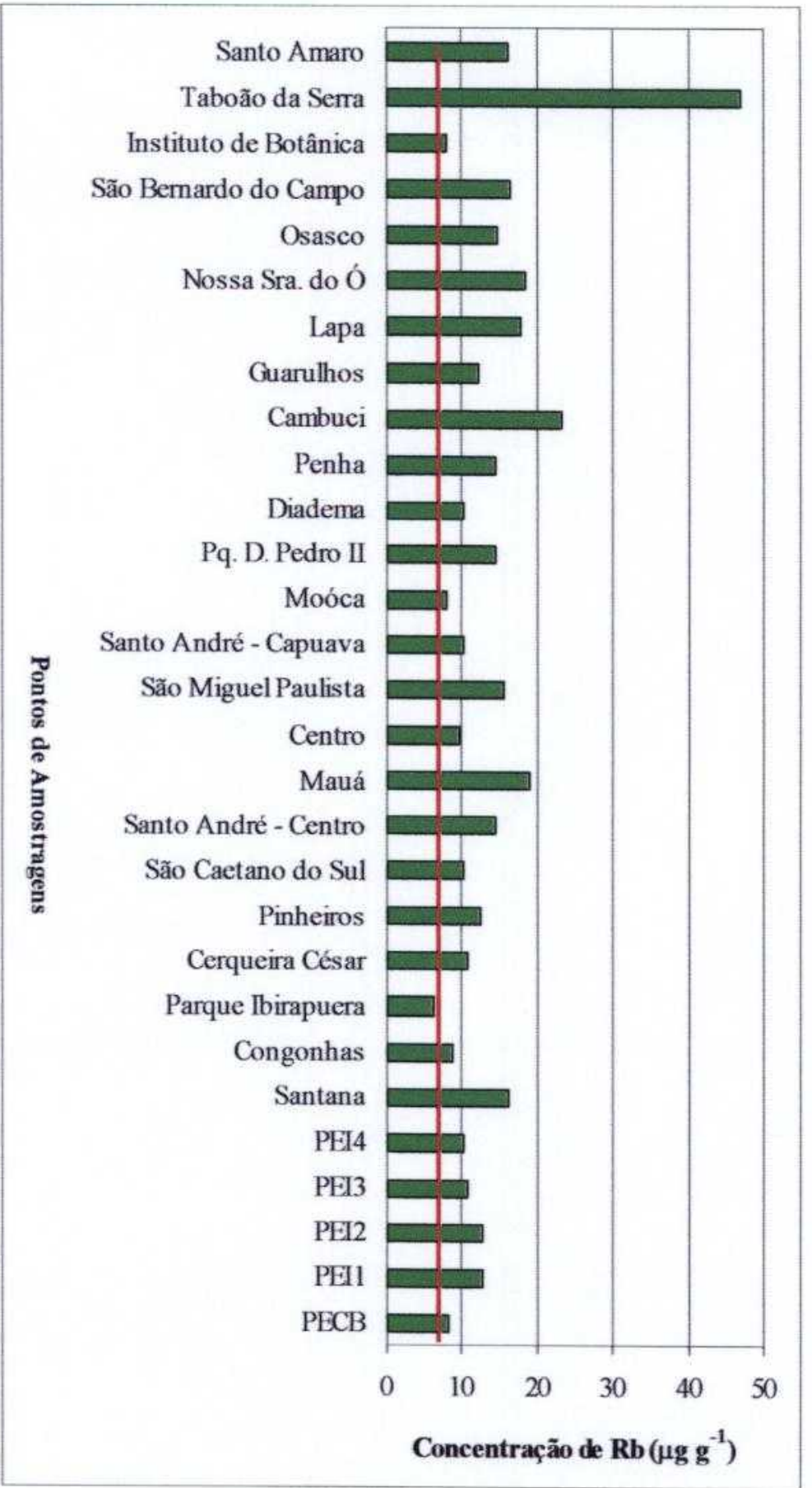

FIGURA 5.6 - Concentrações de Rb obtidas para liquens coletados em diferentes pontos de amostragens. 
Analisando os resultados das TAB. 5.4 e 5.5 verifica-se que para os liquens do Parque Estadual Carlos Botelho (PECB) foram obtidas concentrações de $\mathrm{As}, \mathrm{Ba}, \mathrm{Br}, \mathrm{Cl}$, $\mathrm{Cs}, \mathrm{K}, \mathrm{Mn}, \mathrm{Mo}, \mathrm{Na}, \mathrm{Rb}$ e $\mathrm{U}$ da mesma ordem de grandeza daquelas encontradas para alguns pontos da região metropolitana. As elevadas concentrações destes elementos nos liquens do PECB provavelmente, se deve ao fato destas amostras terem sido coletadas em árvores das margens de uma estrada.

Também nas áreas limpas (PECB e PEI4), foram obtidas elevadas concentrações de $\mathrm{Br}$ e Cl (FIG. 5.7 e 5.8) e a origem destes elementos pode estar associada à influência marinha. Os elementos $\mathrm{Br}$ e $\mathrm{Cl}$ obtidos em concentrações relativamente altas para os liquens dos Parques podem ser devido à região limpa estar localizada próxima ao litoral do Estado de São Paulo. Já, as elevadas concentrações de $\mathrm{Br}$ obtidas para locais como Congonhas, Cerqueira César, Santo André - Centro, Lapa e Taboão da Serra podem ter sua origem associada às emissões veiculares e para as elevadas concentrações de $\mathrm{Cl}$ em Santo Amaro, Taboão da Serra, Instituto de Botânica e São Bernardo do Campo a origem pode ser indústrias de cloro-álcali. 


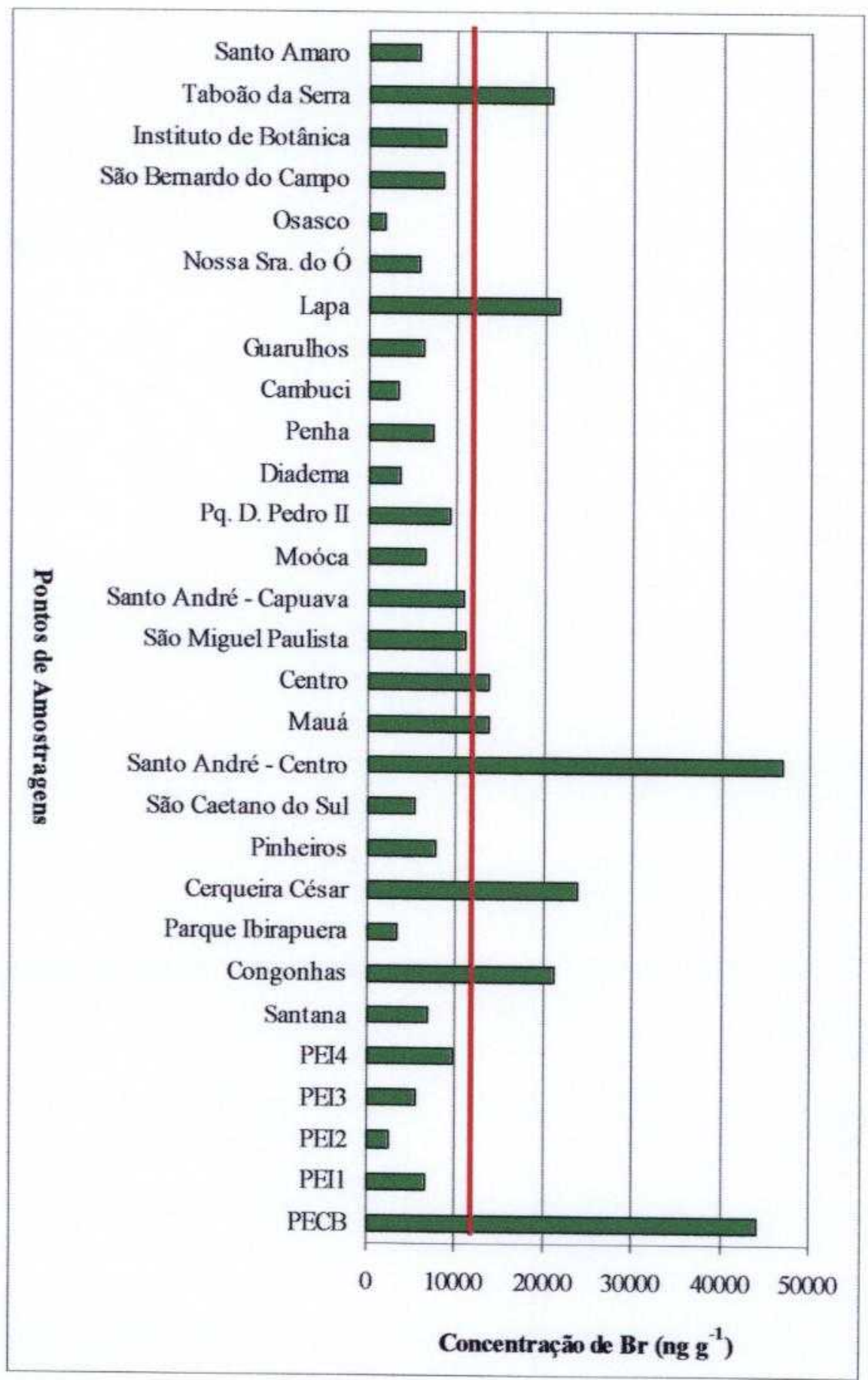

FIGURA 5.7 - Concentrações de $\mathrm{Br}$ obtidas para liquens coletados em diferentes pontos de amostragens. 


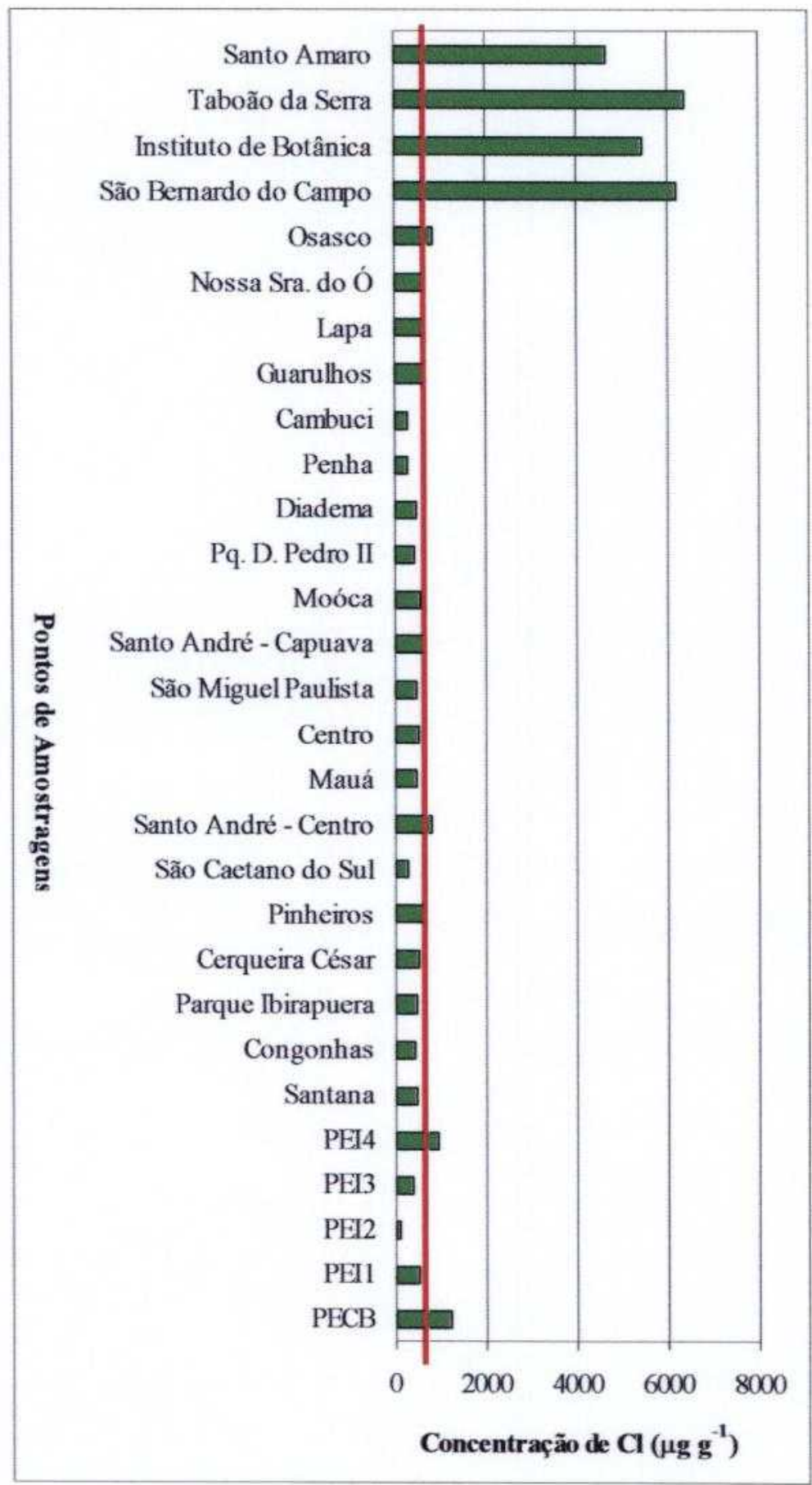

FIGURA 5.8 - Concentrações de $\mathrm{Cl}$ obtidas para liquens coletados em diferentes pontos de amostragens. 
Uma vez concluidas as comparações entre os resultados das concentrações obtidas para os liquens da área limpa com àquelas dos pontos da região metropolitana foi feita uma análise comparativa entre os resultados obtidos em pontos distintos da área metropolitana. Para isso foi aplicado o programa SURFER 8.0 para elaboração de mapas de distribuição das concentrações de elementos os quais são apresentados nas FIG. 5.9 a 5.28. Nestes mapas as linhas de contorno indicam diferentes concentrações de elementos obtidas nos diversos pontos de amostragens. 
A FIG. 5.9 do mapa de distribuição da concentração de As indica que foi obtida uma elevada concentração deste elemento para a área de Cerqueira César seguida da região do Cambuci, Santo André - Capuava, Pq. D. Pedro II e Penha. O As tem sido utilizado em ligas, substâncias que conservam madeira, munições, semi-condutores, baterias, pinturas, indústrias de tecidos e também este elemento é geralmente incorporado ao meio ambiente por meio da combustão de carvão, processamento e fundição de jazidas sulfidricas; detritos de porcos e aves; fertilizantes fosfatados; inseticidas e fungicidas (Reimann et al., 1998). A presença de As na região de Cerqueira César e do Pq. D. Pedro II parece estar mais associada às emissões veiculares em relação às outras fontes de origem visto que este local possui um intenso tráfego de veículos.

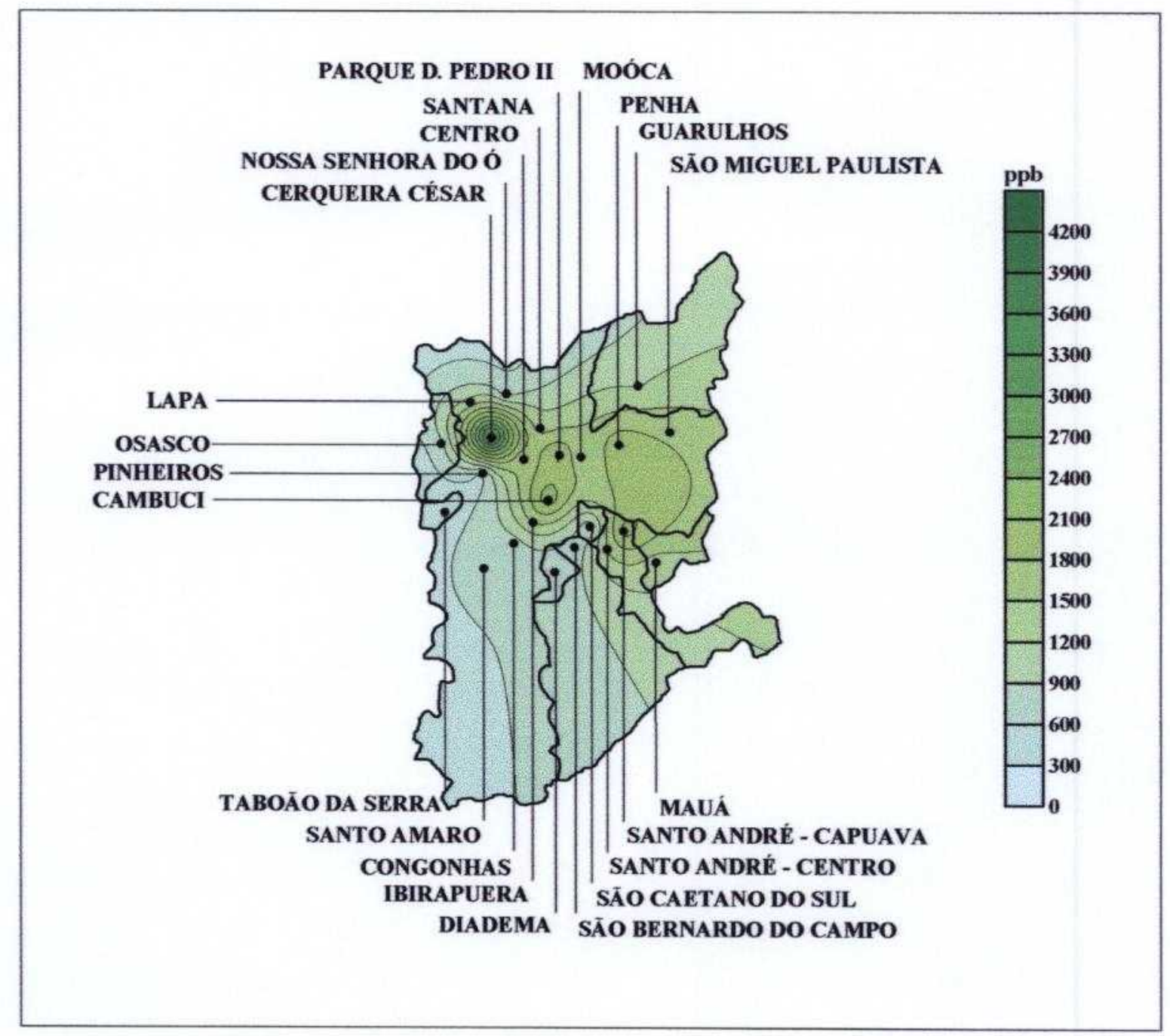

FIGURA 5.9 - Mapa da concentração de As, em $\mathrm{ng} \mathrm{g}^{-1}$, obtido para liquens da região metropolitana de São Paulo. 
As elevadas concentrações de Ba foram obtidas nos liquens de São Caetano do Sul e de pontos ao redor que compreendem a região do $\mathrm{ABC}$ paulista (Santo André Capuava, Santo André - Centro e São Bernardo do Campo) como mostra a FIG. 5.10. O $\mathrm{Ba}$ pode ser introduzido no ambiente das fundições de $\mathrm{Cu}$, indústria automobilística e manufaturas de aço. As altas concentrações de Ba nestas regiões, deve-se provavelmente às inúmeras indústrias e ao pólo petroquímico existente na região.

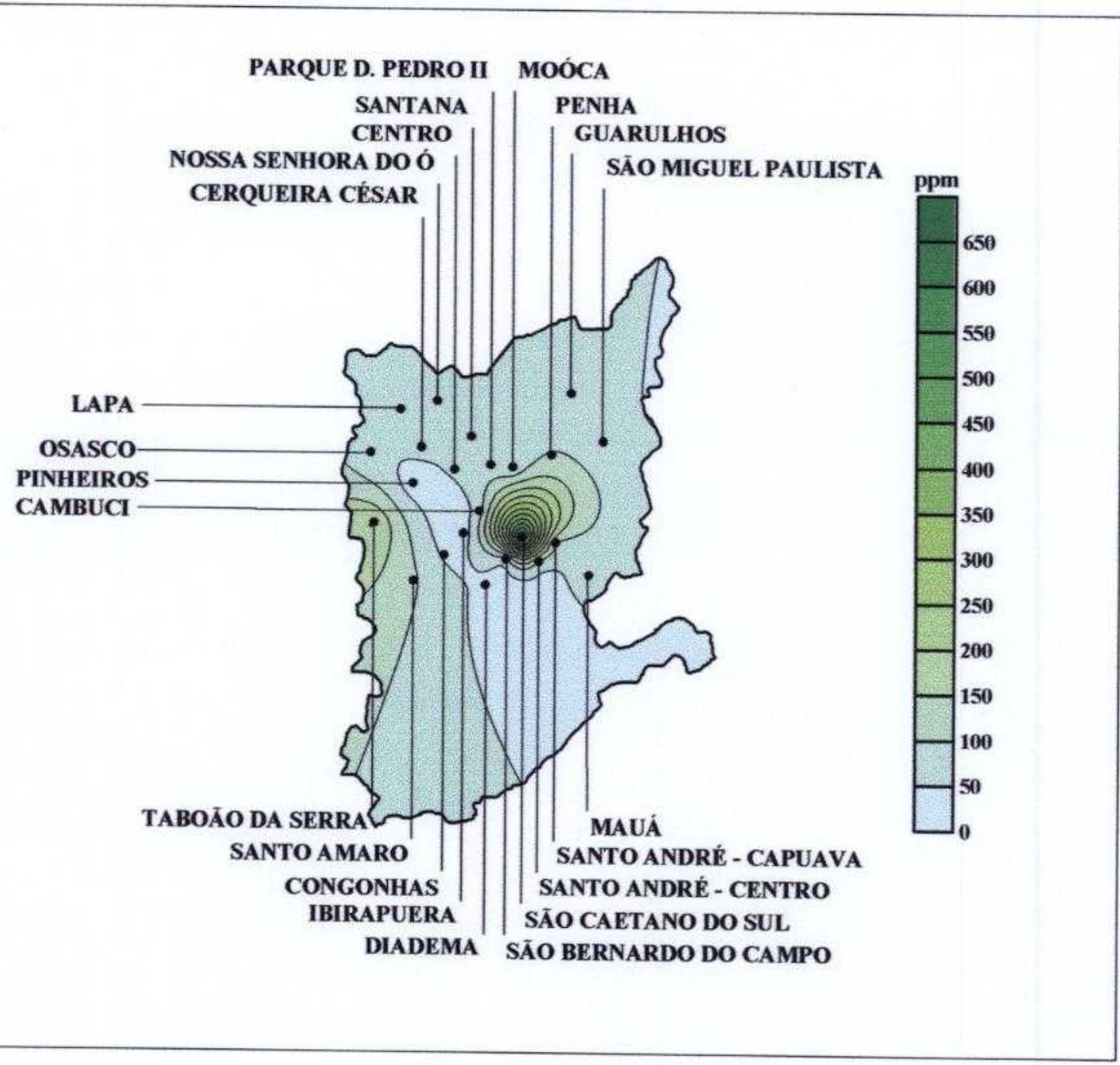

FIGURA 5.10 - Mapa da concentração de $\mathrm{Ba}$, em $\mu \mathrm{g} \mathrm{g}^{-1}$, obtido para liquens da região metropolitana de São Paulo. 
Na FIG. 5.11 pode-se notar que o elemento $\mathrm{Br}$ encontra-se distribuído de forma a concentrar-se em certas regiões: (1) Lapa, Cerqueira César e Centro; (2) Taboão da Serra e Congonhas; (3) Mauá, Santo André - Capuava, Santo André - Centro, São Caetano do Sul e São Bernardo do Campo. O mapa de distribuição da concentração de Br indica que a fonte de emissão deste elemento pode ser tanto de origem veicular como industrial.

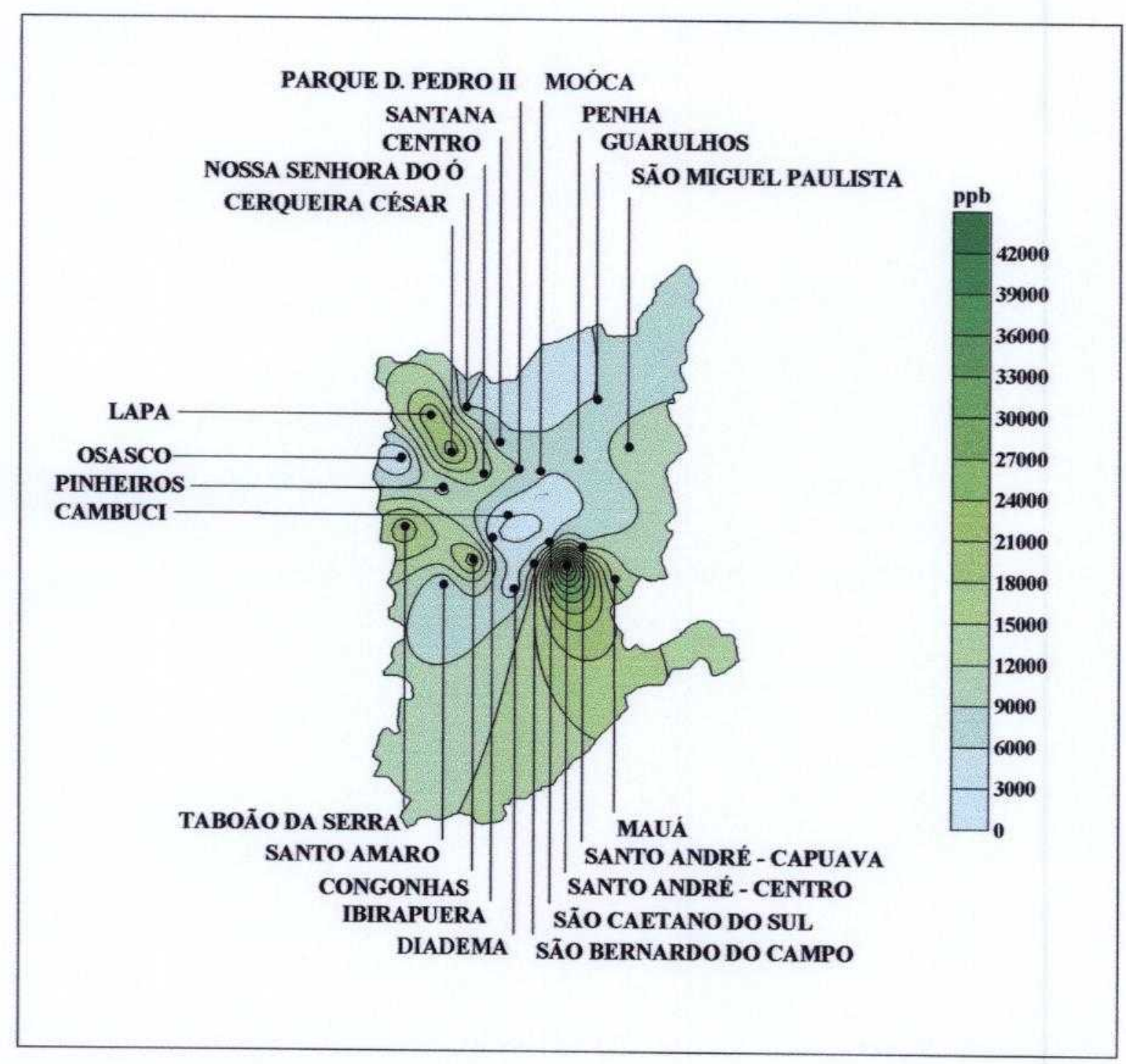

FIGURA 5.11 - Mapa da concentração de $\mathrm{Br}$, em $\mathrm{ng} \mathrm{g}^{-1}$, obtido para liquens da região metropolitana de São Paulo. 
Para o elemento Ca a FIG. 5.12 mostra que há, em geral, uma distribuição uniforme deste elemento para os liquens coletados em uma grande área da região metropolitana. As fontes de origem deste elemento podem ser poeiras do solo, intemperismos de rochas e fontes antrópicas como indústrias de cimento e cal e fertilizantes. Geralmente, para o caso do $\mathrm{Ca}$, as fontes oriundas do solo têm sido consideradas predominantes em relação às antrópicas.

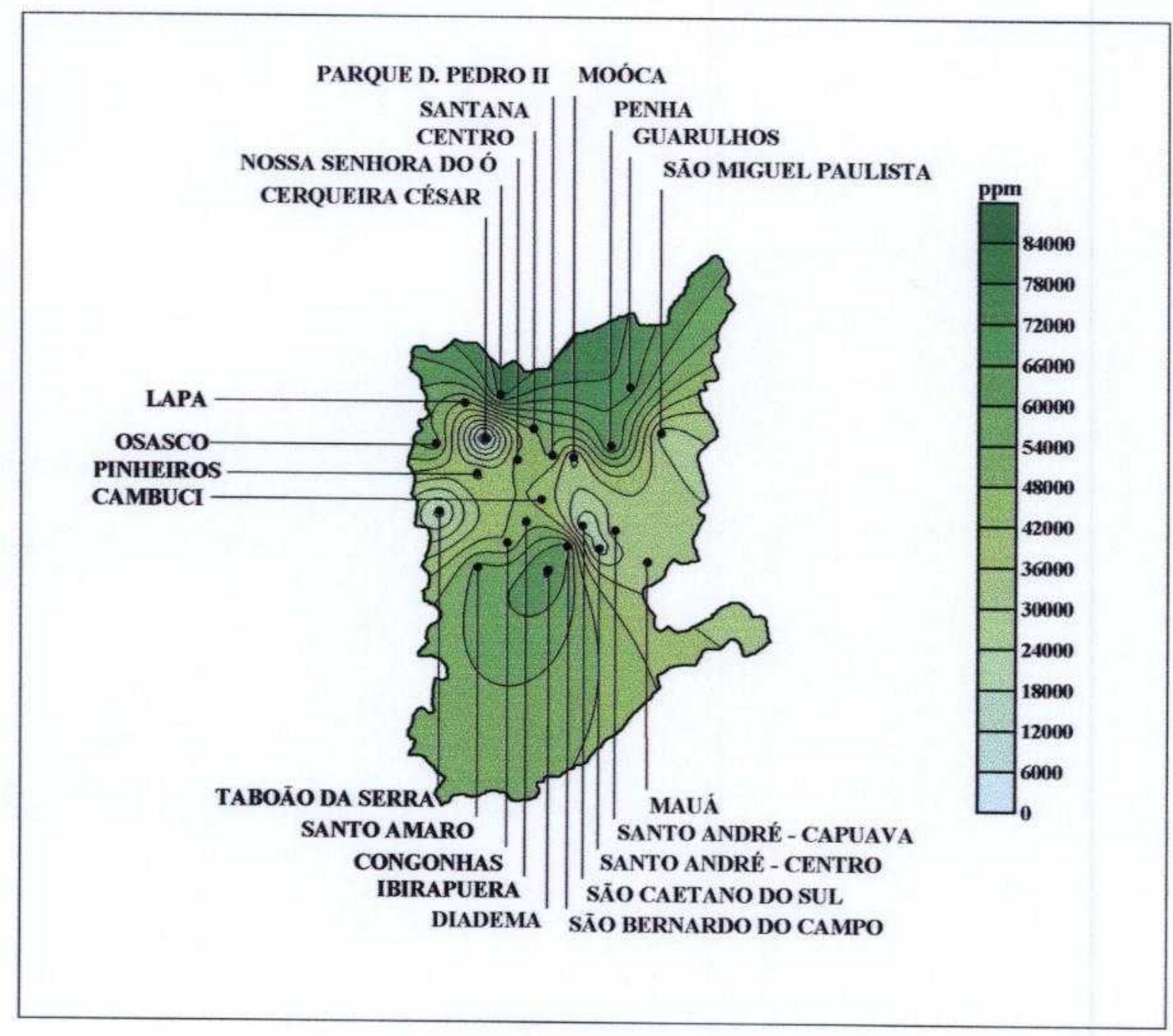

FIGURA 5.12 - Mapa da concentração de $\mathrm{Ca}, \mu \mathrm{g} \mathrm{g}^{-1}$, obtido para liquens da região metropolitana de São Paulo. 
$\mathrm{O}$ elemento $\mathrm{Cl}$ apresentou concentrações elevadas nos liquens da área sudoeste da região metropolitana como Santo Amaro e Taboão da Serra além de São Bernardo do Campo e Instituto de Botânica (FIG. 5.13). As altas concentrações de $\mathrm{Cl}$ nestas regiões podem estar associadas às diversas fontes como indústrias de potássio, fábricas de papel, combustão de materiais plásticos, de veículos à gasolina, e bem como do tratamento de água além de indústrias de produtos clorados.

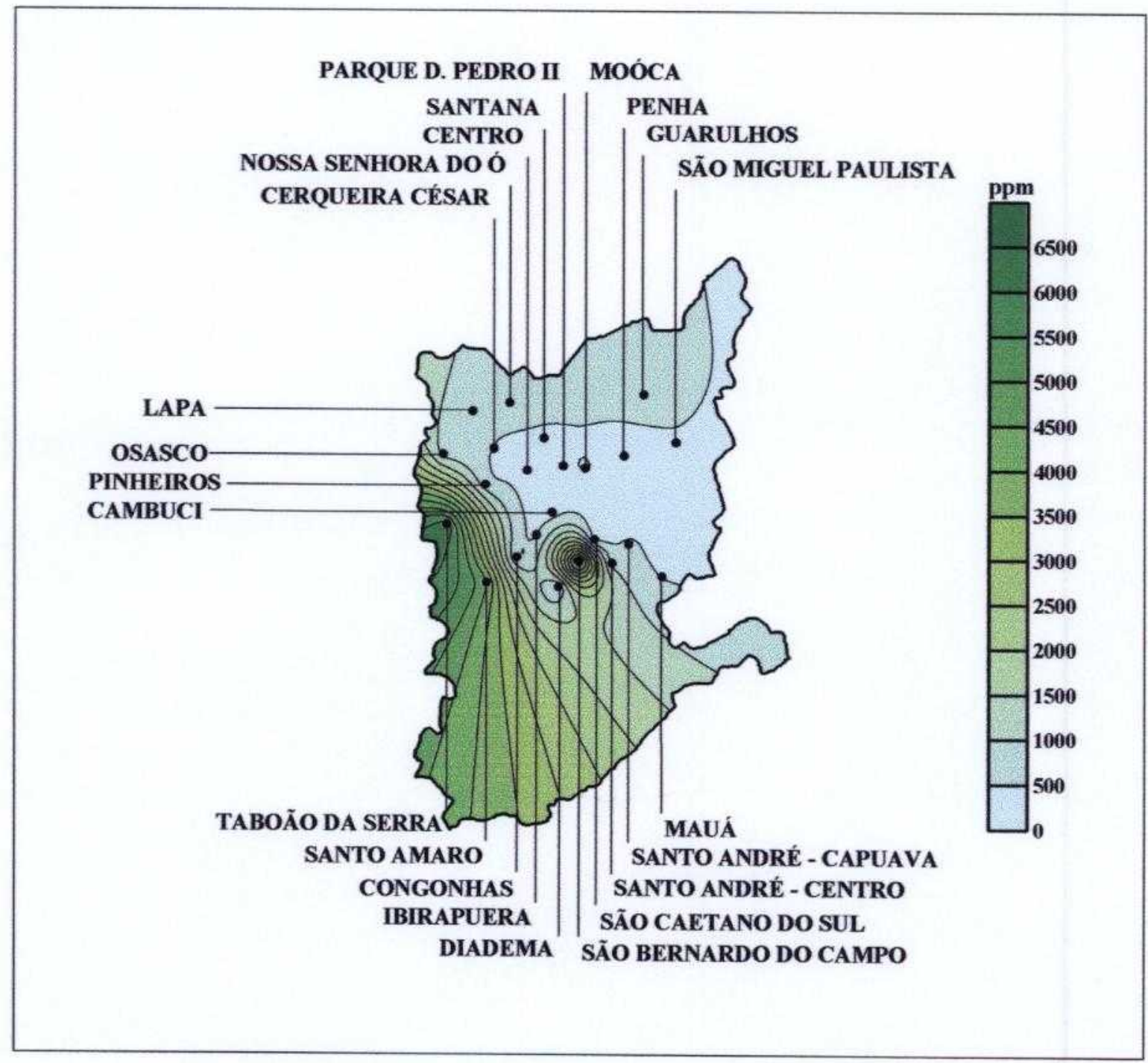

FIGURA 5.13 - Mapa da concentração de $\mathrm{Cl}$, em $\mu \mathrm{g} \mathrm{g}^{-1}$, obtido para liquens da região metropolitana de São Paulo. 
Relativamente ao Co, os liquens da região leste (São Miguel Paulista, Penha e Santo André - Capuava) apresentaram as mais altas concentrações deste elemento (FIG. 5.14). A presença de Co no ar pode estar associada com o processamento e mineração de $\mathrm{Ni}, \mathrm{Ag}, \mathrm{Pb}, \mathrm{Cu}$ e $\mathrm{Fe}$, além de combustão de carvão e fertilizantes. A alta concentração de Co em São Miguel Paulista se deve possivelmente à indústria de processamento de metal existente nesta região, que produz cerca de 16.000 ton/ano de Ni e 600 ton/ano de Co.

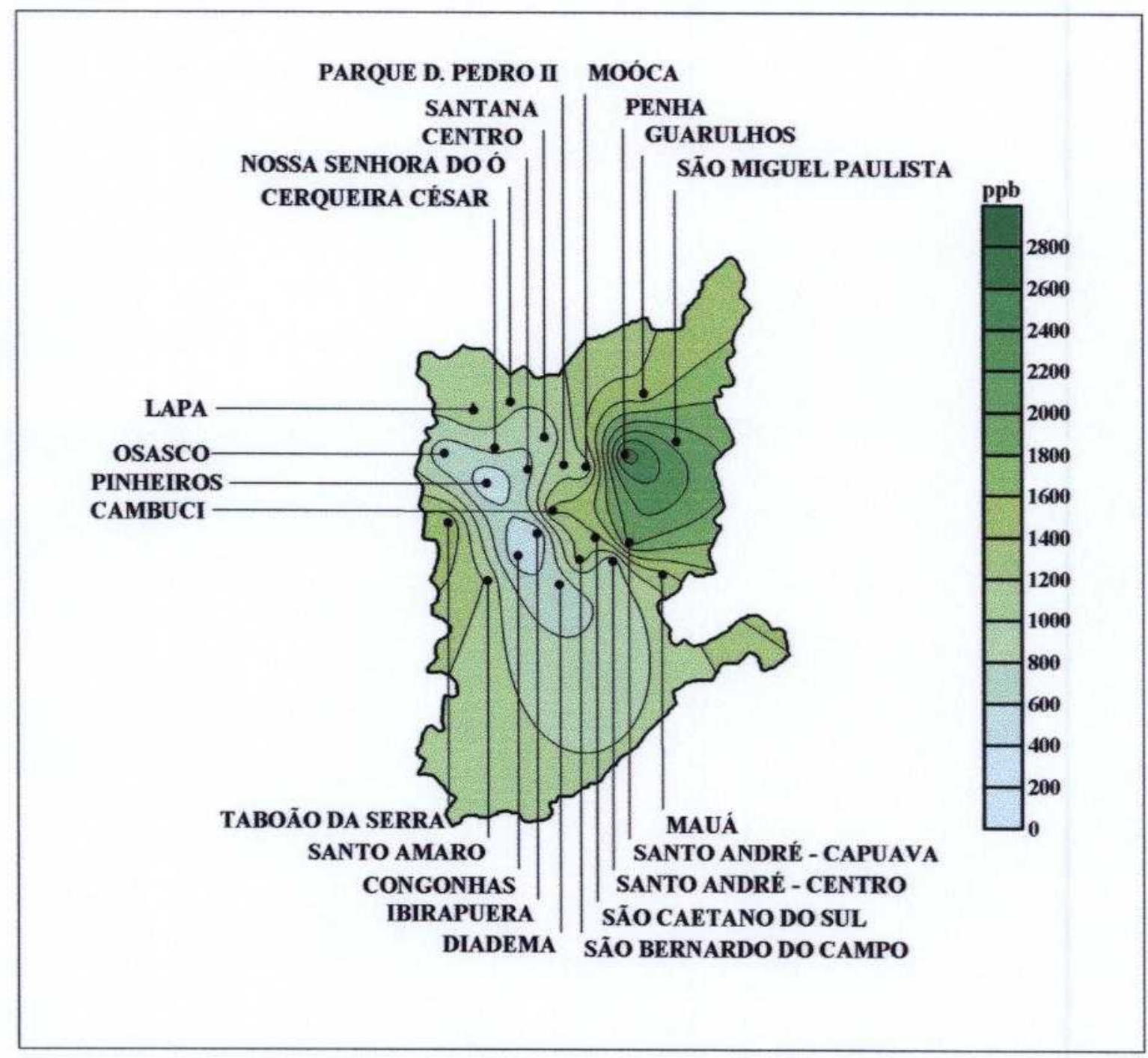

FIGURA 5.14 - Mapa da concentração de $\mathrm{Co}$, em ng $\mathrm{g}^{-1}$, obtido para liquens da região metropolitana de São Paulo. 
As concentrações mais elevadas para $\mathrm{Cr}$ foram obtidas nos liquens da Moóca e em São Caetano do Sul como mostra a FIG. 5.15. A origem do $\mathrm{Cr}$ no ambiente tem sido atribuída às indústrias químicas, manufaturas de aço, eletrometalurgia, fundição de $\mathrm{Cu}$, combustão de gás natural, óleo e carvão, detritos de esgotos domésticos, incineração de lixo, e alguns fertilizantes fosfatados. Com relação às concentrações elevadas de $\mathrm{Cr}$ encontradas neste trabalho, sua origem se deve às emissões industriais.

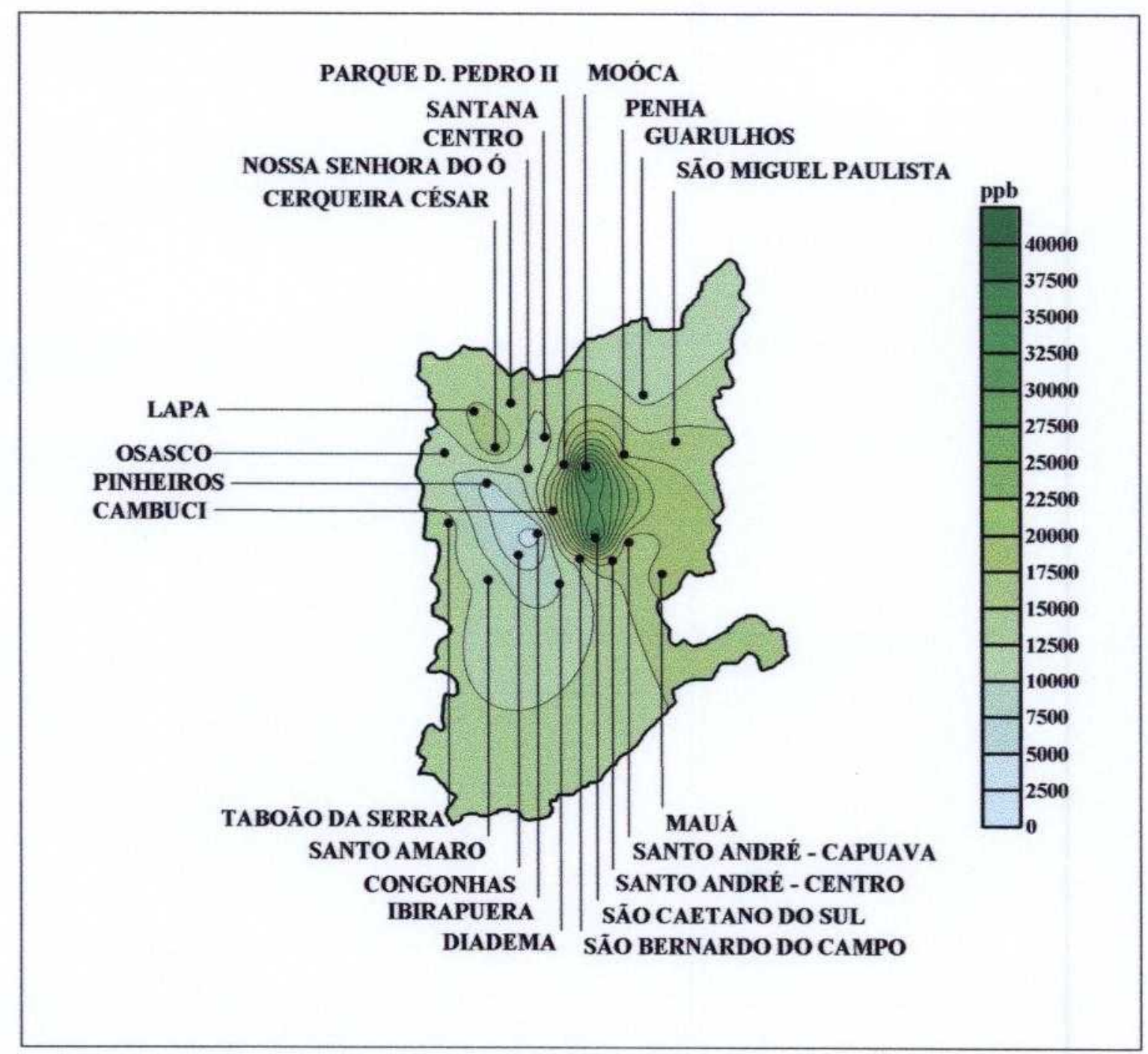

FIGURA 5.15 - Mapa da concentração de $\mathrm{Cr}$, em $\mathrm{ng} \mathrm{g}^{-1}$, obtido para liquens da região metropolitana de São Paulo. 
Os liquens da região do Taboão da Serra apresentaram elevadas concentrações de Cs (FIG 5.16). A origem deste elemento pode ser associada à poeira de solo $\mathrm{e}$ intemperismos de rochas.

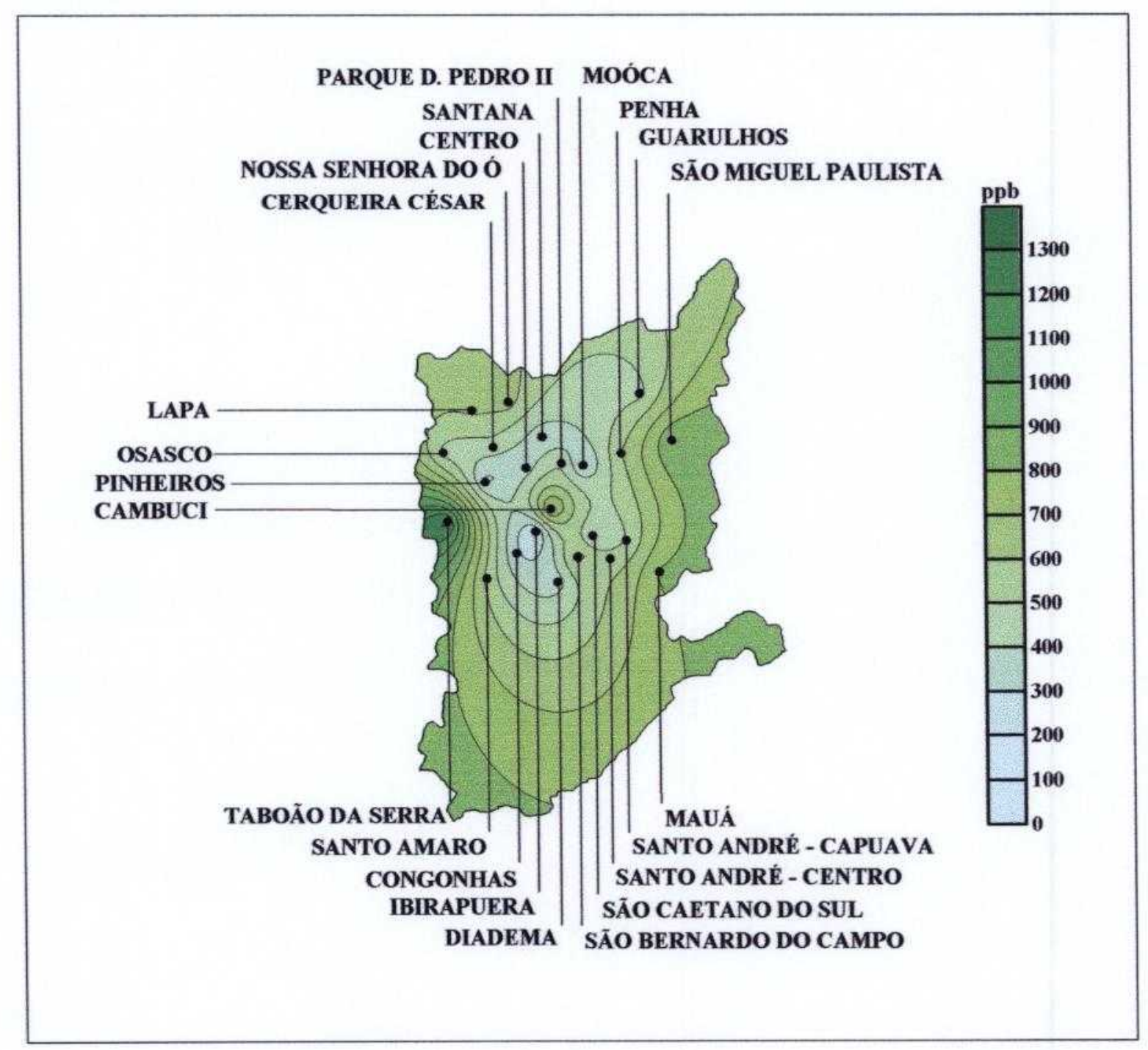

FIGURA 5.16 - Mapa da concentração de Cs, em ng $\mathrm{g}^{-1}$, obtido para liquens da região metropolitana de São Paulo. 
Nas regiões de Cerqueira César, Mauá, São Miguel Paulista e Penha os liquens apresentaram elevadas concentrações de Fe (FIG. 5.17). A presença deste elemento no ar nas regiões de Mauá e São Miguel Paulista pode ser atribuída às indústrias de ligas metálicas. A presença de $\mathrm{Fe}$ assim como de $\mathrm{Co}, \mathrm{Cr}$ e $\mathrm{Mn}$ nos centros urbanos e rodovias tem sido atribuída à emissão dos produtos de desgaste de motores de veículos.

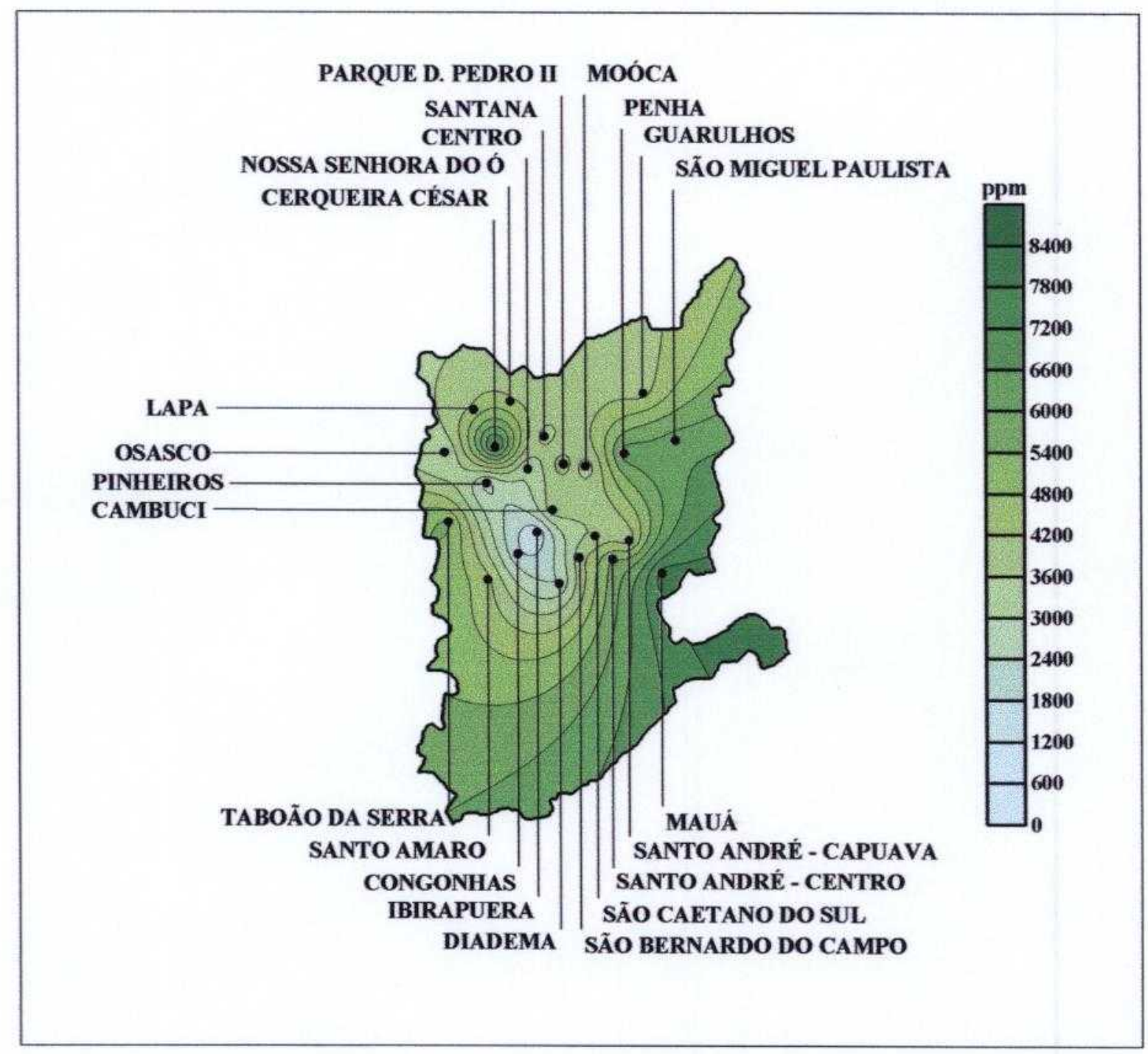

FIGURA 5.17 - Mapa da concentração de $\mathrm{Fe}, \mu \mathrm{g} \mathrm{g}^{-1}$, obtido para liquens da região metropolitana de São Paulo. 
$\mathrm{O}$ elemento $\mathrm{K}$ apresentou-se mais concentrado na região sudoeste (Taboão da Serra e Santo Amaro). Já o La foi encontrado em altos teores nestes dois pontos e também na região leste (Penha, São Miguel Paulista, Santo André - Capuava e Mauá). Para estes elementos a origem de fontes naturais tem sido considerada como sendo mais importante do que as de fontes antrópicas. As concentrações de $\mathrm{K}$ e $\mathrm{La}$ em diversos pontos de amostragens foram da mesma ordem de grandeza, devido provavelmente as suas origens serem de fontes naturais (solo).

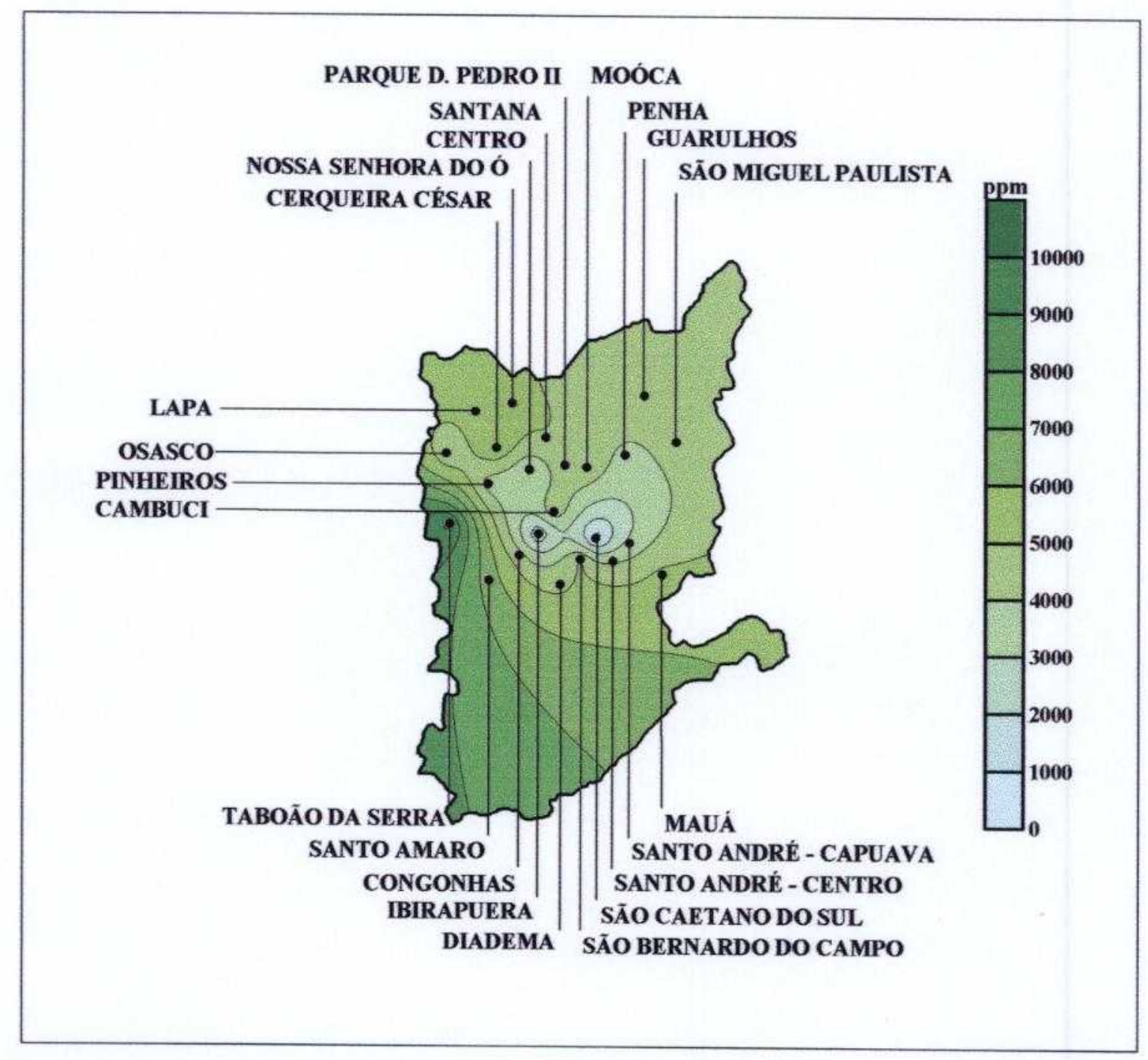

FIGURA 5.18 - Mapa da concentração de $\mathrm{K}$, em $\mu \mathrm{g} \mathrm{g}^{-1}$, obtido para liquens da região metropolitana de São Paulo. 


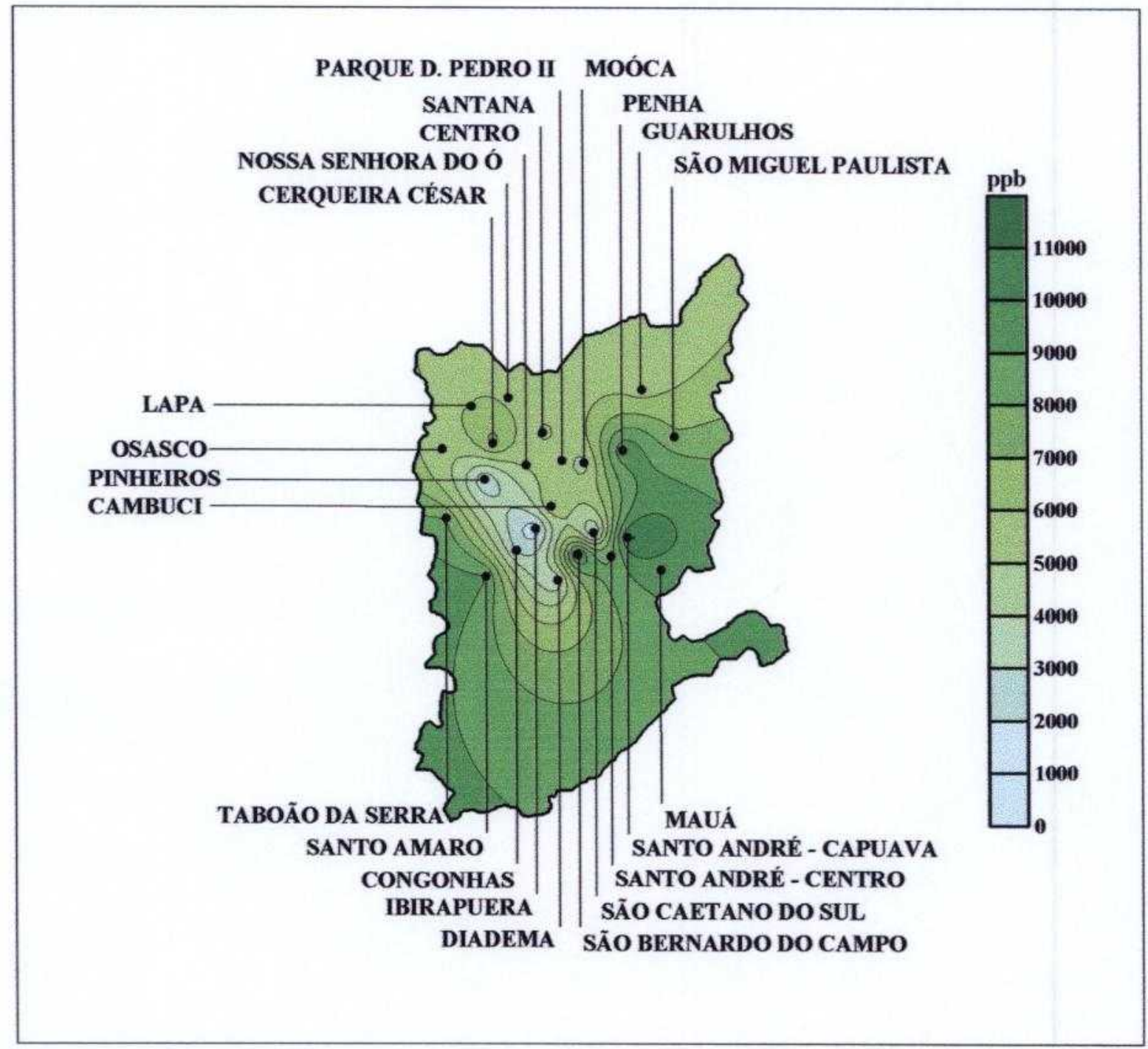

FIGURA 5.19 - Mapa da concentração de $\mathrm{La}$, em $\mathrm{ng} \mathrm{g}^{-1}$, obtido para liquens na região metropolitana de São Paulo. 
As altas concentrações de $\mathrm{Mn}$ foram obtidas para os liquens da região do $\mathrm{ABC}$ paulista como mostra a FIG. 5.20, particularmente em Santo André - Capuava. A origem de Mn é atribuída geralmente às atividades antrópicas como agricultura, tráfego, mineração, fundição e produção de aço. A alta concentração deste elemento obtida para Santo André - Capuava deve-se às indústrias presentes na região.

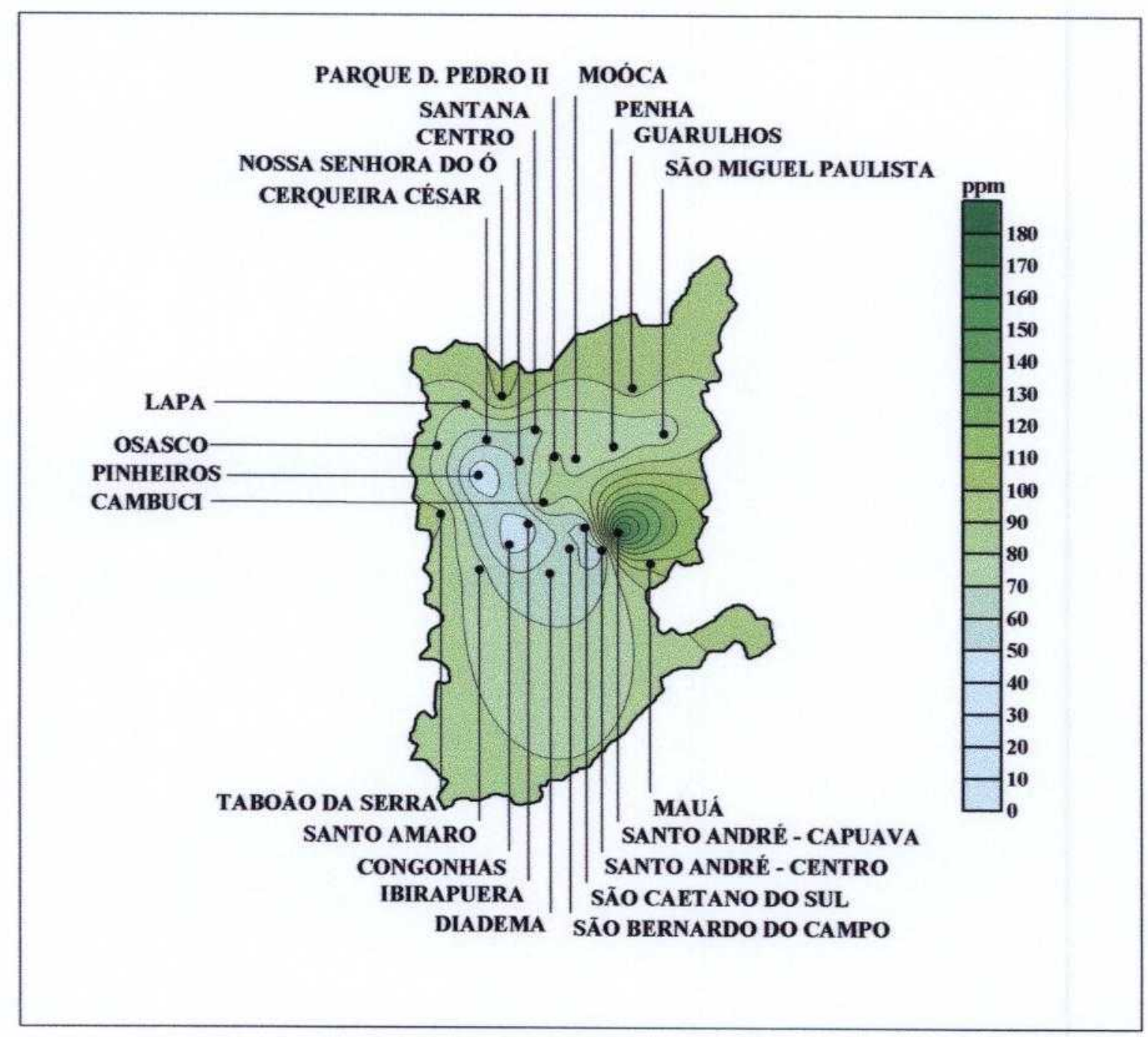

FIGURA 5.20 - Mapa da concentração de Mn, em $\mu \mathrm{g} \mathrm{g}^{-1}$, obtido para liquens da região metropolitana de São Paulo. 
As altas concentrações de Mo foram obtidas para liquens coletados em Cerqueira César, Mooca, Diadema, Santo André e Cambuci (FIG. 5.21). A presença deste elemento na atmosfera tem sido associada à atividade de mineração de $\mathrm{U}$, mineração $\mathrm{e}$ fundição de Mo, refino de petróleo, combustão de petróleo e carvão, fertilizantes fosfatados, detritos de esgotos domésticos e de detergentes fosfatados. A origem das altas concentrações de Mo encontradas na região metropolitana de São Paulo pode ser atribuída à contaminação de origem industrial e veicular.

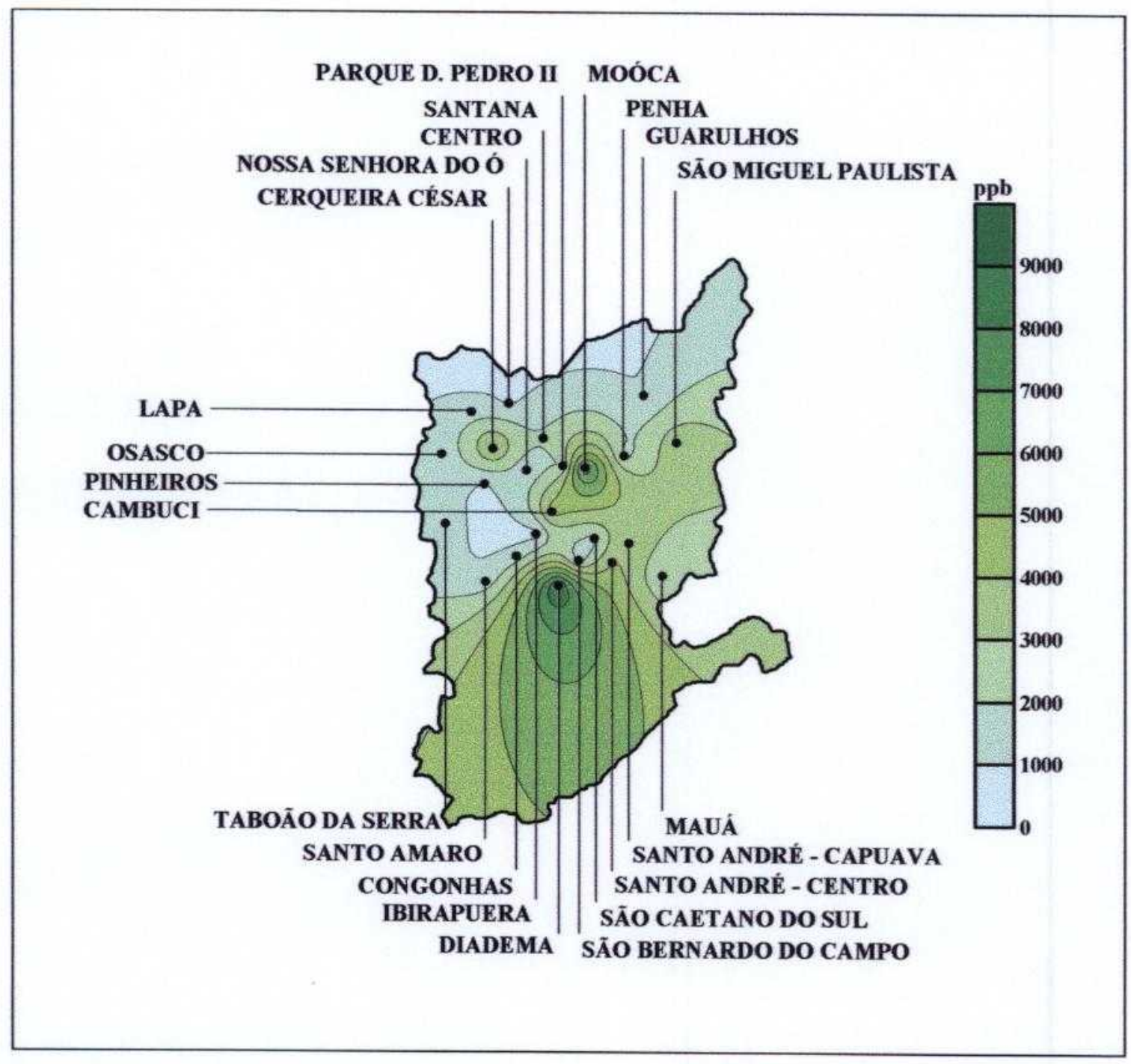

FIGURA 5.21 - Mapa da concentração de Mo, em $\mu \mathrm{g} \mathrm{g}^{-1}$, obtido para liquens da região metropolitana de São Paulo. 
$\mathrm{Na}$ área metropolitana, as amostras coletadas no Parque Ibirapuera e Congonhas apresentaram as mais baixas concentrações de Na, como mostra a FIG. 5.22, quando comparadas com os demais pontos da região metropolitana.

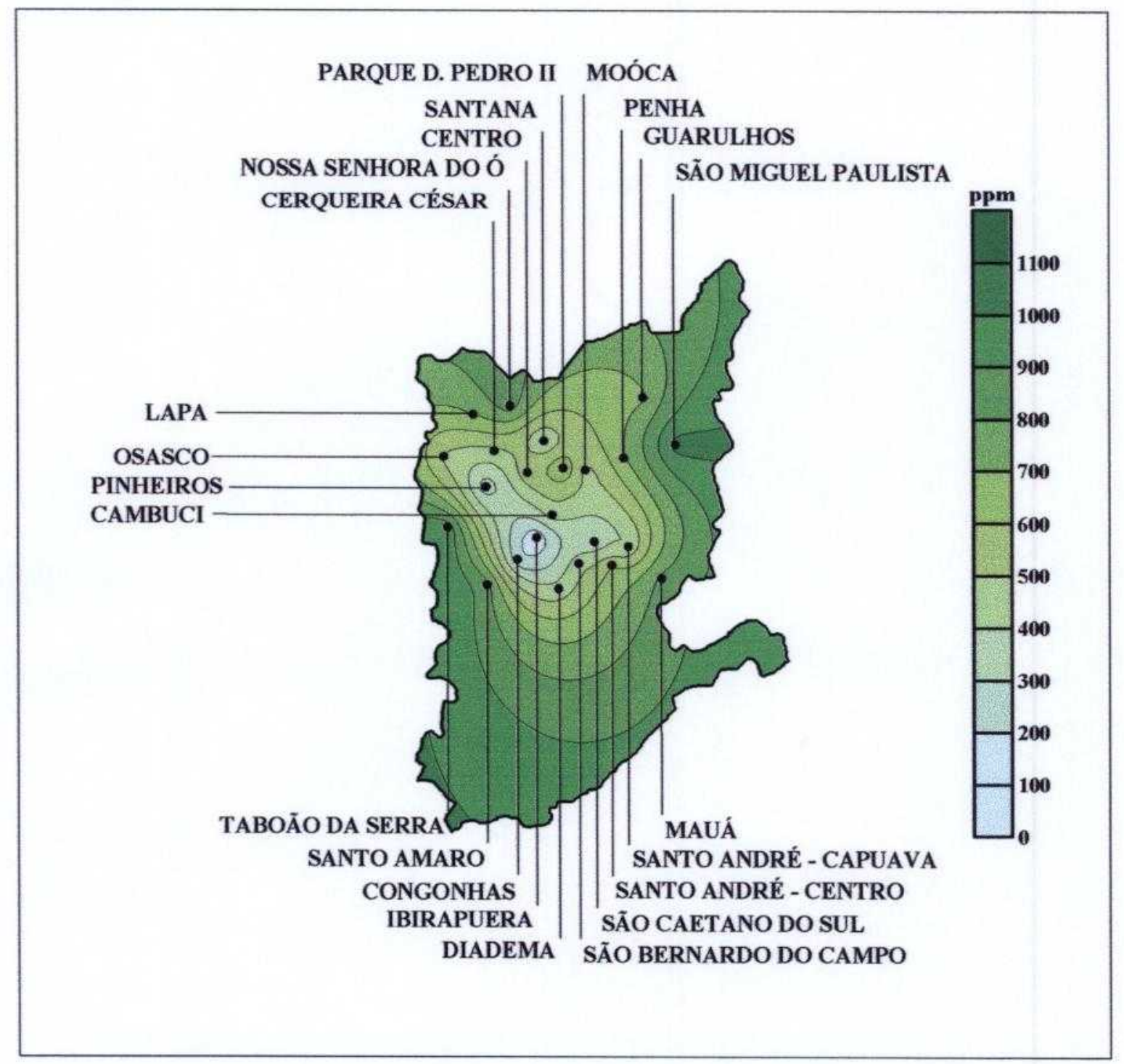

FIGURA 5.22 - Mapa da concentração de $\mathrm{Na}$, em $\mu \mathrm{g} \mathrm{g}^{-1}$, obtido para liquens da região metropolitana de São Paulo. 
O mapa de distribuição do Rb apresentado na FIG. 5.23 indica também que os liquens de Ibirapuera e Congonhas apresentaram baixas concentrações deste elemento. $\mathrm{O}$ líquen coletado no Taboão da Serra apresentou a mais alta concentração de $\mathrm{Na}$ e a sua origem pode ser atribuída ao solo.

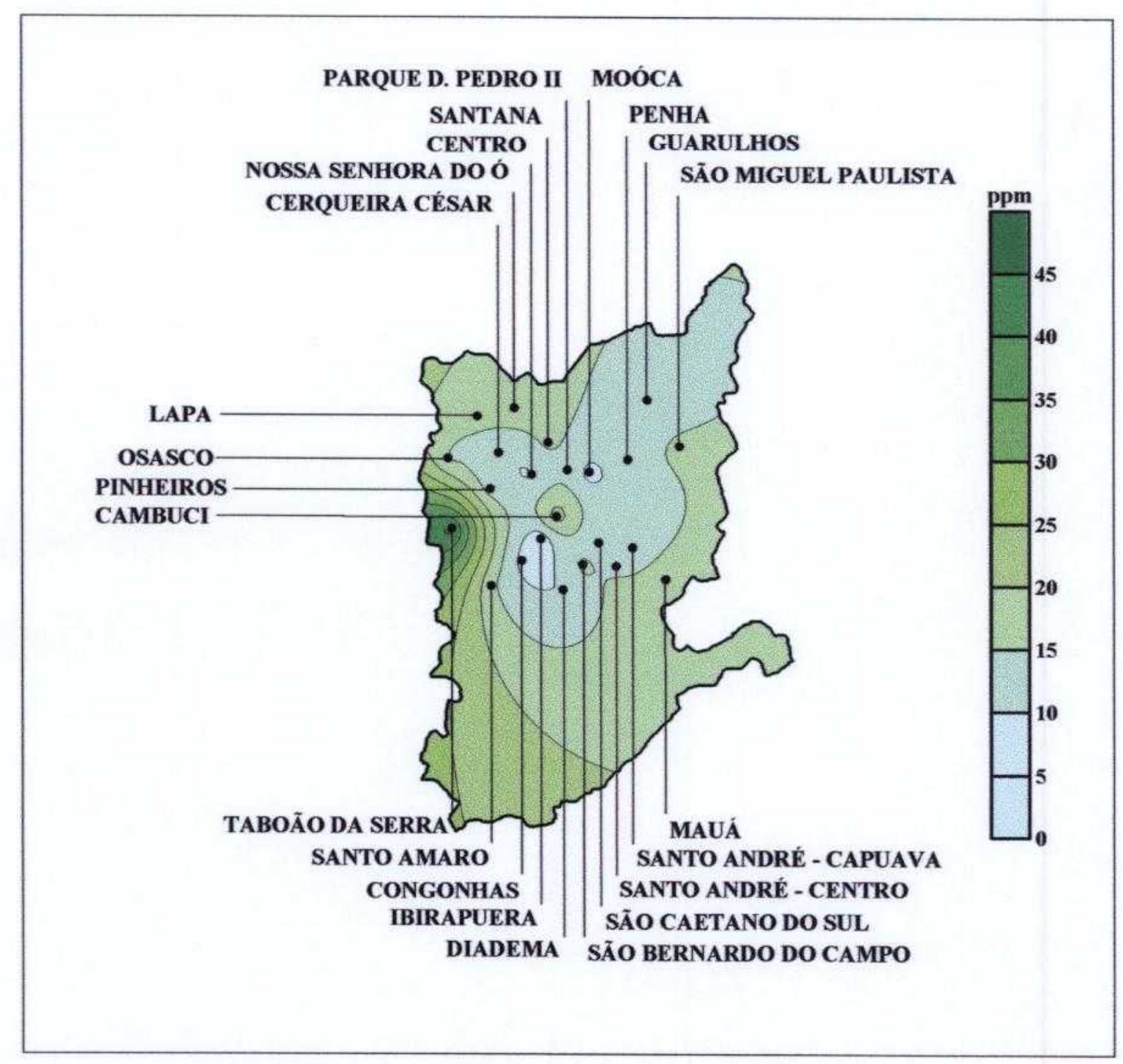

FIGURA 5.23 - Mapa da concentração de $\mathrm{Rb}$, em $\mu \mathrm{g} \mathrm{g}^{-1}$, obtido para liquens da região metropolitana de São Paulo. 
Para o caso do elemento $\mathrm{Sb}$, o mapa de distribuição de concentração (FIG. 5.24) mostra que os liquens de Cerqueira César e Santo André - Capuava apresentaram concentrações mais elevadas que os demais pontos da área metropolitana. A origem deste elemento no ambiente pode ser associada à exaustão veicular, desgaste de partes mecânicas de veículos, incineradores hospitalares e queima de pneus.

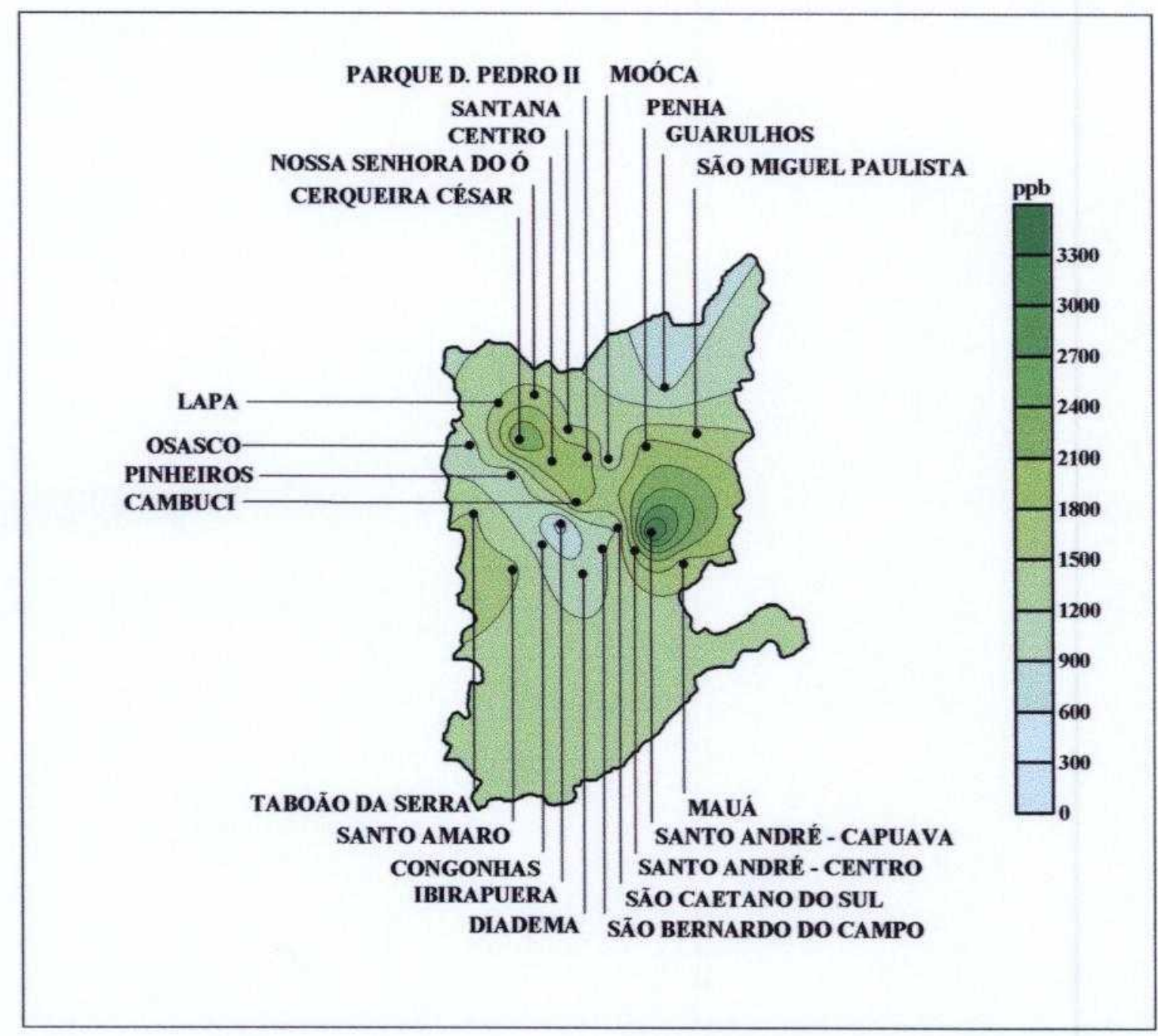

FIGURA 5.24 - Mapa da concentração de $\mathrm{Sb}$, em $\mathrm{ng} \mathrm{g}^{-1}$, obtido para liquens da região metropolitana de São Paulo. 
$\mathrm{O}$ elemento $\mathrm{Sc}$ apresentou as menores concentrações em Pinheiros, Congonhas, Parque Ibirapuera e Diadema e elevadas concentrações em Cerqueira César, São Miguel Paulista, Penha e Mauá (FIG. 5.25). Este elemento é introduzido no ambiente por meio de poeiras trazida pelos ventos o que faz com que a ação do solo seja mais relevante do que as emissões veiculares ou industriais.

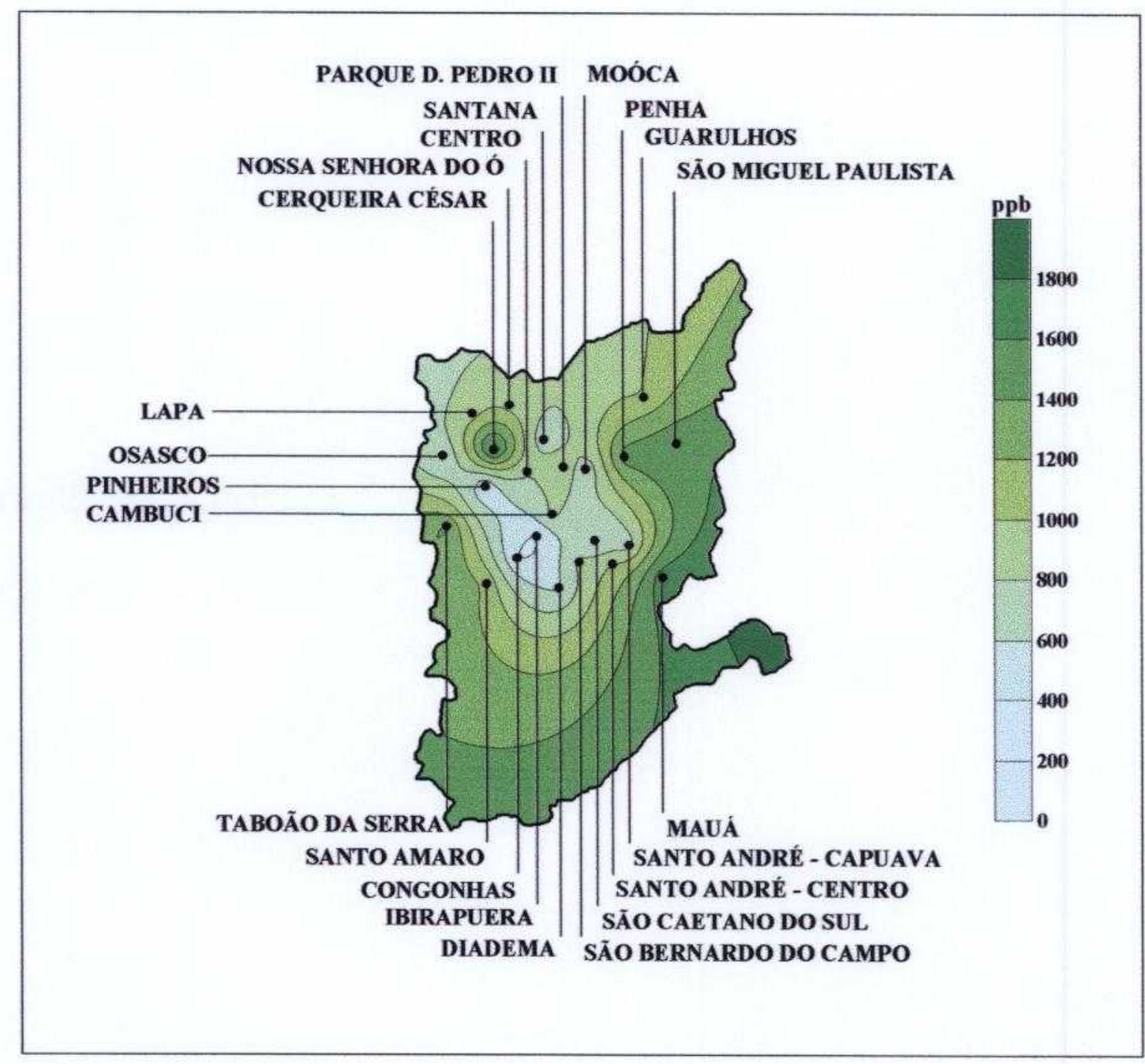

FIGURA 5.25 - Mapa da concentração de $\mathrm{Sc}$, em $\mathrm{ng} \mathrm{g}^{-1}$, obtido para liquens da região metropolitana de São Paulo. 
As concentrações mais altas de Se foram obtidas para liquens coletados na Lapa e Centro como mostra o mapa de distribuição da FIG. 5.26. A origem do Se tem sido atribuída à combustão do carvão, fundições de $\mathrm{Cu}-\mathrm{Pb}$, águas residuais e alguns fertilizantes fosfatados e no caso não foi possível identificar uma provável fonte deste elemento encontrado no Centro e Lapa.

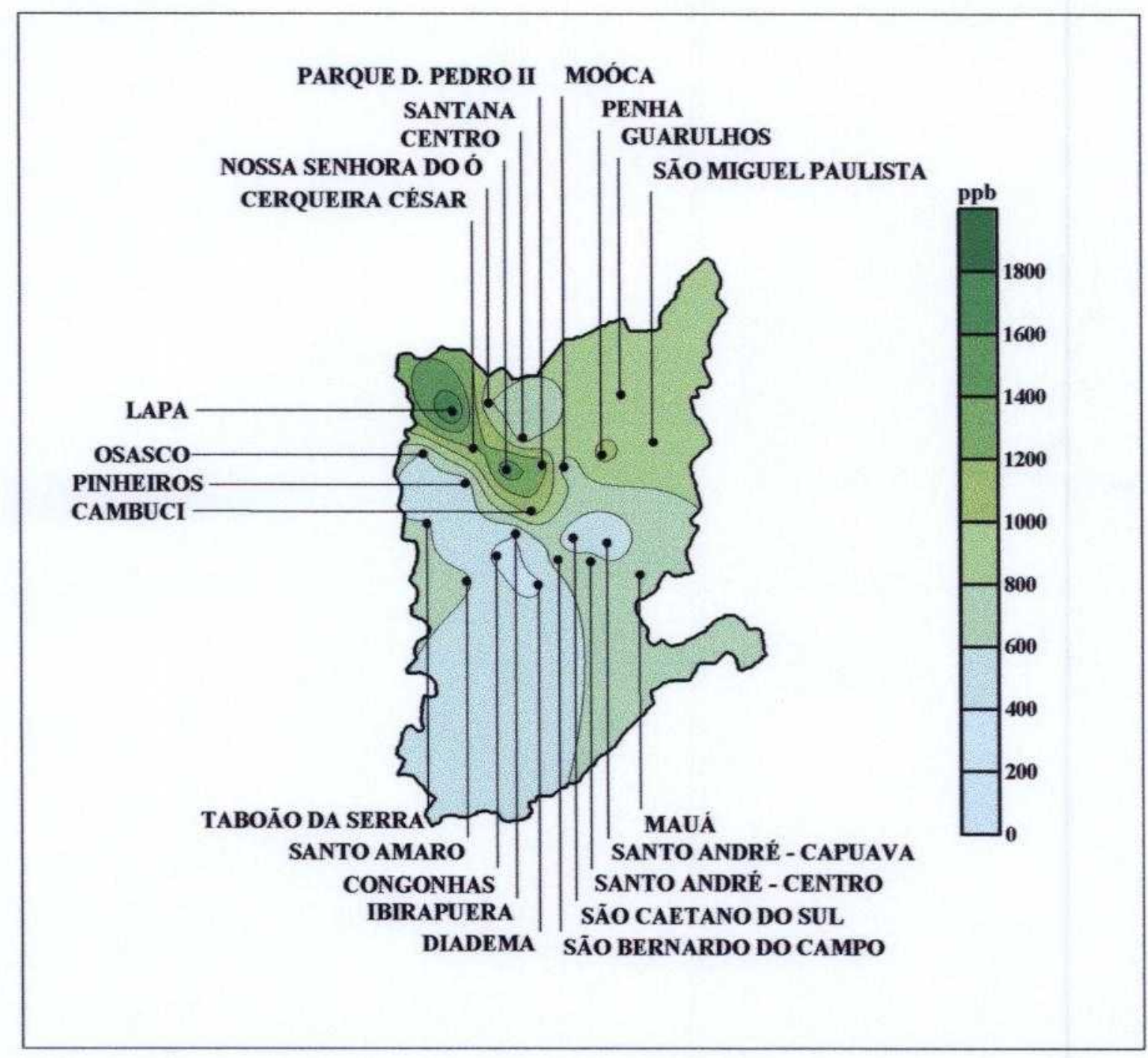

FIGURA 5.26 - Mapa da concentração de Se, em $\mathrm{ng} \mathrm{g}^{-1}$, obtido para liquens da região metropolitana de São Paulo. 
As concentrações mais altas de $\mathrm{U}$ foram obtidas nos liquens coletados na Penha e Guarulhos e as mais baixas para aqueles do Parque Ibirapuera, Pinheiros, Cambuci, Congonhas e São Caetano do Sul (FIG. 5.27).

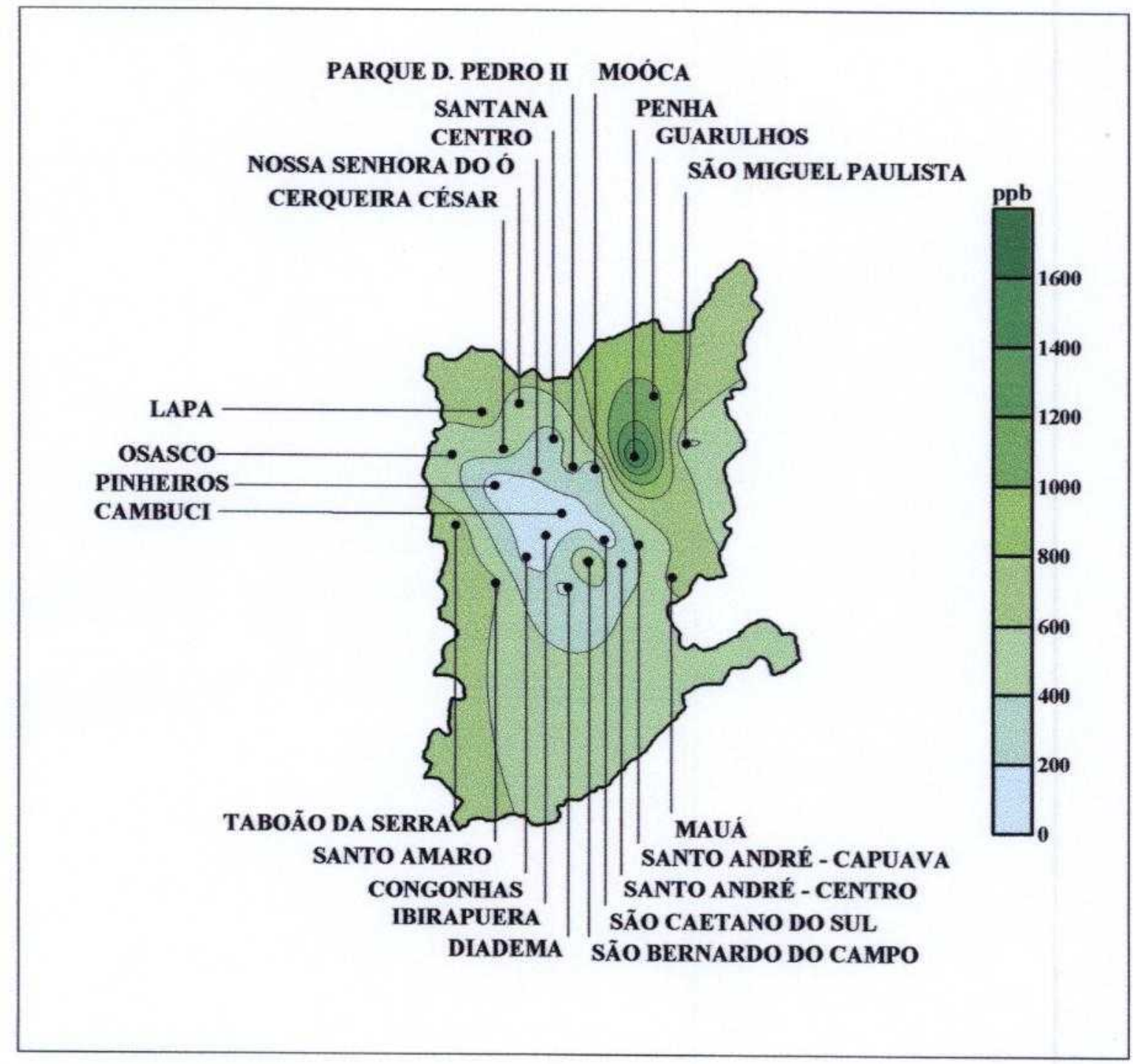

FIGURA 5.27 - Mapa da concentração de $\mathrm{U}$, em ng $\mathrm{g}^{-1}$, obtido para os liquens da região metropolitana de São Paulo. 
Para o $\mathrm{Zn}$ é interessante notar que os liquens de três regiões distintas (Osasco, Congonhas e Santo André - Capuava) (FIG. 5.28) apresentaram concentrações mais elevadas. A origem deste elemento no ambiente tem sido atribuida a fontes veiculares ou industriais. A emissão deste elemento para a atmosfera pode ter a sua origem na queima ou desgaste de pneus (FIG. 5.28).

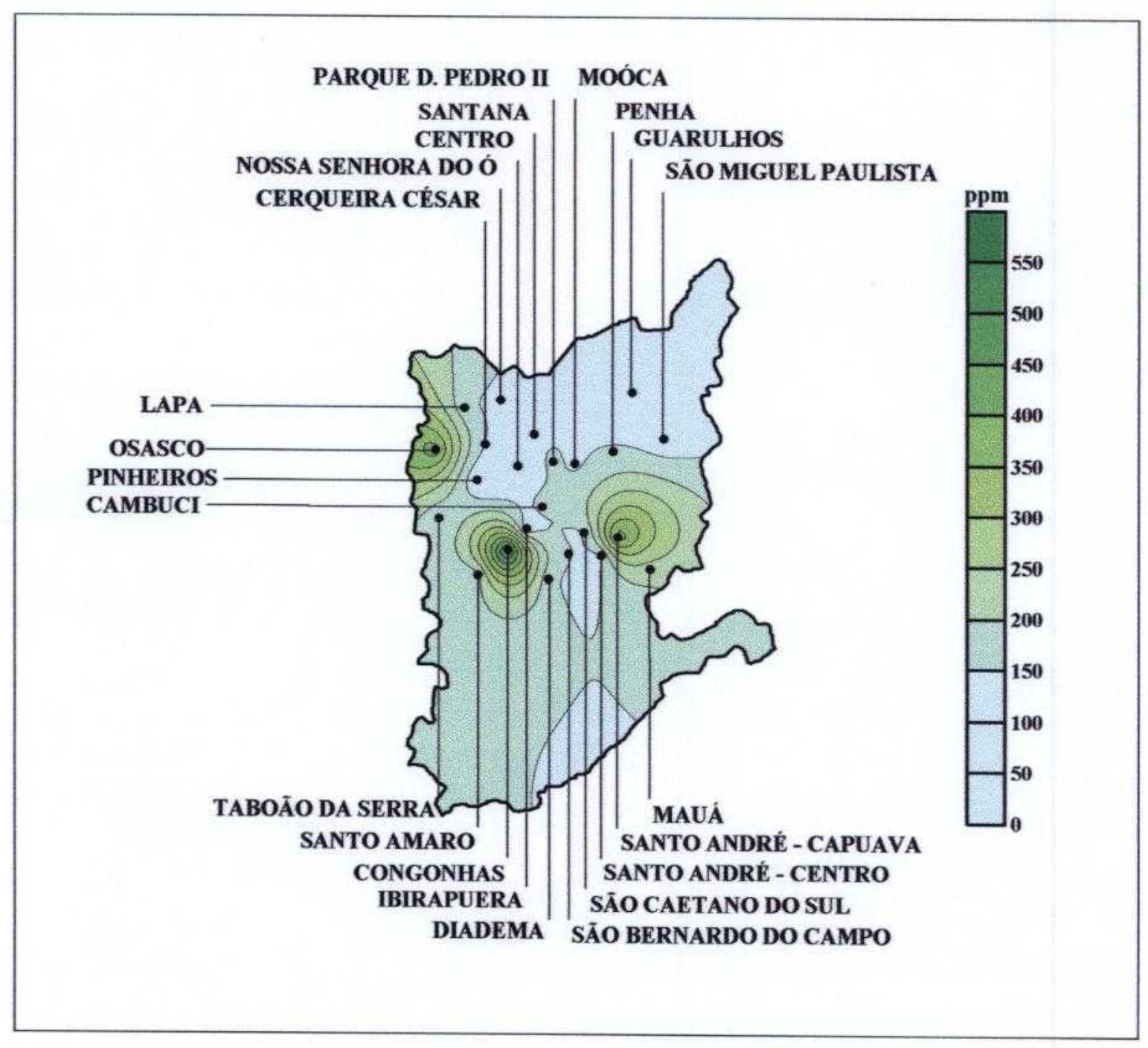

FIGURA 5.28 - Mapa da concentração de $\mathrm{Zn}$, em $\mu \mathrm{g} \mathrm{g}^{-1}$, obtido para liquens da região metropolitana de São Paulo. 


\section{CONCLUSÕES}

Os resultados das análises dos materiais certificados de referência IAEA-336 LICHEN e Mixed Polish Herbs (INCT-MPH-2) indicaram, em geral, uma boa precisão visto que os coeficientes de variação ficaram em torno de 0,9 a 14,6\%. Resultados menos precisos foram obtidos para o elemento Sb no material IAEA-336 LICHEN e para os elementos As, Ba, Br, La, Mn, Mo, Sb e Se no material Mixed Polish Herbs (INCT-MPH2), com coeficientes de variação superiores a $15 \%$. No que se refere à exatidão pode-se afirmar pelo teste $t$ de Student que os resultados obtidos foram concordantes com os valores certificados para a maioria dos elementos. Os elementos que apresentaram médias significativamente diferentes dos valores certificados foram: $\mathrm{La}$, Se e $\mathrm{Zn}$ para o material IAEA-336 LICHEN e Cl, Fe, K, Sb e Zn para o material Mixed Polish Herbs (INCT-MPH2). Por outro lado, os valores de $Z$-score foram $|z|<3$ para a maioria dos resultados o que indica que os dados obtidos estão dentro da faixa dos valores dos certificados a um nível de significância de $1 \%$.

Com relação ao método de NAA utilizado neste trabalho convém salientar que esta técnica foi bastante adequada devido principalmente a possibilidade de análise de vários elementos sem a necessidade de digestão de amostras.

Portanto pelos resultados obtidos nos materiais certificados de referência pôdese concluir que o procedimento de NAA foi adequado para a determinação de diversos elementos acumulados nas amostras de líquen.

A análise de amostras de liquens coletadas em regiões de diferentes niveis de poluição comprovou que as amostras de liquens das regiões consideradas limpas dos Parques Estaduais apresentam concentrações de elementos mais baixas ou da mesma ordem de grandeza daquelas obtidas para amostras da área metropolitana de São Paulo.

No caso, as mais altas concentrações de elementos nos liquens, da ordem de $\mu \mathrm{g}$ $\mathrm{g}^{-1}$, foram obtidas para $\mathrm{Ba}, \mathrm{Br}, \mathrm{Ca}, \mathrm{Cl}, \mathrm{Fe}, \mathrm{K}, \mathrm{Mn}, \mathrm{Na}, \mathrm{Rb}$ e $\mathrm{Zn}$ e seguida de $\mathrm{As}, \mathrm{Co}, \mathrm{Cr}, \mathrm{Cs}$, $\mathrm{La}, \mathrm{Mo}, \mathrm{Sb}, \mathrm{Sc}$, Se e $\mathrm{U}$ que estão presentes aos níveis de $\mathrm{ng}^{\mathrm{g}}{ }^{-1}$. 
No tratamento dos dados analíticos dos liquens pela análise de cluster o dendrograma obtido mostrou que os resultados dos Parques Estaduais Carlos Botelho e Intervales formam um grupo distinto daqueles obtidos para amostras da região metropolitana. Estes resultados confirmam a preservação destes Parques sendo assim considerados como regiões não-poluídas. Também pela análise de cluster, quatro pontos de amostragem da região metropolitana (Congonhas, Parque Ibirapuera, Instituto de Botânica e Pinheiros) apresentaram características similares às regiões consideradas não-poluídas. Este resultado em parte, se deve a determinados elementos, principalmente de origem do solo que apresentaram teores bastante próximos.

Por meio da aplicação da análise discriminante aos resultados analíticos de liquens também foi possível concluir a classificação das amostras em grupos como foi obtido pela análise de clusters.

Os liquens coletados no Parque Estadual Intervales (PEI) apresentaram concentrações inferiores àquelas obtidas para amostras da região metropolitana de São Paulo para os elementos cujas origens estão relacionadas com ações antrópicas. Já para os elementos $\mathrm{Ba}, \mathrm{Ca}, \mathrm{Cs}, \mathrm{K}, \mathrm{Mn}$ e $\mathrm{Rb}$ cujas origens estão associdadas ao solo, as concentrações obtidas para os liquens do PEI foram da mesma ordem de grandeza daquelas obtidas para as amostras da região metropolitana.

Para as amostras de liquens do Parque Estadual Carlos Botelho (PECB), para determinados elementos, suas concentrações foram da mesma ordem de grandeza daquelas da região metropolitana. Este fato pode ser explicado levando-se em conta que estas amostras foram coletadas em árvores das margens de uma estrada.

As altas concentrações de $\mathrm{Br}$ e $\mathrm{Cl}$ obtidas para os dois parques estaduais (PECB e PEI) podem ser explicadas pela proximidade destes pontos de amostragem a costa litorânea do Estado de São Paulo.

Os mapas de distribuição das concentrações de elementos obtidos para liquens coletados na área metropolitana permitiram a localização de pontos que apresentaram concentrações mais elevadas para determinados elementos. Uma vez "pontuadas" estas concentrações, as possiveis fontes de origem foram "especuladas". 
Os mapas de distribuição obtidos mostraram que a poluição na região metropolitana de São Paulo apresenta perfis diferentes devido às inúmeras fontes de emissão de poluentes. De maneira geral pelos resultados obtidos neste trabalho pode-se concluir que as altas concentrações de $\mathrm{Co}, \mathrm{Cr}, \mathrm{Fe}, \mathrm{Mn}, \mathrm{Mo}$ e $\mathrm{Sb}$ se deve principalmente às emisssões de indústrias. Já a presença de elementos $\mathrm{As}, \mathrm{Ba}, \mathrm{Br}, \mathrm{Cl}, \mathrm{Fe}, \mathrm{La}$ e $\mathrm{Zn}$ se deve tanto às emissões veiculares assim como industriais. Os elementos $\mathrm{Ba}, \mathrm{Ca}, \mathrm{Cs}, \mathrm{K}, \mathrm{Mn}$ e Rb presentes nos liquens podem ser atribuídos a fontes oriundas do solo.

Os resultados obtidos neste trabaiho mostraram que para uma identificação exata da fonte emissora de um determinado elemento torna-se necessário a análise de liquens coletados de uma área subdividida em maior pontos de amostragens ou a análise de liquens de diferentes distâncias da fonte suspeita de emissão.

Os resultados obtidos neste trabalho permitiram concluir a viabilidade do uso do fungo liquenizado $C$. texana na avaliação da contaminação aérea da região metropolitana de São Paulo. Suas análises químicas permitiram a avaliação de diversos elementos químicos de interesse sob o ponto de vista de poluição e esses resultados permitiram distinguir regiões de diferentes niveis de poluição.

Convém ainda salientar que a C. texana é uma espécie bastante abundante na região metropolitana de São Paulo e, além disso, trabalhos sobre a aplicação desta espécie no monitoramento de elementos poluentes no Brasil são praticamente inexistentes.

Trata-se no momento de um trabalho de aplicação da $C$. texana no biomonitoramento da poluição atmosférica de elementos químicos e acredita-se que o uso desta espécie poderá trazer inúmeras contribuições no controle da poluição ambiental. 


\section{REFERÊNCIAS BIBLIOGRÁFICAS}

AGUIAR, A. R. Aplicação do método de análise por ativação com nêutrons à determinação de elementos traço em unha humanas. 2001. Dissertação (Mestrado) Instituto de Pesquisas Energéticas e Nucleares, São Paulo.

ASLAN, A.; BUDKA, G.; KARABULUT, A. The amounts Fe, Ba, Sr, K, Ca and Ti in some lichens growing in Erzurum province (Turkey). Journal of Quantitative Spectroscopy \& Radiative Transfer, v. 88, p. 423-431, 2004.

BARBOSA, S. B. Estudos anatômicos em quatro espécies de Parmeliaceae (ascomycota liquenizados). 2005. Dissertação (Mestrado) - Universidade Estadual Paulista, Botucatu.

BERGAMASCHI, L.; RIZZIO, E.; GIAVERI, G.; PROFUMO, A; LOPPI, S.; GALLORINI, M. Determination of baseline element composition of lichens using samples from high elevations. Chemosphere, v. 55, p. 933-939, 2004.

BODE, P. Instrumental and organizational aspects of a neutron activation analysis laboratory. The Netherlands: Delft University of Technology, 1996. cap.6, process
improvement by quality assurance. p. 143-174.

BROWN, D. H.; AVALOS, A.; MILLER, J. E.; BARGAGLI, R. Interactions of lichens with their mineral environment. Cryptogamic Botany, v. 4, p. 135-142, 1994.

BUDKA, D.; MESJASZ-PRZYBYLOWICZ, J.; PRZYBYLOWICZ, W. J. Environmental pollution monitoring using lichens as bioindicators: a micro-PIXE study. Radiation
Physics and Chemistry, v. 71, p. 783-784, 2004 .

CARNEIRO, R. M. A Bioindicadores vegetais de poluição atmosférica: uma contribuição para a saúde da comunidade. 2004.146 p. Dissertação (Mestrado) - Escola de Enfermagem de Ribeirão Preto, Universidade de São Paulo, Ribeirão Preto.

CARBALleIRA, A; CARRAL, E., PUENTE, $X$; VILlaRES R. Regional-scale monitoring of coastal contamination. Nutrients and heavy metals in estuarine sediments and organisms on the coast of Galicia (NW Spain). In: CONTI, M. E.; BOTRE, F. (Eds). The control of Marine Pollution: Current Status and Future Trends. Special issue of International Journal of Environment and Pollution (IJEP), v. 13, n. 1-6, p. 534-572,

CERCASOV, V; PANTELICA, A; SALGEAN, M.; CANIGLIA, G.; SCARLAT, A Comparative study of the suitability of three lichen species to trace-element air monitoring.
Environmental Pollution, v. 119 , p. 129-139, 2002 .

CETESB. Mapa de qualidade do ar: região metropolitana e interior. Disponivel em: $<$ http://www.cetesb.sp.gov.br/Ar/ar geral.asp >. Acesso em: out. 2003.

CHENG, T. P.; MORRIS, J. S.; KOIRTYOHANN, S. R.; SPATE, V. L.; BASKETT, C. K. Study of the correlation of trace elements in carpenter's toenails. Journal of Radioanalytical and Nuclear Chemistry, Articles, v. 195, n. 1, p. 31-42, 1995. 
CLARK, B. M.; MANGELSON, N. F.; St. CLAIR, L. L.; GARDNER, J. S.; COOPER, L. S.; REES, L. B.; GRANT, P. G.; BENCH, G. S. Analysis of lichen thin sections by PIXE and STIM using a proton microprobe. Nuclear Instruments and Methods in Physics Research B, v. 150, p. 248-253,1999.

COCCARO, D. M. B.; SAIKI, M.; VASCONCELLOS, M. B. A.; MARCELLI, M. P. Evaluation of trace elements in different species of lichens by neutron activation analysis. Journal of Radioanalytical and Nuclear Chemistry, v. 244, n. 1, p. 141-145, 1999.

COCCARO, D. M. B. Estudo da determinação de elementos traço em liquens para monitoração ambiental. 2001. Dissertação (Mestrado) - Instituto de Pesquisas Energéticas
e Nucleares, São Paulo.

CONTI, M. E. ; CECHETTI, G. Biological monitoring: lichens as bioindicators of air pollution assessment - a review. Environmental Pollution, v. 114, p. 471-475, 2001. DE SOETE, D.; GIJBELS, R.; HOSTE, J. Neutron activation analysis. New York, N. Y.:
John Wiley and Sons, 1972 .

DIAS DA CUNHA, K. D.; RICKMAN, R. D.; LEITE, C. V. B. Characterization of environmental exposure to mineral sands by PMDS technique. Nuclear Instruments and Methods in Physics Research B, v. 201, p. 615-622, 2003

DIAS DA CUNHA, K. D.; LEITE, C. V. B.; ZAYS, Z. Exposure to mineral sands dust particles. Nuclear Instruments and Methods in Physics Research B, v. 217, p. 649-656,
2004 .

DI LELlA, L. A.; FRATI, L.; LOPPI, S.; PROTANO, G.; RICCOBONO, F. Environmental distribution of uranium and other trace elements at selected Kosovo sites.
Chemosphere, v. 56, p. $861-865,2004$

FREITAS, M. C. ; REIS, M. A ; ALVES, L. C. \& WOLTERBEEK, H. Th. Distribution in Portugal of some pollutants in lichen Parmelia sulcata. Environmental Pollution, v. 106,
$229-235,1999$. FRIEDLANDER, G.; KENNEDY, J. W.; MILLER, J. M. Nuclear and radiochemistry.
New York, N. Y.: John Wiley \& Sons, 1981.

FUGA, A., VASCONCELlOS, M. B. A., SAIKI, M., SIQUEIRA, O. S., HONDA, N. H. Análise de espécies de liquens para uso na biomonitoração de poluentes atmosféricos In: VI ENCONTRO NACIONAL DE APLICAÇÕES DE TÉCNICAS NUCLEARES - VI ENAN, 2002, Rio de Janeiro. Anais do VI ENAN. Rio de Janeiro: Development \& Design:
Fábrica de Imagens, 2002. v. 1. p. $475-478$.

GARTY, J. Biomonitoring atmospheric heavy metals with lichens: Theory and Application. Critical Reviews in Plant Sciences, v. 20, n. 4, p. 309-371, 2001.

GARTY, J.; TOMER, S.; LEVIN, T.; LEHR, H. Lichens as biomonitors around a coalfired power station in Israel. Environmental Research, v. 91, p.186-198, 2003. 
HALE, M. E. The biology of lichens. Melbourne, Australia: Edward Arnold (Australia) Pty Ltd, 1983. cap. 1, morphology of the thallus. p. 1-17.

IAEA-TECDOC-564. Practical aspects of operating a neutron activation analysis Laboratory. International Atomic Energy Agency, IAEA, VIENNA, 1990.

IAEA. INTERNATIONAL ATOMIC ENERGY AGENCY. Certificate of IAEA-336 Reference Material. Trace and minor elements in lichen, Jun., 1999.

INCT. INSTITUTE OF NUCLEAR CHEMISTRY AND TECHNOLOGY. Polish certified reference material. Certificate of Mixed Polish Herbs Reference Material (INCT-MPH-2), 2002.

KELLNER, R.; MERMET, J. M.; OTTO, M.; WIDMER, H. M. Analytical Chemistry. New York, N. Y.: Wiley, 1998. cap. 8, activation analysis. p. 491-513.

LIDÉN, M.; PETTERSSON, M.; BERGSTEN, U.; LUNDMARK, T. Artificial dispersal of endangered epiphytic lichens: a tool for conservation in boreal forest landscapes. Biological Conservation, v. 118, p. 431-442, 2004.

LOPPI, S.; RICCOBONO, F.; ZHANG, Z. H.; SAVIC, S.; IVANOV, D.; PIRINTSOS, S. A. Lichens as biomonitors of uranium in the Balkan area. Environmental Pollution, v. 125, p. 277-280, 2003.

MAGAlHÃES, M. N.; PEDROSO DE LIMA, A. C. Noções de probabilidade $e$ estatistica. São Paulo, S.P.: Edusp, 2004.

MANAHAN, S. E. Environmental chemistry. Boca Raton, F. L.: CRC, 2000. cap. 1, environmental science, technology and chemistry. p. 20-21. cap. 9, the atmosphere and atmospheric chemistry. p. 267-268.

MARCELLI, M. P. History and current knowledge of Brazilian lichenology. In: LICHENOLOGY in Latin America: history, current knowledge and application. São Paulo: CETESB, 1998, p. 25-45.

MARKERT, B.; HERPIN, U.; BERLEKAMP, J.; LIETH, H. The German heavy metal survey by means of mosses. Science of the Total Environment, v. 182, p. 159-168, 1996.

MATA ATLÂNTICA. Vista aérea do ecosssistema de Mata Atlântica. Disponivel em: $\underline{<\mathrm{http}: / / \text { www.isa.org.br/website/noticias/Brasil/imagens/itajai_p.jpg }>\text {. Acesso em: nov. }}$

NASH, T. H.; WIRTH, V. Lichens, bryophytes and air quality. Bibliotheca Lichenologica, v. 30, p. 1-298, 1988.

PARQUE (a) Estadual Carlos Botelho. Coordenadas geográficas e vista áerea. Disponivel em: $<$ http://www aultimaarcadenoe.com/urucutu.htm>. Acesso em: jul. 2004.

PARQUE (b) Estadual Carlos Botelho. Localização e vegetação. Dispon ivel em: $<$ http://www.timberland.com.br/parques_botelho.htm\#localizacao>. Acesso em: jul. 2004. 
PARQUE (c) Estadual Carlos Botelho. Municípios. Disponível em: $<$ http://www.ambiente.sp.gov.br/destaque/pqe_carlosbotelho.htm>. Acesso em: jul. 2004

PARQUE (d) Estadual Carlos Botelho. Relevo, precipitação pluviométrica e nascentes. Disponivel em:

$<$ http://www.pick-upau.com.br/expedicoes/bandeirantes/carlos botelho.htm>. Acesso em: jul. 2004

PARQUE (e) Estadual Carlos Botelho. Unidade de conservação e biodiversidade. Disponivel em: $<$ http://www.escoteiro.com.br/jornal/materia/materia exibe asp?id=96 $>$. Acesso em: jul. 2004

PARQUE (f) Estadual Carlos Botelho. Geomorfologia e vegetação. Disponível em: $<$ http://www portaldomeioambiente.com. br/noticias asp?tarefa $=$ mostra\&id $=320>$. Acesso em: jul. 2004

PARQUE (g) Estadual Intervales. Localização, municípios, precipitação pluviomética, altitude, fauna, flora e clima. Disponivel em:

$<$ http://www.brazilnature.com/intervales/geografia.html >. Acesso em: jul. 2004

PARQUE (h) Estadual Intervales. Vista aérea do Parque Estadual Intervales. Disponível em: $<$ http://www.fflorestal.sp.gov.br/pqe_interv/apresentacao.htm>. Acesso em: jul. 2004.

PARQUE (i) Estadual Intervales. Conservação, vegetação, biodiversidade, relevo, massas de ar, temperatura, chuvas, parques limítrofes, continuum ecológico, Mata Atlantica. Disponivel em:

$<$ http://www.pick-upau.com.br/expedicoes/bandeirantes/intervales/intervales.htm>. Acesso em: jul. 2004

REGIÃO (a) Metropolitana de São Paulo. Cidade de São Paulo: população e área. Disponível em:

$<$ http:/www.brasilrepublica.hpg.ig.com.br/saopaulo.htm>. Acesso em: jul. 2004. REGIÃO (b) Metropolitana de São Paulo. Extensão territorial, população, área
urbanizada, latitude, longitude e PIB. Disponivel em:

$<\mathrm{http}: / /$ pt.wikipedia.org/wiki/Regi\%C3\%A30_Metropolitana_de_S\%C3\%A30_Paulo $>$.

Acesso em: nov. 2005.

REGIÃO (c) Metropolitana de São Paulo. Iindústrias, comércio, serviços e veículos. Disponivel em:

$<$ http://pt.wikipedia.org/wiki/S\%C3\%A30_Paulo_(cidade) >. Acesso em: jul. 2004

REIMANN, C.; de CARITAT, P. Chemical elements in the environment: factsheets for the geochemist and environmental scientist. Berlin: Springer-Verlag Berlin Heidelberg,
1998.

REIMANN C.; HALLERAKER, J. H.; KASHULINA, G.; BOGATYREV, I. Comparison of plant and precipitation chemistry in catchments with different levels of pollution on the Kola Peninsula, Russia. Science of the Total Environment, n. 243-244, p. 169-191, 1999. 
RICHARDSON, D. H. S. Pollution monitoring with lichens - Naturalists Handbook 19 England, UK.: Richmond Publishing Co. Ltd., 1998. p. 1-2.

RIZZIO, E. , BERGAMASCHI, L. , VALCUVIA, M. G. , PROFUMO, A. \& GALLORINI, $M$. Trace elements determination in lichens and in the airborne particulate matter for the evaluation of the atmospheric pollution in a region of Northern Italy. Environment International, v. 26, n. 7-8, p. 543-549, 2001.

SAIKI, M.; CHAPARRO, C. G.; VASCONCELLOS, M. B. A., MARCELLI, M. P Determination of trace elements in lichens by instrumental neutron activation analysis. Journal of Radioanalytical and Nuclear Chemistry, v. 217, n. 1, p. 111-115, 1997.

SEAWARD, M. R. D.; LETROUIT-GALINOU, M. A. Lichens return to the Jardin du Luxemburg after an absence of almost a century. Lichenologist, v. 23, p. 181-186, 1991.

SEINFIELD, J. H. Atmospheric chemistry and physics of air pollution. New York, N.Y.: Wiley, 1986. cap. 1, air pollutants. p. 1-6. cap. 2, effects of air pollution. p. 49-54.

SELL, N. J. Industrial pollution control. 2. ed. New York, N. Y.: Van Nostrand and Reinhold, 1992. cap. 1, the nature of pollution. p. 1-14.

SKOOG, D. A; HOLLER, F. J.; NIEMAN, T. A. Princípios de análise instrumental. Porto Alegre, PR: Booksman, 2002. cap. 32, métodos radioquímicos. p. 714-729.

SLOOF, J. E.; WOLTERBEEK, B. Th. Lichens as biomonitors for radiocaesium following the Chernobyl accident. Journal of Environmental Radioactivity, v. 16, p. 229-242, 1992.

SLOOF, J. E. Environmental lichenology: biomonitoring trace-element air pollution. 1992. cap. 6, p. 101. Ph. D. Thesis - Delft University of Technology, Delft

SPIELMANN, A. A. A familia Parmeliaceae (fungos liquenizados) nos barrancos $e$ peraus da encosta da Serra Geral, Vale do Rio Pardo, Rio Grande do Sul, Brasil. 2005. Dissertação (Mestrado) - Instituto de Botânica da Secretaria do Meio Ambiente, São
Paulo.

THOMAS, P. A.; GATES, T. E. Radionuclides in the lichen-caribou-human food chain near uranium mining operations in northen Saskatchewan, Canada. Environmental Health
Perspectives, v. 107, p. 527-537, 1999 .

VANDECASTEELE, C.; BLOCK, C. B. Modern methods for trace element determination. New York, N. Y.: John Wiley \& Sons Ltd, 1993. cap. 11, activation
analysis. p. 299-318.

VOGEL, A. I. Análise química quantitativa. London, U.K.: LTC, 1992. cap. 4, erros e

YENISOY-KARAKAS, S.; TUNCEL, S. G. Geographic patterns of elemental deposition Science of the Total Environment, n. 329, p. 43-60, 2004 . 

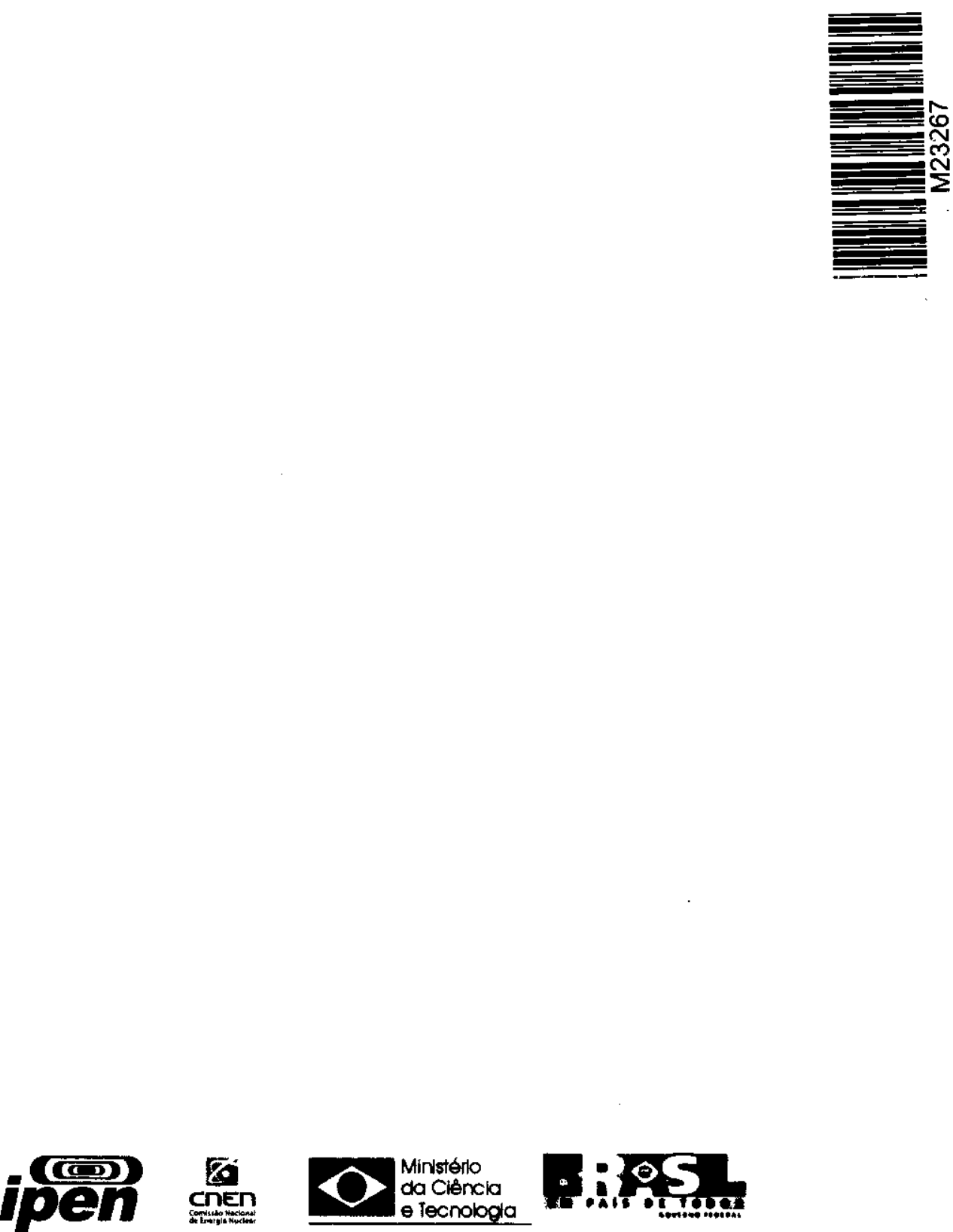

Instituto de Pesquisas Energéticas e Nucleares

Diretorla do Enalno a Informacta Clontfifica o Tocnotogica

Av. Prof. Lineu Preates, 2242 Cidade Unlversltírla CEP: 06808-000

Fone/Fax(0XX11) $3816-9148$

SAO PAULO - SAO PaUlo - Brasll

http: / / wmm.ipen.br

O jpon o ums autarquile vinculada a secrotaria de Clencla, Tocnologla e Desenvolvimento Economico

- Turbemo do Eatado de Sto Peulo, gerida tjenica, admintatrativa o financelramonte pela

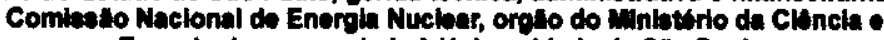

Tecnologia, a aseocteda a Universldade de Silo Paulo. 